\title{
Farm Production Diversity and Dietary Quality in Smallholder Farm Households
}

\author{
Dissertation \\ to obtain the Ph.D. degree \\ at the Faculty of Agricultural Sciences, \\ Georg-August-University Göttingen, Germany

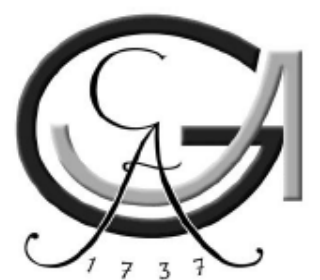

in the International Ph.D. Program for Agricultural Sciences in Göttingen (IPAG)

presented by

Kibrom Tadesse Sibhatu

born in Argzana, Eritrea

Göttingen, November 2016 
D7

Name of Supervisor: Prof. Dr. Matin Qaim

Name of Co-Supervisor: Prof. Dr. Bernhard Brümmer

Member of Examination Committee: Prof. Xiaohua $\mathrm{Yu}, \mathrm{PhD}$

Date of dissertation: $17^{\text {th }}$ November 2016 


\section{Summary}

Investments in agricultural modernization have resulted in remarkable progress in food production over the last century. As a consequence, the global number and the proportion of undernourished people has fallen significantly. Despite this progress, providing sufficient and nutritiously diverse food for all remains a complex global challenge. The scale of global hunger and malnutrition remains staggering: one in nine people continues to be undernourished, and nearly $30 \%$ of the world population is classified as malnourished in terms of specific nutrient deficiencies. Meanwhile, the global number of overweight and obese people is also rising dramatically, including in developing countries where undernutrition is still widespread. Nutritional deficiencies and food insecurity are not only the result of low food quantities consumed, but also of poor dietary quality and diversity. In Asia and sub-Saharan Africa, smallholder farmers are the main providers of the food supply. Paradoxically, smallholders are also the most undernourished group of people, suffering from various nutrition related problems. Nutritional deficiencies cause a large health burden and lead to significant economic losses. Given the magnitude and severity of malnutrition in many developing countries, the question how to make agriculture and food systems more nutritionsensitive is of high relevance for research and policy.

This dissertation attempts to contribute in this direction. It contains three essays. As many of the poor and undernourished people are smallholder farmers in developing countries, it is often argued that diversifying production on these smallholder farms could be a useful approach to improve dietary diversity. Yet, empirical evidence to support this argument is scarce. In the first essay, we address this issue using household-level data from Indonesia, Kenya, Ethiopia, and Malawi. The data from Indonesia and Kenya refer to specific regions within these countries, where smallholder farmers grow cash crops for the market. The data from Ethiopia and Malawi are nationally representative. These four countries cover different situations in terms of farm structures, market access, culture and levels of poverty and malnutrition, so the information may provide broader conceptual and empirical lessons that go beyond case-study evidence. We calculate the number of crop and livestock species 
produced on a farm and dietary diversity scores as indicators of production and consumption diversities, respectively. Both measures are suitable and meaningful for international comparisons. Regression models show that on-farm production diversity is positively associated with dietary diversity in some situations, but not in all. When production diversity is already high, the association is not significant or even turns negative, because of foregone income benefits from specialization. Analysis of other factors reveals that market access has positive effects on dietary diversity, which are larger than those of increased production diversity. Market transactions also tend to reduce the role of farm diversity for household nutrition.

The first essay contributes to an emerging literature that analyzes whether higher levels of farm production diversity contribute to improved dietary quality in smallholder households. Most of this work uses relatively simple indicators for production diversity and dietary quality. In the second essay, we use and compare different indicators, thus testing the robustness of earlier findings and helping to further understand the underlying linkages. The analysis builds on household survey data from Indonesia, Kenya, and Uganda. We estimate Poisson and linear regression models to analyze the relationship between production diversity and dietary quality. Farm diversity measured through a simple species count has a small positive effect on dietary quality, either expressed in terms of dietary diversity scores or micronutrient consumption levels. However, when measuring production diversity in terms of the number of food groups produced, the effect turns insignificant in most cases. Further analysis suggests that diverse subsistence production contributes less to dietary quality than cash income generated through market sales. Much of the food diversity consumed in farm households is purchased from the market. If farm diversification responds to market incentives and builds on comparative advantage, it can contribute to improved income and nutrition. This may also involve cash crop production. On the other hand, increasing the number of food groups produced on the farm independent of market incentives will foster subsistence, reduce cash incomes, and thus rather worsen dietary quality.

In the third essay, we investigate the relative contribution of market purchases and home production to food availability in farm household across agricultural seasons. Issues of seasonality have hardly been addressed in previous work. We use nationally representative 
survey data from Ethiopia. Estimated daily per capita calorie consumption and household dietary diversity scores are used as indicators of food availability for each month over a full calendar year. We find that the farm households extensively engage in selling and buying farm products. We also find that farmers cannot secure their food needs only from what they produce on their farm; most of them are net buyers of food commodities. Although there is a tendency to shift away from purchased foods during the harvesting season, off-farm income clearly stands out as the primary economic activity to secure food in Ethiopian farm households across the different seasons. Interestingly, households with insufficient food availability rely more on own farm production as a source of food, while households with enough food rely more on market purchases. The analysis shows that the contribution of market purchases and own production varies across agroecological and geographical zones. For farmers with better infrastructure conditions, off-farm income plays a larger role to meet their food needs.

Putting the findings from the three essays together, we draw important conclusions. Increasing people's dietary quality and diversity is an important strategy to improve nutrition and health. How exactly to ensure that smallholder farmers have access to sufficient and diverse food will vary from one place to another, depending on the particular conditions. However, unlike sometimes assumed, increasing on-farm diversity does not always seem to be the most effective way to improve dietary quality in smallholder households. From a nutrition perspective, improving market access is more important than farm diversification as such. The results underline that - in most situations - home production cannot be the main or only source of food for sufficiently diverse diets, and especially not outside of the main agricultural seasons. Hence, policies should be steered towards strengthening markets and enhancing off-farm income sources for the rural poor. Additional research is needed to better understand how agriculture and food systems can be made more nutrition-sensitive and sustainable. Production diversity also has an environmental dimension, which was not analyzed here. 


\section{Acknowledgements}

The success of my academic life and the existence of this dissertation in its current form would not have been possible without the assistance and contribution of several people. I would like to sincerely thank all of them. In the first place, I must offer sincere gratitude to my supervisor Prof. Matin Qaim for accepting me as a doctoral student in his research group and for his scientific guidance and valuable advice during the entire process of the dissertation. I thank him very much also for introducing me to the subject matter of this dissertation. Over time, I became very passionate about this research area. Special thanks also to my examination committee members, Prof. Bernhard Brümmer and Prof. Xiaohua Yu, for their generous time and effort. Profs. Brümmer and $\mathrm{Yu}$ also deserve special thanks for their valuable comments on my research papers at our Department's doctoral seminar.

I am very thankful to Dr. Vijesh Krishna for his professional contribution to the first essay of this dissertation and for the continuous discussions throughout the course of my study. I also thank him and his family very much for being trusted and supportive friends, especially during the difficult periods of my study and life in Germany.

Without the generous financial support of Katholischer Akademischer Ausländer-Dienst (KAAD) this study would not have taken place. I would therefore like to thank KAAD very much. I owe a special thanks to María Ximena Ordóñez Orellana for making a difference in my life. And the KAAD staff at the African Department, especially Ms Simone Saure, for the professional support.

Particular thanks goes to my collogues at the CRC 999 (EFForTS) and the RTG 1666 (GlobalFood) at the University of Goettingen for allowing me to use their data. Thanks to the Central Statistical Agency of Ethiopia (CSA) and the World Bank for publishing the household datasets and allowing me to use them. Special thanks to members of the Chair of International Food Economics and Rural Development, Elijah, Michael, Wilhelm, Marcel, Dr. Gödecke, Dr. Schwarze, Simon, Christine, Stefan, Priscilla, Kenneth, Jonida, Christoph, Kathrin, Eva, Andrea, Lisa, Sylvester, Zewdu, Marco, Lisa, and Rosina for the atmosphere and friendly 
discussions. Special thanks to Ilona Hoepfner for assisting me in numerous ways. I am also grateful to Isabel Lambrecht from KU Leuven for her technical advice and sharing helpful resources at the early stages of my dissertation.

I am hugely indebted to my mother Roman Habtu for the unconditional love and support. She is an inspiration for me, though she never went to a school for herself. I dedicate this dissertation to her. Further, I would like to thank an incredible friend and wonderful wife Azeb Tesfamiariam for being so strong throughout the journey and upbringing our sons alone. I am also thankful to my sons Lamiek and Victor for the sacrifice they made. I could not have finished my dissertation without their altruistic sacrifices. I owe a big thanks to all my siblings, Fitwi, Habtemariam, Luula, Asmeret, Shewit, Kesete and Letensea for being a part of my life. I appreciate and thank numerous friends for their moral support and joyful gatherings, especially Abraha, Annika, Dr. Daniel and his family, Dr. Yabibal and his family, Isaias and his family, Jean, Tanja, Marina, Svenja, Teame and Teklezghi. Last but not least, I am very grateful to Desale Weldemichael and his family for standing with us during the difficult moments of our life. They have engraved themselves in our minds forever. 


\section{Table of Contents}

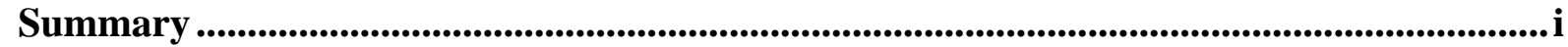

Acknowledgements..........................................................................................................................iv

Table of Contents ..................................................................................................................vi

List of Tables...................................................................................................................ix

List of Figures .....................................................................................................................................

Abbreviations.............................................................................................................

CHAPTER 1 ................................................................................................................................... 1

Introduction ........................................................................................................................... 1

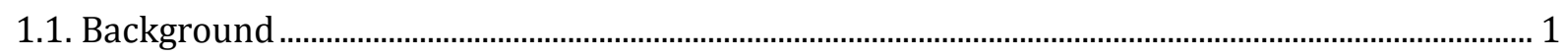

1.2. Conceptualizing Farm Production and Dietary Diversity ............................................................. 3

1.3. Research Problem and Objectives ....................................................................................................... 6

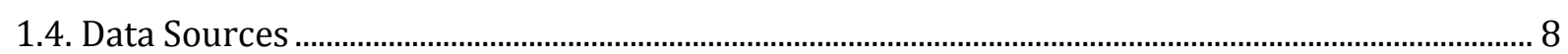

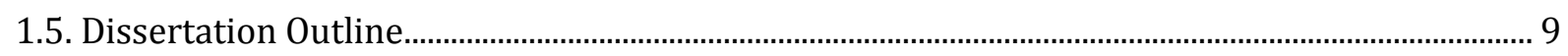

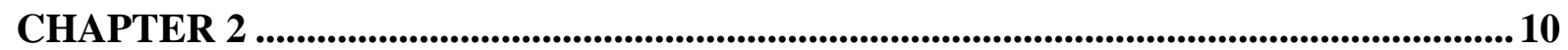

Production Diversity and Dietary Diversity in Smallholder Farm Households.................10

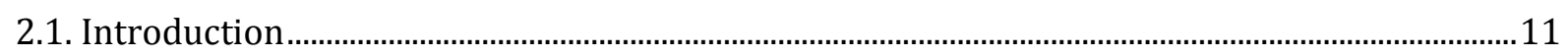

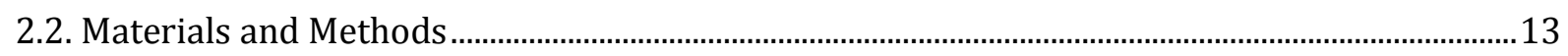

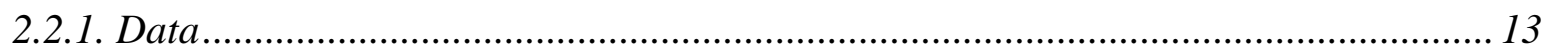

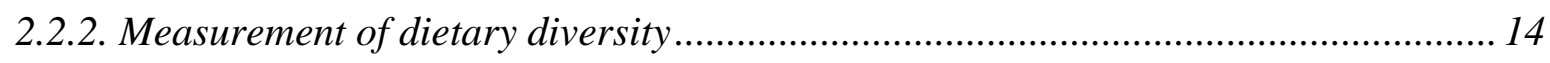

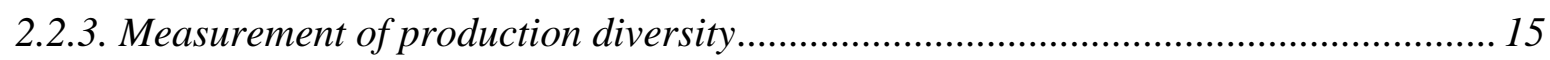

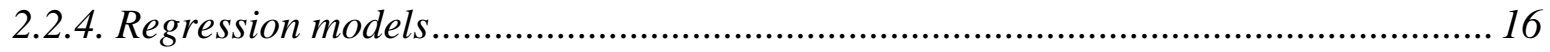

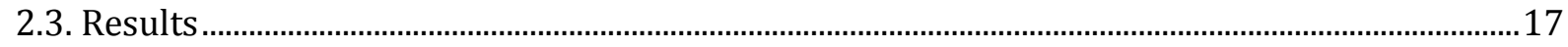

2.3.1. Association between production diversity and dietary diversity.............................. 18

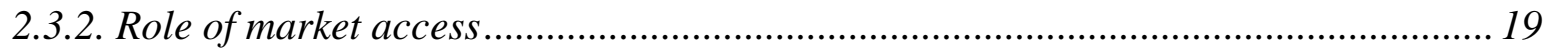

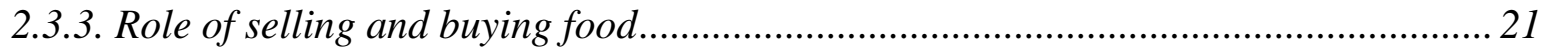

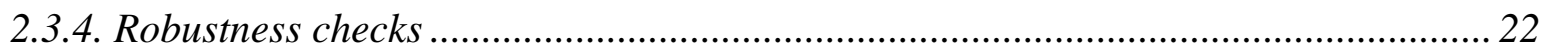




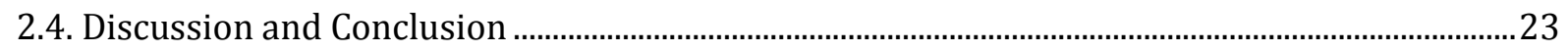

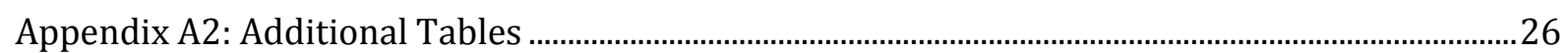

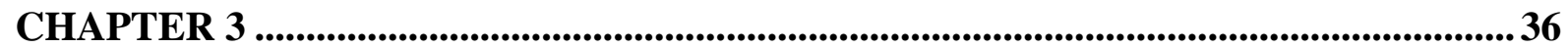

Farm Production Diversity and Dietary Quality: Linkages and Measurement Issues ... 36

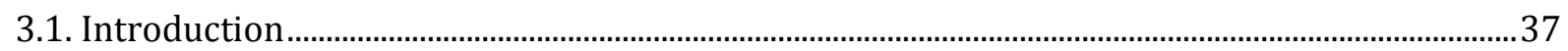

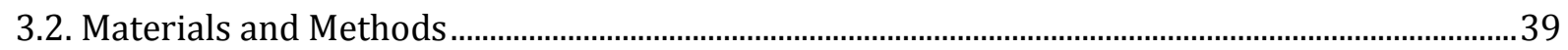

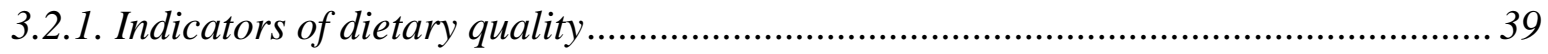

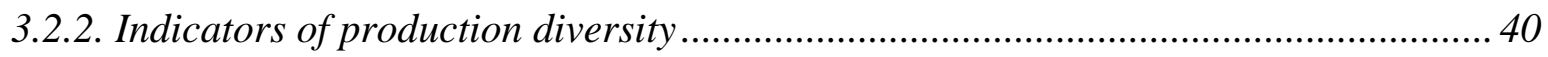

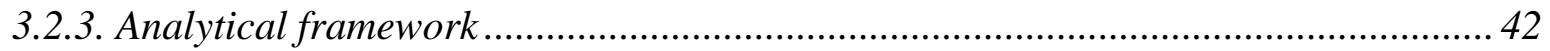

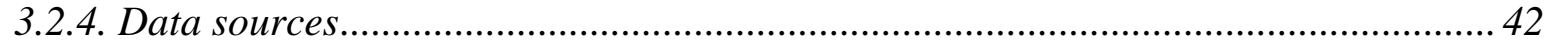

3.3. Results and Discussion.................................................................................................................. 44

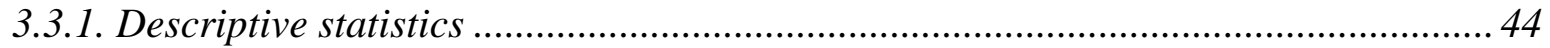

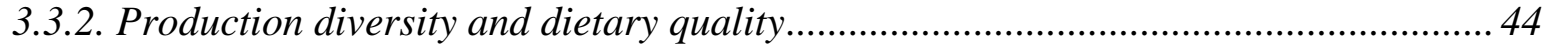

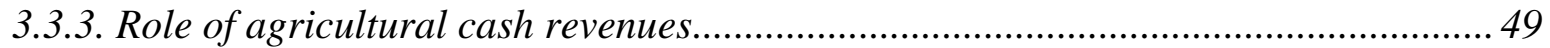

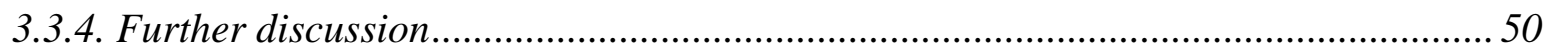

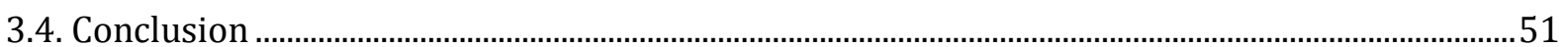

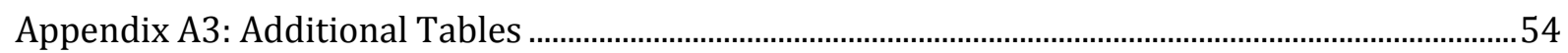

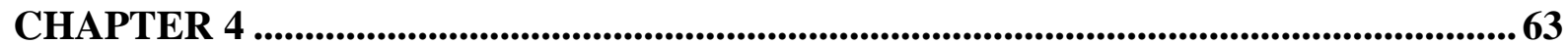

Contributions of Market Purchases and Home Production to Seasonal

Food Availability in Farm Households: Insights From Ethiopia ....................................63

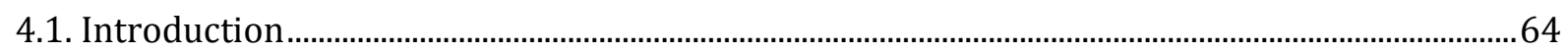

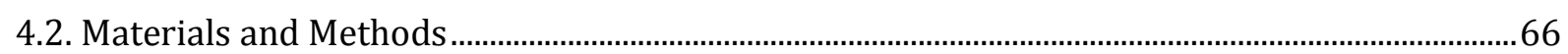

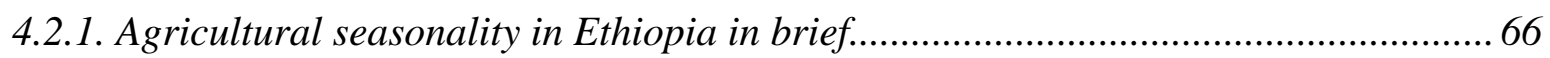

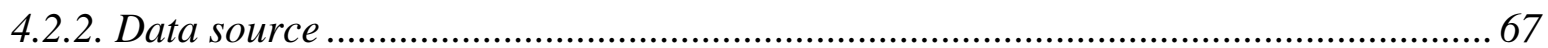

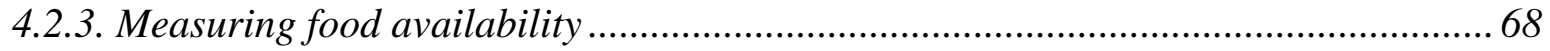

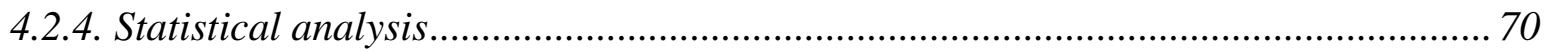

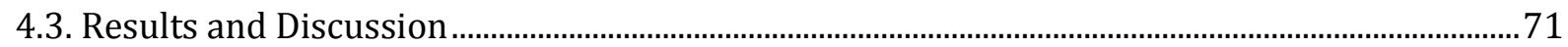

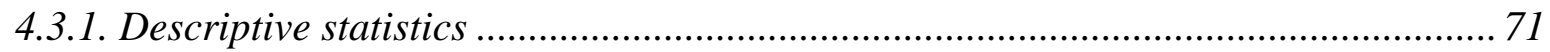

4.3.2. Seasonal market purchases and own on-farm production ....................................... 72

4.3.3. Contribution of market purchases and home production for sufficient food

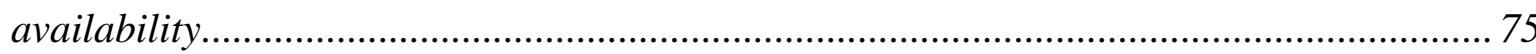




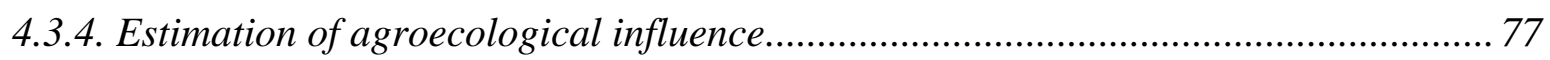

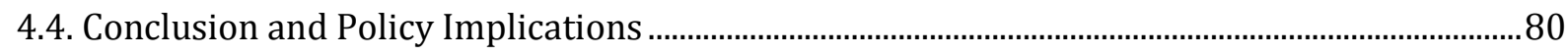

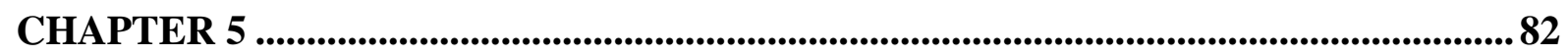

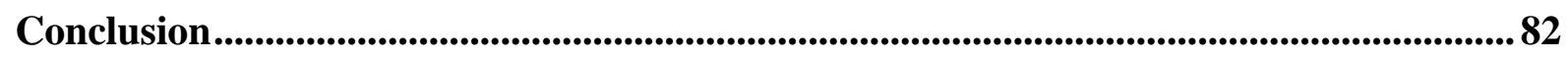

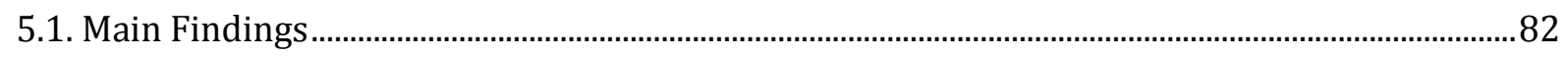

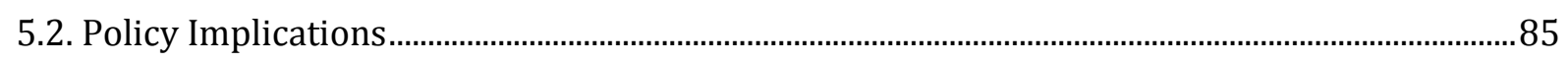

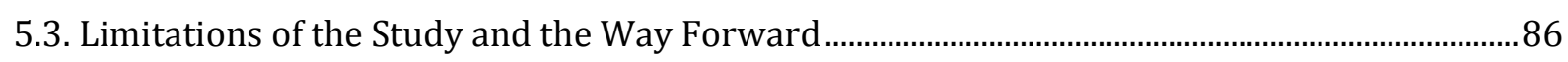

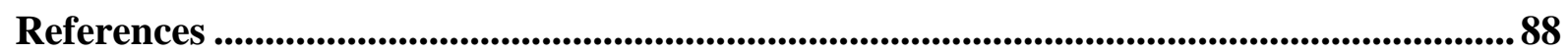




\section{List of Tables}

Table 2. 1: Descriptive statistics by country

Table 2. 2: Association between production diversity and dietary diversity

Table 2. 3: Production diversity, market access, and dietary diversity 20

Table 2. 4: Production diversity, market participation, and dietary diversity in Ethiopia and Malawi (pooled sample) 22

Table 3. 1: Descriptive statistics by country 45

Table 3. 2: Effect of farm production diversity on dietary quality 46

Table 3. 3: Association between agricultural cash revenues and dietary quality 48

Table 3. 4: Correlation between production diversity, agricultural cash revenues, and household income. 50

Table 4. 1: Descriptive statistics 71

Table 4. 2 Food sources variation across agroecological zones and seasons in farm households 79

Table A2. 1: Descriptive statistics by country 26

Table A2. 2: Production diversity, market access, and dietary diversity of healthy foods 27

Table A2. 3: Factors influencing dietary diversity in Indonesia, Kenya,

Ethiopia, and Malawi (pooled sample) 28

Table A2. 4: Factors influencing dietary diversity in Ethiopia and Malawi pooled sample) 
Table A2. 5: Association between production diversity measured with the Margalef index and dietary diversity

Table A2. 6: Production diversity measured with Margalef index, market access, and dietary diversity.

Table A2. 7: Production diversity measured with the Margalef index, market participation and dietary diversity in Ethiopia and Malawi (pooled sample) 32

Table A2. 8: Association between food crop production diversity and dietary diversity

Table A2. 9: Food crop production diversity, market access, and dietary diversity 34

Table A2. 10: Food production diversity, market participation, and dietary diversity in Ethiopia and Malawi (pooled sample) 35

Table A3. 1: Effect of farm species count on dietary quality (pooled sample). 54

Table A3. 2: Effect of farm species count on dietary quality (Indonesian sample) 55

Table A3. 3: Effects of farm species count on dietary quality (Kenyan sample) 56

Table A3. 4: Effects of farm species count on dietary quality (Ugandan sample). 57

Table A3. 5: Effect of production diversity score on dietary quality (pooled sample) 58

Table A3. 6: Effects of production diversity score on dietary quality (Indonesian sample)....59

Table A3. 7: Effect of production diversity score on dietary quality (Kenyan sample) 60

Table A3. 8: Effects of production diversity score on dietary quality (Ugandan sample).......61

Table A3. 9: Association between agricultural cash revenues and dietary quality 62 


\section{List of Figures}

Figure 3. 1: Mean diversity scores and production diversity scores in farm households 51

Figure 4. 1: Seasonal household calorie consumption and dietary diversity score categorized by food sources. .73

Figure 4. 2: Average household dietary diversity of healthy of healthy foods categorized by food sources

Figure 4. 3: Contribution of own production, purchases from farm income, and purchases from off-farm income to household food sufficiency......

Figure 4. 4: Contribution of own production, purchases from farm income, and purchases from off-farm income for households' diverse food availability 


\section{Abbreviations}

CSA Central Statistical Agency of Ethiopia

EHNRI Ethiopian Health and Nutrition Research Institute

FANTA Food and Nutrition Technical Assistance

FAO Food and Agriculture Organization of the United Nations

HDDS Household Dietary Diversity Score

IFAD International Fund for Agricultural Development

IFPRI International Food Policy Research Institute

SDGs Sustainable Development Goals

SMILING Sustainable Micronutrient Interventions to Control Deficiencies and Improve Nutritional Status and General Health in Asia

USDA United States Department of Agriculture

WHO World Health Organization 


\section{CHAPTER 1}

\section{Introduction}

\subsection{Background}

Investments in agricultural modernization over the last century have led to more production of food. The resulting production increases have contributed considerably to reducing hunger and improving peoples' access to calorie-dense staple foods (Pingali, 2015; Khoury et al., 2014; Godfray et al., 2010) and reducing protein shortages (Schneeman, 2000). It is estimated that the total number of undernourished people has fallen by 17 percent in the last few decades (FAO, 2013). In spite of this progress, eradicating several forms of malnutrition and providing sufficiently diverse food for all continues to be one of the big global challenges (Foley et al., 2011). Close to 800 million people are still classified as chronically hungry, meaning that they do not have sufficient access to calories, and an estimated 2 billion people suffer from micronutrient malnutrition mostly due to low intakes of vitamins and minerals such as iron and zinc from their diet (IFPRI, 2016; FAO et al., 2015). The prevalence of undernutrition remains high, especially in Africa and rural Asia (IFPRI, 2016; FAO et al., 2015; Dubé et al., 2012; Godfray et al., 2010).

Hunger and malnutrition continue to be big and complex global problems, particularly in developing countries. Macro- and micronutrient deficiencies impose a large health burden in terms of lost productivity, impaired physical and mental human development, susceptibility to various diseases, and premature deaths (Lim et al., 2012). Therefore, securing food and nutrition is an essential investment in human capital that leads to higher returns and productive lives in the long run. Well-nourished mothers are more likely to give birth to healthy children that can effectively attend school and live healthy and productive lives (IFPRI, 2015). While the concern of malnutrition has existed throughout human history, in the post-modern perspective it goes beyond hunger and undernourishment. Overnutrition and obesity are also on the rise. Overweight and obesity are causing serious health risks, especially in terms of chronic diseases. These problems are also of growing concern in poor countries, where undernutrition is still widespread (Popkin and Slining, 2013). This double 
burden of malnutrition has made food and nutrition policies even more complex (FAO, 2013). Eradicating malnutrition in all its forms is a fundamental part of the post-2015 United Nations Sustainable Development Goals (SDGs) (United Nations, 2015).

Smallholder farmers ${ }^{1}$ lie at the heart of agriculture and the rural economy in the developing world, both in terms of food production and the number of people involved. Across the world, nearly two billion people live in about 500 million smallholder farm households. Smallholder farmers in Asia and sub-Saharan Africa provide up to 80 percent of the food supply (FAO, 2014; IFAD, 2013; FAO, 2012). Paradoxically, many of the very poorest and world's undernourished people live in smallholder farm households (FAO, 2014, IFAD, 2013; Barrett, 2010; Herrero et al., 2010; Muller, 2009; Pinstrup-Andersen, 2007). Therefore, addressing the problems in the smallholder sector and making small farm agriculture more nutrition-sensitive should have high policy priority.

Generally, several challenges have to be faced. First, increasing agricultural production and productivity on small farms is needed, which can help poor households to generate additional income and escape from poverty (Godfray et al., 2010). Second, increasing food production is needed to feed the unacceptably high number of undernourished people and to face further population growth (Godfray et al., 2010; World Economic Forum, 2013). Third, continued effort is needed to produce and deliver sufficiently diverse and healthy foods. Diversity is particularly needed to reduce widespread micronutrient deficiencies. Fourth, diets are shifting, especially among the urban middle classes in developing countries. Demand for meat, dairy, and other animal products is growing rapidly, which means additional challenges in terms of feed supply, resource scarcity, and environmental sustainability (Qaim, 2016a). Fifth, the demand for agricultural products used for non-food and non-feed uses is also rising. Biofuels as well as plant-produced fibers and substances for industrial purposes are gaining in importance. Given these challenges, it is important to investigate the underlying linkages

\footnotetext{
${ }^{1}$ There is no clear consensus on the definition of smallholder (small-scale) farmers. The Food and Agriculture Organization of the United Nations (FAO) use farm size to scale farmers into small and large. According to FAO, smallholder farmers are marginal or sub-marginal farm households who own or manage farms with land areas less than 10 hectares (FAO, 2012). However, the land sizes that smallholder farmers work on vary widely from one location to another. Smallholder farmers are also characterized by extensive use of family labor for production and by consuming part of their farm produce at home.
} 
between agriculture and dietary quality, as well as how to sustainably provide sufficient and nutritious foods, particularly to the very poorest people living in remote and environmentally fragile rural areas of the developing world.

This dissertation contributes to the literature by analyzing the relationship between farm production diversity and dietary quality and the underlying mechanisms. It also analyzes the relative contribution of home production and market purchases to seasonal food availability in smallholder farm households.

\subsection{Conceptualizing farm production and dietary diversity}

Farm production diversity is a key component of agrobiodiversity. It is used to refer to the variety of crop and livestock species produced on a farm. A wider deployment of farm diversity is considered as an essential component of sustainable and secure food supply because every food item from a given farm species could provide unique nutritional importance (Deckelbaum et al., 2006). In some regions of the developing world, particularly in Africa, polyculture is a tradition; the number of different species produced is often high.

In the empirical literature, a commonly used indicator of production diversity on a farm is a simple count of the different crop and livestock species produced. This indicator has been adopted from the fields of biodiversity and agroecology to measure the diversity of multispecies on a farm (Herforth, 2010; Di Falco and Chavas, 2009). The simple species count indicator is used to detect differences between farms, regions and dominant farm types (Last et al., 2014). Another species richness indicator often used and simple to calculate and interpret is a modified Margalef species richness index (Di Falco and Chavas, 2009; Meng et al., 1998; Smale et al., 1998; Margalef, 1958). The Margalef index considers the area under the different crop species through weighting. A recent body of literature has also developed new diversity scores trying to account for the nutritional functions of different types of food crops produced (Luckett et al., 2015, Remans et al., 2014; DeClerck et al., 2011). The nutritional functional diversity score proposed by Luckett et al. (2015) counts a farm species only as additional when its nutritional profile is sufficiently different from the other species 
that were already counted on the same farm. Otherwise, the species is considered nutritionally redundant. When livestock production is involved, which is a typical characteristic of smallholder farmers in developing countries, it might be difficult to apply both the Margalef index and the nutritional functional diversity score, as these are more useful in a crop context.

In terms of consumption, food diversity is considered a key element of a balanced diet. It is assumed that the intake of nutrients and foods are related with many interlinkages, as people do not consume nutrients or single foods, but combinations of food items (Waijers et al., 2007). Diets among the poor in developing countries are often characterized by insufficient diversity. Poor households mainly consume starchy staple foods and too low quantities of vegetables, fruits and animal products. Starchy staples are rich in carbohydrate, but low in micronutrients. There are several reasons why dietary diversity is a good indicator of dietary quality, particularly in the context of developing countries. First, higher dietary diversity ensures intake of adequate nutrients (Frison et al., 2006; Steyn et al., 2006; Kennedy et al., 2007; Arimond and Ruel, 2004). Second, dietary diversity was shown to be associated with better nutritional outcomes such as improved child anthropometrics (Ruel, 2003; Arimond and Ruel, 2004), as well as with higher concentration of hemoglobin in human blood (Keding et al., 2012). Third, collecting data on food items is easy in survey studies and can be applied at individual or household levels (FANTA, 2006). The individual level is of particular importance when the focus is on specific age and gender groups.

In empirical studies, food variety scores and dietary diversity scores are frequently used to measure dietary quality (Jones et al., 2014; Swindale and Bilinsky, 2006; Ruel, 2003; Drewnowski et al., 1997; Kant et al., 1993). The food variety score is a simple count of unique food items consumed over a specific reference period (Drewnowski et al., 1997), while the dietary diversity score is the number of food groups consumed over a given recall period (Kennedy et al., 2007), often 24 hours or 7 days. Due to the differences in dietary habits as well as the methodology used for data collection by different researchers, food variety scores are less useful for an inter-country comparison. Against this background, the household dietary diversity score (HDDS) has become a widely used measure (Pellegrini and Tosciotti, 2014). At an individual level, the dietary diversity score indicates nutritional adequacy, whilst at the household level it is more a reflection of general economic status and 
access to a variety of foods (FAO, 2011; Kennedy et al., 2007; Steyn et al., 2006). However, in spite of its usefulness for a first general assessment of dietary quality, HDDS also has a few drawbacks (Hirvonen et al., 2015; Maxwell et al., 2014; Coates, 2013). Not all food groups considered in the calculation contribute to the supply of essential nutrients in the same way. Moreover, food groups are counted regardless of the actual quantities consumed; very small quantities of certain food types may not add much to healthy nutrition. To address these shortcomings, more comprehensive data about the food quantities and nutrients consumed are required (de Haen et al., 2011). Recent studies have used calorie and micronutrient consumption levels to assess nutritional impacts of innovations in African food supply chains (Chiputwa and Qaim, 2016; Chege et al., 2015).

Food and nutrition security requires a sufficient degree of dietary diversity to ensure adequate macro- and micronutrients intakes (United Nations, 2015; Bouis and Hunt, 1999). Several studies have shown that the level of dietary diversity is a good indicator of people's broader nutritional status in many situations (Headey and Ecker, 2013; Arimond et al., 2010; Moursi et al., 2008; Savy et al., 2006; Steyn et al., 2006; Savy et al., 2005; Arimond and Ruel, 2004; Torheim et al., 2004; Ruel, 2003; Kant et al., 1993). Studies also show that dietary diversity can be used as a proxy for general socio-economic performance at the household level (Hoddinott and Yohanness, 2002; Hatløy et al., 2000). More diverse diets rich in fruits and vegetables also tend to be associated with lower rates of overweight and obesity (Popkin and Slining, 2013). Increasing dietary diversity is therefore an important strategy to improve nutrition and health. As smallholder farm households consume a significant portion of what they produce, their agricultural production also needs to be nutrition-sensitive via on-farm diversification, so that a wide range of different types of foods are available and accessible (Pingali, 2015).

A positive relationship between farm production diversity and dietary diversity is plausible. However, counting the total number of crop species on a farm may not reflect the nutritional contribution of the farm species. Different species have different nutritional functions, so that the type of farm diversification can matter for effects on household diets (Berti, 2015; Remans et al., 2014; De Clerck et al., 2011). For instance, the dietary quality effect of growing sorghum in addition to maize may be smaller than that of adding a pulse or vegetable 
crop to a cereal-dominated production system. In another way, nutritional functional composition of some species might be redundant. Further, assuming smallholder farmers are pure subsistence farmers without selling and buying food is too simplistic. Beyond farming, most smallholder households in developing countries have off-farm sources of income as well (Frelat et al., 2016). They are indeed net buyers of food items (World Bank, 2007b), further adding to complexity. When relying on markets, nutrition effects in farm households will also depend on how well the markets function and who within the household controls the income from commercial farm sales and off-farm employment. It is known that gender aspects can play important roles in determining household food and nutrition security (Olney et al., 2009). Hence, the direction and strength of the production-consumption diversity relationship will be situation-specific.

Taking into account that own production is not the only source of food to smallholder farmers and considering possible similarities/differences in the nutritional functions of the different commodities produced on a farm, the relationship between production and consumption becomes more complex. Instead of producing everything at home, households can buy diverse foods in the market when they generate sufficient income. Farm diversification may contribute to income growth and income stability up to a certain point, but beyond that point, further diversification may also reduce household income, because benefits from specialization cannot be realized.

\subsection{Research Problem and Objectives}

As stated above, in Africa and Asia the majority of the undernourished people live in rural areas. Many of them are smallholder farmers. Against this background, further diversifying production on these smallholder farms is often perceived as a useful approach to improve dietary diversity and nutrition (Jones et al., 2014; Pellegrini and Tasciotti, 2014; Remans et al., 2011; Powell et al., 2015). This stems from the notion that production diversity could enhance households' food diversity and availability from own production as smallholder farmers consume some portion of their produce at home (FAO, 2014). Several recent development initiatives have promoted smallholder diversification through introducing 
additional crop and livestock species with the intention to improve household nutrition (Powell et al., 2015; Fanzo et al., 2013; Burlingame and Dernini, 2012). As farm diversity can help to increase agrobiodiversity too, the strategy is welcome from an environmental perspective (Burlingame and Dernini, 2012; Frison et al., 2006; Deckelbaum et al., 2006). However, is there really such a clear link between production diversity on the farm and consumption diversity in the farm household? And what are other factors influencing this relationship and dietary diversity in smallholder farm households? Does the way consumption and production is measured affect the relationship between production diversity and dietary diversity in an important way? These are under-researched questions of relevance for improving agriculture and nutrition in the small farm sector (Jones et al., 2014; PinstrupAndersen, 2013; Gómez et al., 2013). Here, we aim to address these questions using data from several developing countries.

In addition, how is the relative contribution of own production and market purchases to food availability across agricultural seasons in developing countries? Recent findings suggest that several factors such as off-farm income and improved market access are essential for food availability in farm households in sub-Saharan African countries (Frelat et al., 2016). But this existing research does not take seasonality into account. Availability of food is not uniform across time in farm households; it varies across agricultural seasons (Hassen et al., 2016; Hirvonen et al., 2015; Kearney, 2010). Hirvonen et al. (2015) have shown that dietary diversity and calorie consumption vary across seasons in Ethiopia. There is also some evidence suggesting that food purchases in the market play an important role for household food provisioning (Luckett et al., 2015). To the best of our knowledge, there is no study that has disaggregated food sources into own production, purchases from farm income, and purchases from off-farm income, to assess variation and contribution to seasonal food availability in farm households. This research gap is also addressed here.

The general objective of this dissertation is to understand the relationship between production diversity and dietary quality and the underlying mechanisms, as well us the relative contribution of market purchases and home production to seasonal food availability in smallholder farm households. Specifically, we seek to: 
1. investigate the link between on-farm production diversity and dietary diversity in smallholder farm households,

2. assess what other factors, particularly market access, determine the linkage between onfarm production diversity and dietary diversity,

3. examine if the way consumption and production diversity are measured affects the relationship between production diversity and dietary diversity,

4. test the robustness of the findings of previous studies to further understand the underlying linkage between production diversity and dietary diversity, and

5. examine the relative contribution of market purchases and on-farm production of foods to food availability and food security in smallholder farm households across agricultural seasons.

The dissertation includes three essays. The first two research objectives are pursued in the first essay, objectives three and four are dealt with in the second essay, and objective five is at the core of the third essay. The findings of this research may contribute to policymaking aimed at improving food and nutrition security in smallholder farm households.

\subsection{Data Sources}

The farm household datasets, on which the empirical analysis of this dissertation is built, comes from five countries and three groups of surveys. Across the three essays, we use about 14 thousand observations. The surveys were carried out by different research teams and for different purposes. The first group that includes datasets from Indonesia, Kenya, and Uganda is from the Chair of International Food Economics and Rural Development at the University of Goettingen, Germany. Staff of the Chair collected the datasets for different research projects in 2012. Cash crop producers in specific regions in each of the three countries were sampled. The second group is from the World Bank Living Standards Measurement Study Integrated Surveys on Agriculture (LSMS-ISA) (World Bank, 2013). The first round of the LSMS-ISA data (2010-11) from Ethiopia and the third round of the LSMS-ISA (2010-11) from Malawi are used. These datasets are nationally representative samples of farm households (World Bank, 2013; CSA and World Bank; 2013). The third household survey 
group is from the 2010/11 Household Consumption and Expenditure Survey (HCES) in Ethiopia collected by the country's Central Statistical Agency (CSA, 2012). The HCES is representative at national level and was carried out between July 2010 and June 2011. Overall, the datasets used in this study include different kinds of farmers, data collected in different seasons, and from different agro-climatic environments in Africa and Asia. All surveys used structured questionnaires with the same format for the production and consumption related aspects, except for the HCES, which concentrates on consumption and does not include details of agricultural production. Further descriptions of the different surveys are provided in the methodology sections of each essay.

\subsection{Dissertation Outline}

This dissertation comprises three essays and is organized as follows. Chapter Two presents the first essay. The linkages between on-farm production diversity and dietary diversity and factors that influence this relationship are analyzed. Chapter Three presents the second essay. The focus is on further examining linkages and measurement issues relating to production diversity and dietary quality. Chapter Four presents the third essay. The relative contribution of home production and market purchases across agricultural seasons is examined. Chapter Five provides the overall conclusions and discusses implications and limitations of the research. 


\title{
CHAPTER 2
}

\section{Production Diversity and Dietary Diversity in Smallholder Farm Households ${ }^{2}$}

\begin{abstract}
Undernutrition and micronutrient malnutrition remain problems of significant magnitude in large parts of the developing world. Improved nutrition requires not only better access to food for poor population segments, but also higher dietary quality and diversity. As many of the poor and undernourished people are smallholder farmers, diversifying production on these smallholder farms is widely perceived as a useful approach to improve dietary diversity. Yet, empirical evidence on the link between production and consumption diversity is scarce. Here, this issue is addressed with household-level data from Indonesia, Kenya, Ethiopia, and Malawi. Regression models show that on-farm production diversity is positively associated with dietary diversity in some situations, but not in all. When production diversity is already high, the association is not significant or even turns negative, because of foregone income benefits from specialization. Analysis of other factors reveals that market access has positive effects on dietary diversity, which are larger than those of increased production diversity. Market transactions also tend to reduce the role of farm diversity for household nutrition. These results suggest that increasing on-farm diversity is not always the most effective way to improve dietary diversity in smallholder households and should not be considered a goal in itself. Additional research is needed to better understand how agriculture and food systems can be made more nutrition-sensitive in particular situations.
\end{abstract}

\footnotetext{
${ }^{2}$ This chapter was published as: Sibhatu, K.T., Krishna, V.V., Qaim, M. (2015). Production diversity and dietary diversity in smallholder farm households. Proceedings of the National Academy of Sciences of the United States of America 112: 10657-10662.
} 


\subsection{Introduction}

Hunger and malnutrition are complex global problems. In spite of improvements in food and nutrition security over the last few decades, the prevalence of undernutrition remains high, especially in Africa and Asia (IFPRI, 2014; Dubé et al., 2012; Godfray et al., 2010). Close to 800 million people are still classified as chronically hungry, meaning that they do not have sufficient access to calories (FAO et al., 2015). An estimated 2 billion people suffer from micronutrient malnutrition, mostly due to low intakes of vitamins and minerals such as iron and zinc (Godfray et al., 2010). Nutritional deficiencies are responsible for a large health burden in terms of lost productivity, impaired physical and mental human development, susceptibility to various diseases, and premature deaths (Lim et al., 2012). Nutritional deficiencies are not only the result of low food quantities consumed, but also of poor dietary quality and diversity. In fact, the level of dietary diversity was shown to be a good indicator of people's broader nutritional status in many situations (Headey and Ecker, 2013; Arimond et al., 2010; Moursi et al., 2008; Steyn et al., 2006; Arimond and Ruel, 2004; Ruel, 2003; Kant et al., 1993). More diverse diets tend to be associated also with lower rates of overweight and obesity - other nutritional problems of rising magnitude in many parts of the world (Popkin and Slining, 2013). Increasing dietary diversity is therefore an important strategy to improve nutrition and health. This implies that agricultural production also needs to be diversified, so that a wide range of different types of foods are available and accessible also to poor population segments (Pingali, 2015). Over the last 50 years, agricultural modernization has contributed to narrowing global production patterns with a focus on a limited number of major crop plants (Khoury et al., 2014).

In Africa and Asia, the majority of the undernourished people live in rural areas. Many of them are smallholder farmers (Pinstrup-Andersen, 2007). Against this background, further diversifying production on these smallholder farms is often perceived as a useful approach to improve dietary diversity and nutrition (Jones et al., 2014; Pellegrini and Tasciotti, 2014; Remans et al., 2011; Powell et al., 2015). Several recent development initiatives have promoted smallholder diversification through introducing additional crop and livestock species with the intention to improve household nutrition (Burlingame and Dernini, 2012; 
Fanzo et al., 2013). As farm diversity can help to increase agrobiodiversity too, this approach is also welcome from environmental perspectives (Burlingame and Dernini, 2012; Frison et al., 2006; Deckelbaum et al., 2006). But is there really such a clear link between production diversity on the farm and consumption diversity in the farm household? And what are other factors influencing this relationship and dietary diversity in smallholder farm households more generally? These are under-researched questions of relevance for improving agriculture and nutrition in the small farm sector (Pinstrup-Andersen, 2013; Gómez et al., 2013). Here, we address these questions empirically with data from several developing countries.

A positive relationship between farm production diversity and dietary diversity is plausible, as much of what smallholder farmers' produce is consumed at home (World Bank, 2007a). However, assuming that all smallholders are pure subsistence farmers without selling and buying any food is too simplistic. Taking into account market transactions, the relationship between production diversity and dietary diversity becomes more complex. Instead of producing everything at home, households can buy food diversity in the market when they generate sufficient income (Jones et al., 2014). Farm diversification may contribute to income growth and stability up to a certain point, but beyond that point further diversification may reduce household income due to foregone benefits from specialization (Chege et al., 2015). As lower household incomes tend to be associated with lower dietary quality, the relationship between production and consumption diversity may even turn negative in some situations. Beyond farming, the majority of smallholder households in developing countries also have off-farm income sources (Haggblade et al., 2007), further adding to the complexity. When relying on markets, nutrition effects in farm households will also depend on how well the markets function and who within the household controls the income from commercial farm sales and off-farm employment (Chege et al., 2015; Fischer and Qaim, 2012; von Braun and Kennedy, 1994). As is well known, gender aspects can play important roles in determining household food and nutrition security (Olney et al., 2009). Hence, the direction and strength of the production-consumption diversity relationship will be situation-specific. While recent case studies of the nutritional impacts of smallholder farm diversification projects exist (Rajendran et al., 2014; Keding et al., 2012; Herforth, 2010; Olney et al., 2009), linkages and influencing factors have not been analyzed from a broader perspective. 
We analyze the relationship between production and consumption diversity in smallholder farm households with data from four developing countries, namely Indonesia, Kenya, Ethiopia, and Malawi. These four countries were chosen because recent household-level data suitable for the analysis were available, which is not the case for many other countries. Moreover, these four countries cover different situations in terms of farm structures, market access, culture, and levels of poverty and malnutrition, so that the data may be useful to derive some broader conclusions that are relevant beyond a particular case. The data from Indonesia and Kenya refer to specific regions within these countries, where smallholder farmers grow cash crops for the market (see Materials and Methods). The data from Ethiopia and Malawi are nationally representative.

\subsection{Materials and Methods}

\subsubsection{Data}

The data used in this study are from cross-section surveys of farm households in Indonesia, Kenya, Ethiopia, and Malawi. The surveys were carried out for different purposes. In Indonesia and Kenya, cash crop producers in specific regions were sampled, as is further described below. These samples from Indonesia and Kenya are not nationally representative. The surveys in Ethiopia and Malawi were carried out as part of the World Bank's Living Standards Measurement Study - Integrated Surveys on Agriculture (LSMS-ISA) (World Bank, 2013). The samples from Ethiopia and Malawi are nationally representative. In all four country surveys, a wide array of household socioeconomic information was captured, including details of agricultural production and food consumption at the household level. All four surveys employed a seven-day consumption recall for a large number of food items, which we used to calculate measures of dietary diversity.

The data from Indonesia include 674 observations from farm households in the province of Jambi, Sumatra. The data were collected in 2012 through multi-stage random sampling to capture the province's regional diversity (Krishna et al., 2015). In Jambi, farmers primarily grow rubber and oil palm as plantation crops. Most farms do not grow other crops, although a 
few are involved in rice cultivation, horticulture, livestock keeping, and aquaculture. The data from Kenya include 397 observations of smallholder farmers in Kiambu County, Central Province, that produce vegetables and other horticultural crops for markets in Nairobi. The data were collected in 2012 through multi-stage random sampling (Chege et al., 2015). In addition to horticultural crops, sample farmers in Kenya cultivate maize, other staple food crops, as well as non-food cash crops such as tea and coffee. Many farms also keep livestock on a small scale.

The data for Ethiopia are taken from the 2010/2011 Ethiopia Socioeconomic Survey supported by LSMS-ISA (World Bank, 2013). The total dataset includes close to 4000 household observations from rural areas and small towns. Out of this total, we excluded those that were not involved in own agricultural production and that had missing data for relevant variables, thus remaining with 2045 observations. The data for Malawi are taken from the 2010/2011 Malawi Integrated Household Survey supported by LSMS-ISA (Jones et al., 2014; World Bank, 2013). The total dataset includes over 12,000 households, of which we use 5114 observations after excluding non-farm households and those with missing data. Farmers in Ethiopia and Malawi are mostly subsistence-oriented, growing various food crops and keeping livestock primarily for home consumption. In some regions, farmers also grow cash crops such as cotton, tea, coffee, and sugarcane.

\subsubsection{Measurement of dietary diversity}

Dietary diversity is usually measured using two indicators: the food variety score and the dietary diversity score (FAO, 2011; Swindale and Bilinsky, 2006; Ruel, 2003; Kant et al., 1993). The food variety score is a simple count of the different food items consumed during the recall period. This is a useful indicator for nutritional assessments within one setting. However, due to cultural differences in dietary habits the food variety score is less suitable for comparisons across countries. Moreover, the item count depends much on the level of food group disaggregation in the questionnaire, which varies by survey. Hence, for cross-country analyses and comparisons the dietary diversity score is preferred (Pellegrini and Tasciotti, 2014; FAO, 2011). The dietary diversity score is the number of food groups consumed by the household during the recall period. 
There is no international consensus on which food groups to include in the calculation of dietary diversity scores. Many studies classify all foods consumed into 12 groups (FAO, 2011; Swindale and Bilinsky, 2006), an approach that we follow for the main part of the analysis. The following 12 food groups are included to calculate household dietary diversity scores: cereals; white tubers and roots; legumes, nuts and seeds; vegetables; fruits; meat; eggs; fish and fish products; milk and milk products; sweets and sugars; oils and fats; spices, condiments, and beverages. However, research has shown that the last three food groups contribute little to the micronutrient density of the diet, so that - depending on the purpose there are also studies that have calculated dietary diversity scores only based on the remaining 9 food groups (FAO, 2011; Arimond et al., 2010). We use dietary diversity scores only including the 9 more healthy food groups in a sensitivity analysis.

\subsubsection{Measurement of production diversity}

In the main part of the analysis, we use the number of crop and livestock species produced on a farm as the measure of production diversity. This is a simple, unweighted count measure. In a set of robustness checks, we use two alternative measures to examine whether this influences the results significantly. First, we use the Margalef species richness index. The Margalef index is often used in the agrobiodiversity literature and accounts for the area cultivated with different crop species on the farm $^{3}$ (Di Falco and Chavas, 2009; Smale et al., 1998). Second, we use a simple, unweighted count of only the food crop species produced on a farm (food crop production diversity). As some of the farms also produce non-food cash crops (e.g., rubber, oil palm, tea, coffee) that do not directly contribute to household dietary diversity, this differentiation may be important from a nutrition perspective. Mean values of these alternative measures of production diversity are shown in Table 2.1.

\footnotetext{
${ }^{3}$ The modified Margalef index $(D)$ is computed as $(S-1) / \ln (A)$, where $S$ is the total number of crop species cultivated by the household and $\ln (A)$ is the natural logarithm of total cultivated area in square meters, with $A \geq$ 1. The larger the index, the greater would be the crop species diversity in a given farm. However, this index may not be compatible to measure diversity in crop-livestock systems, particularly in areas where grazing land is communal.
} 


\subsubsection{Regression models}

To analyze the relationship between on-farm production diversity and dietary diversity we use regression models of the following form:

$$
D D_{i}=\alpha_{0}+\alpha_{1} P D_{i}+\alpha_{2} P D_{i}^{2}+\varepsilon_{i}
$$

where $D D_{i}$ is the dietary diversity score and $P D_{i}$ is production diversity in farm household $i$. A positive and significant estimate for $\alpha_{1}$ implies that higher production diversity is associated with higher dietary diversity, as is commonly assumed. Inclusion of $P D_{i}^{2}$ as the square term of production diversity tests whether the relationship is linear. A negative and significant estimate for $\alpha_{2}$ implies that the strength of the association is diminishing at higher levels of production diversity. $\varepsilon_{i}$ is a random error term.

$D D_{i}$ is a count variable that can take values between 1 and 12 (or between 1 and 9 when only including the more healthy food groups) and is not normally distributed. We use a Poisson estimator with a maximum-likelihood procedure for model estimation (Greene, 2012). With the Poisson distribution, the coefficient estimates can be interpreted as semi-elasticities. That is, a coefficient estimate states by what percentage the dietary diversity score changes when the explanatory variable changes by one unit.

In extended model specifications, we add additional explanatory variables to analyze the role of market access for dietary diversity as follows:

$$
D D_{i}=\alpha_{0}+\alpha_{1} P D_{i}+\alpha_{2} P D_{i}^{2}+\alpha_{3} M A_{i}+\alpha_{4}\left(P D_{i} \times M A_{i}\right)+\varepsilon_{i}
$$

where $M A_{i}$ is a vector of market access indicators such as distance to the closest market and the availability of off-farm income sources for household $i$. Market distance refers to the number of kilometers farmers have to cover to reach the next marketplace to sell their produce. This is usually the next town where they can also buy food and other goods. We use the distance as reported by survey respondents. Data on travel time or road quality were not consistently available across the surveys. Off-farm income is measured with a dummy variable that takes a value of one if the household has any income from off-farm employment or self-employed non-farm activities. 
Market access tends to improve household income, so $\alpha_{3}$ is expected to be positive (negative for market distance, because larger distance means worse market access). With the interaction term between $P D_{i}$ and $M A_{i}$ we test whether market access influences the effect of production diversity on household dietary diversity. Increasing market transactions are expected to reduce the role of production diversity. As a robustness check, we extend the model in equation [2] by including additional variables that may affect dietary diversity, such as farm and household size, as well as age, education, and gender of the household head.

The regression models are estimated separately for each country and also with the data pooled for all four countries. In the pooled data models, we include dummy variables to control for country fixed effects, such as unobserved socioeconomic or cultural differences. The data within and across countries cover a wide spectrum of conditions; all models are estimated with robust standard errors to account for heteroscedasticity (Greene, 2012). Given the different sampling frameworks across countries, which also imply differences in data variability, country-level comparisons are not representative and should be interpreted with some caution.

\subsection{Results}

Descriptive statistics for key variables used in this analysis are shown in Table 2.1 (additional variables are shown in Table A2.1). The average size of farms in the pooled sample covering all four countries is 1.3 hectares, but farm sizes and other socioeconomic characteristics vary significantly within and across countries. There are also wide variations in terms of production diversity and dietary diversity. We use the number of crop and livestock species produced on a farm as the measure of production diversity (in a robustness check we also use other measures). Farmers in the Indonesian sample have very low production diversity with only 1.7 species produced on average. The sample from Indonesia refers to one province in Sumatra, where many farmers do not produce any food but have specialized on rubber and oil palm as plantation crops. In the other countries, production diversity is considerably higher. The highest production diversity is observed in Ethiopia, where farms produce 10.2 different crop and livestock species on average. 
There are different ways to measure dietary diversity; the two most common indicators are the food variety score and the dietary diversity score (Jones et al., 2014; Ruel, 2003). The dietary diversity score, which measures the number of food groups consumed over a given period, is considered more suitable for international comparisons (see Materials and Methods). Table 2.1 shows that household dietary diversity is higher in Indonesia and Kenya than in Ethiopia and Malawi. This is interesting, because the sample farms in Indonesia and Kenya are more specialized on the production of cash crops. Evidently, specialization and lower production diversity are not necessarily associated with lower dietary diversity, when diverse types of foods can be purchased from the market. These relations are analyzed in more detail in the following.

Table 2. 1: Descriptive statistics by country

\begin{tabular}{|c|c|c|c|c|c|}
\hline Household characteristics & Pooled & Indonesia & Kenya & Ethiopia & Malawi \\
\hline Farm size (ha) & $\begin{array}{l}1.26 \\
(2.60)\end{array}$ & $\begin{array}{l}4.50 \\
(7.42)\end{array}$ & $\begin{array}{c}0.71 \\
(0.94)\end{array}$ & $\begin{array}{c}1.63 \\
(1.91)\end{array}$ & $\begin{array}{c}0.74 \\
(0.60)\end{array}$ \\
\hline $\begin{array}{l}\text { Production diversity (number of } \\
\text { crop/livestock species produced) }\end{array}$ & $\begin{array}{c}6.13 \\
(4.75)\end{array}$ & $\begin{array}{c}1.74 \\
(0.91)\end{array}$ & $\begin{array}{c}7.82 \\
(2.58)\end{array}$ & $\begin{array}{l}10.19 \\
(5.81)\end{array}$ & $\begin{array}{l}4.80 \\
(3.08)\end{array}$ \\
\hline $\begin{array}{l}\text { Food crop production diversity (number of } \\
\text { food crop species produced) }\end{array}$ & $\begin{array}{c}3.62 \\
(2.96)\end{array}$ & $\begin{array}{c}0.29 \\
(0.76)\end{array}$ & $\begin{array}{c}4.72 \\
(1.51)\end{array}$ & $\begin{array}{c}6.30 \\
(3.64)\end{array}$ & $\begin{array}{c}2.90 \\
(1.90)\end{array}$ \\
\hline Margalef species richness index & $\begin{array}{c}0.44 \\
(0.47)\end{array}$ & $\begin{array}{c}0.16 \\
(0.10)\end{array}$ & $\begin{array}{c}0.79 \\
(0.28)\end{array}$ & $\begin{array}{c}0.85 \\
(0.65)\end{array}$ & $\begin{array}{c}0.28 \\
(0.25)\end{array}$ \\
\hline $\begin{array}{l}\text { Food variety score (number of food items } \\
\text { consumed) }\end{array}$ & $\begin{array}{l}15.94 \\
(8.43)\end{array}$ & $\begin{array}{l}29.58 \\
(8.11)\end{array}$ & $\begin{array}{l}24.68 \\
(4.64)\end{array}$ & $\begin{array}{l}7.91 \\
(2.31)\end{array}$ & $\begin{array}{l}16.68 \\
(6.72)\end{array}$ \\
\hline $\begin{array}{l}\text { Dietary diversity score (number of food } \\
\text { groups consumed) }\end{array}$ & $\begin{array}{l}7.99 \\
(2.48)\end{array}$ & $\begin{array}{l}10.02 \\
(1.29)\end{array}$ & $\begin{array}{l}11.40 \\
(0.97)\end{array}$ & $\begin{array}{c}5.42 \\
(1.70)\end{array}$ & $\begin{array}{l}8.48 \\
(2.02)\end{array}$ \\
\hline Market distance $(\mathrm{km})$ & $\begin{array}{c}21.27 \\
(33.37)\end{array}$ & $\begin{array}{c}6.55 \\
(7.41)\end{array}$ & $\begin{array}{c}3.09 \\
(3.58)\end{array}$ & $\begin{array}{c}63.53 \\
(47.50)\end{array}$ & $\begin{array}{c}8.17 \\
(5.71)\end{array}$ \\
\hline Off-farm income (dummy) & 0.36 & 0.48 & 0.51 & 0.32 & 0.35 \\
\hline Number of observations & 8230 & 674 & 397 & 2045 & 5114 \\
\hline
\end{tabular}

Notes: Mean values are shown with standard deviations in parentheses. Additional variables are shown in Table A2.1.

\subsubsection{Association between production diversity and dietary diversity}

Table 2.2 shows results of regression models where dietary diversity is used as dependent variable and farm production diversity as explanatory variable. Farm production diversity is positively associated with dietary diversity, but the effect is relatively small. In the pooled sample, producing one additional crop or livestock species leads to a $0.9 \%$ increase in the number of food groups consumed. 
The magnitude of this effect varies by country. In Kenya and Ethiopia, the coefficient estimates are very small and not statistically significant. In these two countries, average production diversity is quite high; further increasing farm diversity would hardly contribute to higher dietary diversity. In Indonesia, the estimated coefficient is larger, which is due to the low average production diversity observed. Many farmers in the Indonesian sample only grow rubber. Those that grow an additional crop usually adopt oil palm, which contributes to higher household incomes. Hence, the improvement in dietary quality in Indonesia is attributable primarily to rising incomes from cash crop sales rather than more diverse subsistence production.

Table 2. 2: Association between production diversity and dietary diversity

\begin{tabular}{lccccc}
\hline Explanatory variables & Pooled & Indonesia & Kenya & Ethiopia & Malawi \\
\hline Production diversity & $0.009^{* * *}$ & $0.054^{* * * *}$ & 0.003 & 0.002 & $0.015^{* * *}$ \\
& $(0.002)$ & $(0.015)$ & $(0.010)$ & $(0.004)$ & $(0.002)$ \\
Production diversity squared & $-1.4 \mathrm{E}-04^{*}$ & $-0.007^{* * *}$ & $1.4 \mathrm{E}-04$ & $1.3 \mathrm{E}-04$ & $-3.2 \mathrm{E}-04^{* *}$ \\
& $(8.6 \mathrm{E}-05)$ & $(0.003)$ & $(5.7 \mathrm{E}-04)$ & $(1.5 \mathrm{E}-04)$ & $(1.4 \mathrm{E}-04)$ \\
Model intercept & $1.613^{* * *}$ & $2.238^{* * *}$ & $2.403^{* * *}$ & $1.653^{* * *}$ & $2.074^{* * *}$ \\
& $(0.012)$ & $(0.018)$ & $(0.038)$ & $(0.024)$ & $(0.009)$ \\
Number of observations & 8230 & 674 & 397 & 2045 & 5114 \\
\hline
\end{tabular}

Notes: The dependent variable in all models is the dietary diversity score of households, including 12 food groups. Models were estimated with a Poisson estimator. Coefficient estimates are shown with robust standard errors in parentheses. The pooled data model was estimated with country fixed effects. See Table A2.3 for full results. $* * *, * * *$ Statistically significant at the $10 \%, 5 \%$, and $1 \%$ level, respectively.

The models in Table 2.2 also include a square term for farm production diversity, which is negative in most cases. This means that the effect on dietary diversity diminishes, probably because foregone benefits from specialization become more relevant for farms that are already highly diversified.

\subsubsection{Role of market access}

We now analyze more explicitly how access to markets affects dietary diversity by including additional explanatory variables into the regression models. One indicator of market access is the geographic distance from the farm household to the closest market where food can be sold or bought. The estimated coefficients are negative in all models (Table 2.3), implying that households in remoter regions have lower dietary diversity. Better market access through reduced distances could therefore contribute to higher dietary diversity. Comparing the 
magnitude of the estimated coefficients in the pooled model reveals that reducing market distance by 10 kilometers has the same effect on dietary diversity as increasing farm production diversity by one additional crop or livestock species.

Table 2. 3: Production diversity, market access, and dietary diversity

\begin{tabular}{lccccc}
\hline Explanatory variables & Pooled & Indonesia & Kenya & Ethiopia & Malawi \\
\hline Production diversity & $0.010^{* * *}$ & $0.048^{* * *}$ & 0.001 & 0.006 & $0.011^{* * *}$ \\
& $(0.002)$ & $(0.016)$ & $(0.010)$ & $(0.004)$ & $(0.003)$ \\
Production diversity squared & $-1.5 \mathrm{E}-04$ & $-0.008^{* * *}$ & $2.0 \mathrm{E}-04$ & $1.1 \mathrm{E}-04$ & $-1.5 \mathrm{E}-04$ \\
& $(9.7 \mathrm{E}-05)$ & $(0.003)$ & $(0.001)$ & $(1.5 \mathrm{E}-04)$ & $(1.5 \mathrm{E}-04)$ \\
Market distance & $-0.001^{* * *}$ & -0.002 & -0.006 & $-0.001^{*}$ & $-0.014^{* * *}$ \\
& $(2.6 \mathrm{E}-04)$ & $(0.002)$ & $(0.005)$ & $(3.1 \mathrm{E}-04)$ & $(0.002)$ \\
[Production diversity] x [Market & $1.6 \mathrm{E}-05$ & $-6.9 \mathrm{E}-05$ & $5.0 \mathrm{E}-04$ & $-2.0 \mathrm{E}-05$ & $4.3 \mathrm{E}-04^{*}$ \\
distance] & $(2.0 \mathrm{E}-05)$ & $(0.001)$ & $(5.5 \mathrm{E}-04)$ & $(2.6 \mathrm{E}-05)$ & $(2.2 \mathrm{E}-04)$ \\
Off-farm income & $0.039^{* * *}$ & -0.009 & $0.059^{* *}$ & $0.073^{* *}$ & $0.083^{* * *}$ \\
& $(0.008)$ & $(0.020)$ & $(0.029)$ & $(0.029)$ & $(0.013)$ \\
[Production diversity] x [Off-farm & $-0.002^{*}$ & $0.020^{* *}$ & -0.002 & $-3.5 \mathrm{E}-04$ & $-0.004^{*}$ \\
income] & $(0.001)$ & $(0.010)$ & $(0.003)$ & $(0.002)$ & $(0.002)$ \\
Model intercept & $1.662^{* * *}$ & $2.250^{* * *}$ & $2.425^{* * *}$ & $1.652^{* * *}$ & $2.111^{* * *}$ \\
& $(0.014)$ & $(0.021)$ & $(0.043)$ & $(0.031)$ & $(0.015)$ \\
Number of observations & 8230 & 674 & 397 & 2045 & 5114 \\
\hline
\end{tabular}

Notes: The dependent variable in all models is the dietary diversity score of households, including 12 food groups. Models were estimated with a Poisson estimator. Coefficient estimates are shown with robust standard errors in parentheses. The pooled data model was estimated with country fixed effects. See Table A2.3 for full results. ${ }^{*}{ }^{* *},{ }^{* * *}$ Statistically significant at the $10 \%, 5 \%$, and $1 \%$ level, respectively.

The interaction term between production diversity and market distance is insignificant in most cases (Table 2.3). The positive and significant interaction coefficient in the Malawi model suggests that the role of production diversity is more important in remoter regions where farms tend to be more subsistence-oriented. This effect is expected.

Another indicator of market access is the availability of off-farm income sources. Many smallholders complement their farm income with off-farm income when employment opportunities in other sectors arise. Results in Table 2.3 show that off-farm income is associated with higher dietary diversity. Cash earnings from off-farm activities increase the households' ability to buy diverse foods from the market. Interestingly, this effect is much larger than the effect from increasing farm production diversity. The interaction term between off-farm income and production diversity shows mixed results. The negative coefficients in some of the models imply that the availability of off-farm income reduces the role of farm production diversity for household nutritional quality. 
The result that market access improves dietary diversity is interesting, but a relevant question is whether this also leads to more healthy diets. Depending on the type of food outlets available in a particular context, buying food may possibly be associated with rather unhealthy dietary diversification, for instance, through increased consumption of fats, sweets, or sugary beverages. To examine this further, we re-estimated the models by using alternative dietary diversity scores as dependent variables, only including more healthy food groups (see Materials and Methods). The finding that better market access tends to increase dietary diversity also holds with this alternative specification (Table A2.2).

\subsubsection{Role of selling and buying food}

The role of markets can also be assessed by looking more directly at what households sell and buy. This information is only available for the samples from Ethiopia and Malawi, but this part of the analysis is also more interesting for these countries, because sample farmers in Indonesia and Kenya are much more commercialized anyway. We proceed with a pooled sample from Ethiopia and Malawi only. In column (1) of Table 2.4 we include a dummy as additional explanatory variable that takes a value of one if the household sells at least parts of its farm produce to the market. The estimated coefficient is positive and significant. It is also much larger than the production diversity coefficient. This comparison suggests that facilitating the commercialization of smallholder farms may be a better strategy to improve nutrition than promoting more diversified subsistence production. Furthermore, the negative and significant interaction term confirms that market participation reduces the role of production diversity for dietary quality.

In column (2) of Table 2.4, we use a different dependent variable and now look at dietary diversity only with respect to the food purchased in the market. The farm production diversity coefficient in this model is significantly negative, meaning that more diversified farms tend to buy less diversified foods in the market. This is perhaps not surprising: if the farm produces diverse foods itself, diversity from the market may not be needed to the same extent. However, diversified own production can substitute for diversity from the market only partially, as more than half of all the food consumed in sample households is purchased (Table A2.1). The negative interaction terms between farm production diversity, distance to 
market, and harvest sold suggest that subsistence orientation tends to reduce the diversity of foods purchased in the market. The other coefficients in column (2) of Table 2.4 are as expected. Better market access in terms of shorter distance and more off-farm income opportunities increase the level of purchased food diversity.

Table 2. 4: Production diversity, market participation, and dietary diversity in Ethiopia and Malawi (pooled sample)

\begin{tabular}{lcc}
\hline Explanatory variables & $\begin{array}{c}(1) \\
\text { Dietary diversity score with } \\
\text { respect to all foods }\end{array}$ & $\begin{array}{c}(2) \\
\text { Dietary diversity score with } \\
\text { respect to purchased foods }\end{array}$ \\
\hline Production diversity & $0.010^{* * * *}$ & $-0.013^{* * * *}$ \\
& $(0.002)$ & $(0.003)$ \\
Production diversity squared & $6.2 \mathrm{E}-06$ & $0.001^{* * * *}$ \\
& $(1.1 \mathrm{E}-04)$ & $(1.5 \mathrm{E}-04)$ \\
Market distance & $-4.4 \mathrm{E}-04^{*}$ & $-0.002^{* * * *}$ \\
& $(2.7 \mathrm{E}-04)$ & $(4.7 \mathrm{E}-04)$ \\
[Production diversity] x [Market & $-2.6 \mathrm{E}-05$ & $-9.1 \mathrm{E}-05^{* * *}$ \\
distance] & $(2.2 \mathrm{E}-05)$ & $(3.8 \mathrm{E}-05)$ \\
Produce sold to market & $0.045^{* * *}$ & 0.020 \\
& $(0.016)$ & $(0.021)$ \\
[Production diversity] x [Produce & $-0.005^{* * *}$ & $-0.007^{* * *}$ \\
sold] & $(0.002)$ & $(0.002)$ \\
Off-farm income & $0.075^{* * * *}$ & $0.099^{* * * *}$ \\
& $(0.011)$ & $(0.015)$ \\
[Production diversity] x [Off-farm & -0.001 & 0.001 \\
income] & $(0.001)$ & $(0.002)$ \\
Malawi (dummy) & $0.479^{* * * *}$ & $0.572^{* * * *}$ \\
Model intercept & $(0.011)$ & $(0.017)$ \\
& $1.613^{* * * *}$ & $1.450^{* * * *}$ \\
Number of observations & $(0.016)$ & $(0.023)$ \\
\hline Notes: For the & 7159 & 7159 \\
\hline
\end{tabular}

Notes: For the calculation of the dietary diversity scores, 12 food groups were included. Models were estimated with a Poisson estimator. Coefficient estimates are shown with robust standard errors in parentheses. ${ }^{* * *},{ }^{* * *}$ Statistically significant at the $10 \%, 5 \%$, and $1 \%$ level, respectively.

\subsubsection{Robustness checks}

There are several other factors that may influence dietary diversity in smallholder farm households. The objective of this study is to better understand the role of farm production diversity in different situations, not to fully explain dietary diversity and all its influencing factors. Nevertheless, farm production diversity may be correlated with some of the omitted factors, which could potentially bias the estimation results. To test for such bias, we reestimated the regression models, this time including socioeconomic and demographic 
characteristics - such as farm and household size, as well as age, education, and gender of the household head - as additional explanatory variables. Some of these other factors are significant, but the estimation coefficients for farm production diversity and market access do not change much (Tables A2.3 and A2.4). We interpret this as evidence that the main results do not suffer from omitted variable bias.

In other sets of robustness checks, we used alternative measures of production diversity, namely the Margalef species richness index, which weights by the area grown with different crops, and a species count only including food crops as opposed to non-food cash crops (see Materials and Methods). We re-estimated the different regression models with these alternative measures (Tables A2.5-A2.10). The findings are largely in line with those discussed above. Hence, the results do not seem to be driven by the way production diversity is measured. Interestingly, when only including food crops the effect of production diversity on dietary diversity is even smaller and insignificant in most cases (Tables A2.8 and A2.9), whereas the negative effect on food diversity purchased from the market gets stronger (Table A2.10). These results underline the importance of market interactions and strengthen the statement that non-food cash crop production can also contribute to improved dietary quality through the income pathway.

\subsection{Discussion and Conclusion}

Increasing people's dietary diversity is an important strategy to improve nutrition and health. At aggregate level, this also requires diversification of agricultural systems. A research and policy focus on only a few cereal crops, as was sometimes observed during past decades, may have been useful to address issues of calorie undersupply, but seems less suitable to deal with problems of various nutritional deficiencies. While sustainably increasing the productivity of cereal crops remains a continuous challenge, agricultural research and policy efforts need to be broadened and also include the promotion of plant and animal species that were rather neglected in the past. Improved technologies and market potentials for a broader set of agricultural species would increase farmers' incentives to adopt alternatives best suited to 
their conditions. The optimal mix will vary from one location to another. More diverse agricultural systems are also good for biodiversity and the environment.

Yet, this plea for more diverse agriculture should not be misunderstood in a way that every individual farm should increase the level of production diversity. Especially in smallholder systems of Africa, the number of different species produced is often quite high anyway. Resource-poor farmers diversify their sources of food and income as a risk-coping strategy. Our analysis with data from different African and Asian countries showed that farm production diversity is positively associated with dietary diversity in some situations, but not in all. The results also revealed that the effect is not linear. When production diversity is already high, the dietary diversity relationship is not significant, or it even turns negative, because of foregone income resulting from farm diversification beyond optimal levels.

We also showed that smallholder access to agricultural markets and off-farm employment has positive effects on household dietary diversity. These market effects are larger than those of increased production diversity in most cases. Comparisons show that more commercialized farms that produce cash crops for the market have more diverse diets than subsistence farms on average. Households with higher cash incomes tend to buy more diverse foods from the market. This food diversity from the market cannot be fully substituted through diverse subsistence production.

While improved market access often provides incentives for farmers to specialize, actual outcomes depend on many factors, not all of which were analyzed here. Where properly functioning markets for various commodities exist, commercial orientation of farms and high levels of production diversity are not necessarily a contradiction. More research is needed to better understand how agriculture and food systems can be made more nutrition-sensitive in particular situations. This also needs to take into account institutional and cultural aspects at the local level. Promoting production diversity may help in some situations. But our results suggest that increasing on-farm diversity among smallholders is not always the most effective way to improve dietary diversity and should not be considered a goal in itself.

In conclusion, the common assumption that higher farm production diversity is always conducive for household nutrition needs adjustment. The most suitable policy mix to improve 
nutrition in smallholder farm households will vary from case to case. In many situations, facilitating market access through improved infrastructure and other policies to reduce transaction costs and price distortions seems to be more promising than promoting further production diversification as such. 


\section{Appendix A2: Additional Tables}

Table A2. 1: Descriptive statistics by country

\begin{tabular}{|c|c|c|c|c|c|}
\hline Household characteristics & Pooled & Indonesia & Kenya & Ethiopia & Malawi \\
\hline \multirow[t]{2}{*}{ Farm size (ha) } & 1.26 & 4.50 & 0.71 & 1.63 & 0.74 \\
\hline & $(2.60)$ & $(7.42)$ & $(0.94)$ & $(1.91)$ & $(0.60)$ \\
\hline \multirow{2}{*}{$\begin{array}{l}\text { Production diversity (number of crop/livestock } \\
\text { species produced) }\end{array}$} & 6.13 & 1.74 & 7.82 & 10.19 & 4.80 \\
\hline & $(4.75)$ & $(0.91)$ & $(2.58)$ & $(5.81)$ & $(3.08)$ \\
\hline \multirow{2}{*}{$\begin{array}{l}\text { Food crop production diversity (number of } \\
\text { food crop species produced) }\end{array}$} & 3.62 & 0.29 & 4.72 & 6.30 & 2.90 \\
\hline & $(2.96)$ & $(0.76)$ & $(1.51)$ & $(3.64)$ & $(1.90)$ \\
\hline \multirow[t]{2}{*}{ Margalef species richness index } & 0.44 & 0.16 & 0.79 & 0.85 & 0.28 \\
\hline & $(0.47)$ & $(0.10)$ & $(0.28)$ & $(0.65)$ & $(0.25)$ \\
\hline Produce sold to market (dummy) & -- & -- & -- & 0.41 & 0.12 \\
\hline \multirow[t]{2}{*}{ Household size (number of people) } & 4.87 & 4.20 & 4.47 & 5.25 & 4.83 \\
\hline & $(2.07)$ & $(1.52)$ & $(1.71)$ & $(2.12)$ & $(2.10)$ \\
\hline \multirow[t]{2}{*}{ Age of HH head (years) } & 41.96 & 45.71 & 52.01 & 44.51 & 39.71 \\
\hline & $(14.82)$ & $(12.17)$ & $(13.66)$ & $(15.08)$ & $(14.55)$ \\
\hline Male HH head (dummy) & 0.83 & 0.95 & 0.88 & 0.82 & 0.82 \\
\hline \multirow[t]{2}{*}{ Education of HH head (years) } & 5.38 & 7.50 & 9.64 & 1.54 & 6.29 \\
\hline & $(4.40)$ & $(3.63)$ & $(3.70)$ & $(2.81)$ & $(4.06)$ \\
\hline \multirow[t]{2}{*}{ Market distance $(\mathrm{km})$} & 21.27 & 6.55 & 3.09 & 63.53 & 8.17 \\
\hline & $(33.37)$ & $(7.41)$ & $(3.58)$ & $(47.50)$ & $(5.71)$ \\
\hline Off-farm income (dummy) & 0.36 & 0.48 & 0.51 & 0.32 & 0.35 \\
\hline \multirow{2}{*}{$\begin{array}{l}\text { Food variety score (number of food items } \\
\text { consumed) }\end{array}$} & 15.94 & 29.58 & 24.68 & 7.91 & 16.68 \\
\hline & $(8.43)$ & (8.11) & (4.64) & $(2.31)$ & (6.72) \\
\hline \multirow{2}{*}{$\begin{array}{l}\text { Food variety score only with respect to } \\
\text { purchased foods }\end{array}$} & -- & -- & -- & 4.50 & 12.13 \\
\hline & & & & $(2.27)$ & $(5.82)$ \\
\hline \multirow{2}{*}{$\begin{array}{l}\text { Dietary diversity score (number of food } \\
\text { groups consumed) }\end{array}$} & 7.99 & 10.02 & 11.40 & 5.42 & 8.48 \\
\hline & $(2.48)$ & (1.29) & $(0.97)$ & (1.70) & $(2.02)$ \\
\hline \multirow{2}{*}{$\begin{array}{l}\text { Dietary diversity score of healthy foods } \\
\text { (number of healthy food groups consumed) }\end{array}$} & 5.51 & 7.02 & 7.33 & 3.24 & 6.07 \\
\hline & (1.97) & (1.29) & $(0.84)$ & (1.31) & (1.53) \\
\hline \multirow{2}{*}{$\begin{array}{l}\text { Dietary diversity score only with respect to } \\
\text { purchased foods }\end{array}$} & -- & -- & -- & 3.47 & 7.37 \\
\hline & & & & (1.68) & $(2.33)$ \\
\hline \multirow[t]{2}{*}{ Food purchase from market ( $\%$ of total food) } & -- & -- & -- & 54.75 & 61.33 \\
\hline & & & & $(21.11)$ & (19.68) \\
\hline Number of observations & 8230 & 674 & 397 & 2045 & 5114 \\
\hline
\end{tabular}

Notes: Mean values are shown with standard deviations in parentheses. HH, household. 
Table A2. 2: Production diversity, market access, and dietary diversity of healthy foods

\begin{tabular}{lccccc}
\hline Explanatory variables & Pooled & Indonesia & Kenya & Ethiopia & Malawi \\
\hline Production diversity & $0.015^{* * *}$ & $0.067^{* * *}$ & 0.003 & $0.018^{* * *}$ & $0.013^{* * *}$ \\
& $(0.002)$ & $(0.022)$ & $(0.014)$ & $(0.006)$ & $0.003)$ \\
Production diversity squared & $-2.8 \mathrm{E}-04^{* *}$ & $-0.011^{* * *}$ & $1.3 \mathrm{E}-04$ & $-2.0 \mathrm{E}-04$ & $-1.9 \mathrm{E}-04$ \\
& $(1.3 \mathrm{E}-04)$ & $(0.004)$ & $(0.001)$ & $(2.0 \mathrm{E}-04)$ & $(1.6 \mathrm{E}-04)$ \\
Market distance & $-0.001^{* *}$ & -0.002 & -0.010 & $-1.2 \mathrm{E}-04$ & $-0.014^{* * *}$ \\
& $(3.3 \mathrm{E}-04)$ & $(0.002)$ & $(0.007)$ & $(4.0 \mathrm{E}-04)$ & $(0.002)$ \\
[Production diversity] x [Market & $6.4 \mathrm{E}-05^{* *}$ & $-1.1 \mathrm{E}-04$ & 0.001 & $7.4 \mathrm{E}-06$ & $3.9 \mathrm{E}-04^{*}$ \\
distance] & $(2.6 \mathrm{E}-05)$ & $(0.001)$ & $(0.001)$ & $(3.3 \mathrm{E}-05)$ & $(2.3 \mathrm{E}-04)$ \\
Off-farm income & $0.040^{* * *}$ & -0.014 & 0.001 & $0.095^{* *}$ & $0.084^{* * *}$ \\
& $(0.011)$ & $(0.029$ & $(0.036)$ & $(0.039)$ & $(0.014)$ \\
[Production diversity] x [Off-farm & -0.002 & $0.028^{* *}$ & -0.003 & $-1.8 \mathrm{E}-04$ & $-0.004^{*}$ \\
income] & $(0.001)$ & $(0.014)$ & $(0.004)$ & $(0.003)$ & $(0.002)$ \\
Indonesia (dummy) & $0.845^{* * *}$ & -- & -- & -- & -- \\
Kenya (dummy) & $(0.017)$ & & & -- & - \\
Malawi (dummy) & $0.820^{* * *}$ & -- & & - & - \\
Model intercept & $(0.016)$ & & - & - & $1.770^{* * *}$ \\
Number of observations & $0.669^{* * *}$ & -- & & & $(0.016)$ \\
\hline
\end{tabular}

Notes: The dependent variable in all models is the dietary diversity score of households, only including the 9 more healthy food groups (excluding sweets and sugars; oils and fats; spices, condiments, and beverages). Models were estimated with a Poisson estimator. Coefficient estimates are shown with robust standard errors in parentheses. ${ }^{*},{ }^{* * * * *}$ Statistically significant at the $10 \%, 5 \%$, and $1 \%$ level, respectively. 
Table A2. 3: Factors influencing dietary diversity in Indonesia, Kenya, Ethiopia, and Malawi (pooled sample)

\begin{tabular}{|c|c|c|c|c|}
\hline Explanatory variables & $(1)$ & $(2)$ & (3) & (4) \\
\hline \multirow[t]{2}{*}{ Production diversity } & $0.009^{* * * *}$ & $0.010^{* * *}$ & $0.010^{\text {**** }}$ & $0.008^{* * * *}$ \\
\hline & $(0.002)$ & $(0.002)$ & $(0.002)$ & $(0.002)$ \\
\hline \multirow[t]{2}{*}{ Production diversity squared } & $-1.4 \mathrm{E}-04^{*}$ & $-1.7 \mathrm{E}-04$ & $-1.5 \mathrm{E}-04$ & $-1.3 \mathrm{E}-04$ \\
\hline & $(8.6 \mathrm{E}-05)$ & $(9.7 \mathrm{E}-05)$ & $(9.7 \mathrm{E}-05)$ & $(9.4 \mathrm{E}-05)$ \\
\hline \multirow[t]{2}{*}{ Market distance } & -- & $-0.001^{* * *}$ & $-0.001^{* * * *}$ & $-0.001^{* * *}$ \\
\hline & & $(2.6 \mathrm{E}-04)$ & $(2.6 \mathrm{E}-04)$ & $(2.5 \mathrm{E}-04)$ \\
\hline \multirow[t]{2}{*}{ Off-farm income } & -- & -- & $0.039^{* * *}$ & $0.037^{* * *}$ \\
\hline & & & $(0.008)$ & $(0.008)$ \\
\hline \multirow[t]{2}{*}{ Age of $\mathrm{HH}$ head } & -- & -- & -- & $-0.001^{* * *}$ \\
\hline & & & & $(1.9 \mathrm{E}-04)$ \\
\hline \multirow[t]{2}{*}{ Farm size } & -- & -- & -- & $0.006^{* * *}$ \\
\hline & & & & $(0.001)$ \\
\hline \multirow[t]{2}{*}{ Farm size squared } & -- & -- & -- & $-5.9 \mathrm{E}-05^{* *}$ \\
\hline & & & & $(2.9 \mathrm{E}-05)$ \\
\hline \multirow[t]{2}{*}{ Household size } & -- & -- & -- & $0.007^{* * *}$ \\
\hline & & & & $(0.001)$ \\
\hline \multirow[t]{2}{*}{ Male HH head } & -- & -- & -- & $0.029^{* * *}$ \\
\hline & & & & $(0.007)$ \\
\hline \multirow[t]{2}{*}{ Education of $\mathrm{HH}$ head } & -- & -- & -- & $0.009^{* * *}$ \\
\hline & & & & $(0.001)$ \\
\hline \multirow{2}{*}{$\begin{array}{l}\text { [Production diversity]x[Market } \\
\text { distance] }\end{array}$} & -- & $1.5 \mathrm{E}-05$ & $1.6 \mathrm{E}-05$ & $3.1 \mathrm{E}-06$ \\
\hline & & $(2.0 \mathrm{E}-05)$ & $(2.0 \mathrm{E}-05)$ & $(1.9 \mathrm{E}-05)$ \\
\hline \multirow{2}{*}{$\begin{array}{l}\text { [Production diversity]x[Off-farm } \\
\text { income] }\end{array}$} & -- & -- & $-0.002^{*}$ & -0.001 \\
\hline & & & $(0.001)$ & $(0.001)$ \\
\hline \multirow[t]{2}{*}{ Indonesia (dummy) } & $0.675^{* * *}$ & $0.622^{* * *}$ & $0.615^{* * *}$ & $0.545^{* * *}$ \\
\hline & $(0.011)$ & $(0.013)$ & $(0.013)$ & $(0.014)$ \\
\hline \multirow[t]{2}{*}{ Kenya (dummy) } & $0.748^{* * *}$ & $0.690^{* * * *}$ & $0.686^{* * * *}$ & $0.623^{* * *}$ \\
\hline & $(0.008)$ & $(0.011)$ & $(0.011)$ & $(0.013)$ \\
\hline \multirow[t]{2}{*}{ Malawi (dummy) } & $0.485^{* * *}$ & $0.433^{* * *}$ & $0.431^{* * * *}$ & $0.386^{* * *}$ \\
\hline & $(0.008)$ & $(0.011)$ & $(0.011)$ & $(0.011)$ \\
\hline \multirow[t]{2}{*}{ Model intercept } & $1.613^{* * *}$ & $1.673^{* * *}$ & $1.662^{* * *}$ & $1.615^{* * *}$ \\
\hline & $(0.012)$ & $(0.014)$ & $(0.014)$ & $(0.017)$ \\
\hline Number of observations & 8230 & 8230 & 8230 & 8230 \\
\hline
\end{tabular}

Notes: The dependent variable in all models is the dietary diversity score of households, including 12 food groups. Models were estimated with a Poisson estimator. Coefficient estimates are shown with robust standard errors in parentheses. HH, household. Variable mean values and units of measurement are shown in Table A2.1. ${ }^{* * *},{ }^{* * *}$ Statistically significant at the $10 \%, 5 \%$, and $1 \%$ level, respectively. 
Table A2. 4: Factors influencing dietary diversity in Ethiopia and Malawi (pooled sample)

Explanatory variables

Production diversity

Production diversity squared

Market distance

Produce sold

Off-farm income

Age of $\mathrm{HH}$ head

Farm size

Household size

Male HH head

Education of $\mathrm{HH}$ head

Education squared

[Production diversity] x [Market distance]

[Production diversity] x [Produce sold]

[Production diversity] x [Off-farm income]

Malawi (dummy)

Model intercept

Number of observations
(1)

Dietary diversity score with respect to all foods

$0.009^{* * *}$

(0.002)

9.2E-06

(1.0E-04)

$-3.6 \mathrm{E}-04$

(2.6E-04)

$0.039^{* *}$

(0.015)

$0.069^{* * *}$

$(0.011)$

$-0.001^{\text {**** }}$

(2.4E-04)

$0.006^{*}$

(0.003)

$0.011^{* * *}$

(0.002)

$0.027^{* * *}$

(0.009)

$0.009^{* * *}$

(0.002)

0.001 **

(1.4E-04)

$-4.1 \mathrm{E}-05^{* *}$

(2.1E-05)

$-0.004^{* * *}$

(0.002)

$-0.001$

(0.001)

$0.379^{* * * *}$

(0.012)

$1.577^{\text {*** }}$

(0.020)

7159
(2)

Dietary diversity score with respect to purchased foods

$-0.012^{*}$

(0.003)

$0.001^{\text {*** }}$

(1.5E-04)

$-0.002^{* * *}$

(4.6E-04)

0.012

(0.021)

$0.089^{* * *}$

(0.014)

$-0.002^{* * *}$

(3.2E-04)

0.006

$(0.005)$

$0.011^{* * *}$

(0.002)

$0.031^{* * *}$

$(0.012)$

$0.008^{* * * *}$

(0.003)

$0.001^{\text {**** }}$

(1.8E-04)

$-1.2 \mathrm{E}-04^{* * * *}$

(3.7E-05)

$-0.006^{* *}$

(0.002)

0.001

(0.002)

$0.481^{* * *}$

(0.018)

$1.436^{* * *}$

(0.028)

7159

Notes: For the calculation of the dietary diversity scores, 12 food groups were included. Models were estimated with a Poisson estimator. Coefficient estimates are shown with robust standard errors in parentheses. $\mathrm{HH}$, household. Variable mean values and units of measurement are shown in Table A2.1. *, ****** Statistically significant at the $10 \%, 5 \%$, and $1 \%$ level, respectively. 
Table A2. 5: Association between production diversity measured with the Margalef index and dietary diversity

\begin{tabular}{|c|c|c|c|c|c|}
\hline Explanatory variables & Pooled & Indonesia & Kenya & Ethiopia & Malawi \\
\hline \multirow[t]{2}{*}{ Margalef index } & $0.049^{* * *}$ & $0.310^{* *}$ & -0.024 & $0.038^{* *}$ & $0.094^{* * * *}$ \\
\hline & $(0.011)$ & $(0.158)$ & $(0.080)$ & $(0.018)$ & $(0.027)$ \\
\hline \multirow[t]{2}{*}{ Margalef index squared } & 0.001 & -0.321 & 0.029 & 0.004 & -0.013 \\
\hline & $(0.003)$ & $(0.320)$ & $(0.047)$ & $(0.005)$ & $(0.021)$ \\
\hline Indonesia (dummy) & $\begin{array}{c}0.652^{* * * *} \\
(0.010)\end{array}$ & -- & -- & -- & -- \\
\hline Kenya (dummy) & $\begin{array}{c}0.750^{* * * *} \\
(0.008)\end{array}$ & -- & -- & -- & -- \\
\hline Malawi (dummy) & $\begin{array}{c}0.480^{* * * *} \\
(0.009)\end{array}$ & -- & -- & -- & -- \\
\hline \multirow[t]{2}{*}{ Model intercept } & $1.644^{* * * *}$ & $2.267^{* * *}$ & $2.432^{* * *}$ & $1.652^{* * * *}$ & $2.114^{* * *}$ \\
\hline & $(0.010)$ & $(0.016$ & $(0.031)$ & $(0.013)$ & $(0.006)$ \\
\hline Number of observations & 8230 & 674 & 397 & 2045 & 5114 \\
\hline
\end{tabular}

Notes: The dependent variable in all models is the dietary diversity score of households, including 12 food groups. Models were estimated with a Poisson estimator. Coefficient estimates are shown with robust standard errors in parentheses. ${ }^{*},{ }^{* *},{ }^{* * *}$ Statistically significant at the $10 \%, 5 \%$, and $1 \%$ level, respectively. 
Table A2. 6: Production diversity measured with Margalef index, market access, and dietary diversity

\begin{tabular}{|c|c|c|c|c|c|}
\hline Explanatory variables & Pooled & Indonesia & Kenya & Ethiopia & Malawi \\
\hline \multirow[t]{2}{*}{ Margalef index } & $0.058^{* * * *}$ & 0.244 & -0.025 & $0.062^{* * *}$ & $0.079^{* * *}$ \\
\hline & $(0.012)$ & $(0.158)$ & $(0.081)$ & $(0.026)$ & $(0.036)$ \\
\hline \multirow[t]{2}{*}{ Margalef index squared } & $-3.0 \mathrm{E}-04$ & -0.304 & 0.039 & 0.001 & 0.009 \\
\hline & $(0.004)$ & $(0.298)$ & $(0.045)$ & $(0.005)$ & $(0.023)$ \\
\hline \multirow[t]{2}{*}{ Market distance } & $-0.001^{* * *}$ & -0.001 & $-0.004^{*}$ & $-9.3 \mathrm{E}-05$ & -0.001 \\
\hline & $(2.2 \mathrm{E}-04)$ & $(0.001)$ & $(0.002)$ & $(2.4 \mathrm{E}-04)$ & $(0.001)$ \\
\hline [Margalef index] x [Market & $1.6 \mathrm{E}-04$ & -0.001 & 0.002 & 0.001 & 0.001 \\
\hline distance] & $(1.8 \mathrm{E}-04)$ & $(0.006)$ & $(0.003)$ & $(0.003)$ & $(0.003)$ \\
\hline \multirow[t]{2}{*}{ Off-farm income } & $0.040^{* * *}$ & 0.003 & 0.015 & $0.069^{* * * *}$ & $0.081^{* * *}$ \\
\hline & $(0.007)$ & $(0.018)$ & $(0.023)$ & $(0.023)$ & $(0.011)$ \\
\hline [Margalef index] x [Off-farm & $-0.024^{* *}$ & $0.145^{*}$ & -0.033 & -0.001 & $-0.046^{*}$ \\
\hline income] & $(0.011)$ & $(0.088)$ & $(0.028)$ & $(0.019)$ & $(0.024)$ \\
\hline Indonesia (dummy) & $\begin{array}{c}0.593^{* * * *} \\
(0.012)\end{array}$ & -- & -- & -- & -- \\
\hline Kenya (dummy) & $\begin{array}{l}0.690^{\text {*** }} \\
(0.012)\end{array}$ & -- & -- & -- & -- \\
\hline Malawi (dummy) & $\begin{array}{c}0.428^{* * * *} \\
(0.011)\end{array}$ & -- & -- & -- & -- \\
\hline \multirow[t]{2}{*}{ Model intercept } & $1.691^{* * * *}$ & $2.273^{* * *}$ & $2.440^{* * *}$ & $1.668^{* * *}$ & $2.088^{* * *}$ \\
\hline & $(0.013)$ & $(0.019)$ & $(0.035)$ & $(0.022)$ & $(0.011)$ \\
\hline Number of observations & 8230 & 674 & 397 & 2045 & 5114 \\
\hline
\end{tabular}


Table A2. 7: Production diversity measured with the Margalef index, market participation and dietary diversity in Ethiopia and Malawi (pooled sample)

(1)

Explanatory variables

Margalef index

Market distance

[Margalef index] x [Market distance]

Produce sold to market

[Margalef index] x [Produce sold]

Off-farm income

Malawi (dummy)

Model intercept

Number of observations
[Margalef index] x [Off-farm income]
Dietary diversity score with respect to all foods

$\begin{array}{cc}0.071^{* * *} & -0.066^{* * *} \\ (0.016) & (0.024) \\ 0.004 & 0.039^{* * *} \\ (0.004) & (0.008) \\ -0.001^{* * *} & -0.003^{* * *} \\ (2.2 \mathrm{E}-04) & (4.0 \mathrm{E}-04) \\ -1.2 \mathrm{E}-04 & -0.001^{*} \\ (1.9 \mathrm{E}-04) & (3.5 \mathrm{E}-04) \\ 0.037^{* * *} & -0.010 \\ (0.012) & (0.018) \\ -0.042^{* * *} & -0.046^{*} \\ (0.015) & (0.025) \\ 0.072^{* * *} & 0.096^{* * *} \\ (0.009) & (0.012) \\ -0.011 & 0.014 \\ (0.014) & (0.021) \\ 0.447^{* * *} & 0.574^{* * *} \\ (0.012) & (0.017) \\ 1.648^{* * *} & 1.425^{* * *} \\ (0.015) & (0.022) \\ 7159 & 7159\end{array}$

\section{(2)}

Dietary diversity score with respect to purchased foods

Notes: For the calculation of the dietary diversity scores, 12 food groups were included. Models were estimated with a Poisson estimator. Coefficient estimates are shown with robust standard errors in parentheses. ${ }^{*},{ }^{* *}$, Statistically significant at the $10 \%, 5 \%$, and $1 \%$ level, respectively. 
Table A2. 8: Association between food crop production diversity and dietary diversity

\begin{tabular}{|c|c|c|c|c|c|}
\hline Explanatory variables & Pooled & Indonesia & Kenya & Ethiopia & Malawi \\
\hline Food crop production & 0.002 & 0.014 & 0.005 & -0.005 & $0.009^{* * * *}$ \\
\hline diversity & $(0.003)$ & $(0.016)$ & $(0.016)$ & $(0.006)$ & $(0.003)$ \\
\hline Food crop production & $3.4 \mathrm{E}-04$ & -0.005 & $1.6 \mathrm{E}-06$ & $0.001^{* *}$ & $2.0 \mathrm{E}-05$ \\
\hline diversity squared & $(2.1 \mathrm{E}-04)$ & $(0.005)$ & $(0.002)$ & (3.7E-04) & $(2.7 \mathrm{E}-04)$ \\
\hline Indonesia (dummy) & $\begin{array}{c}0.646^{* * *} \\
(0.012)\end{array}$ & -- & -- & -- & -- \\
\hline Kenya (dummy) & $\begin{array}{l}0.758^{\text {*** }} \\
(0.009)\end{array}$ & -- & -- & -- & -- \\
\hline Malawi (dummy) & $\begin{array}{c}0.470^{* * * *} \\
(0.009)\end{array}$ & -- & -- & -- & -- \\
\hline Model intercept & $\begin{array}{l}1.657^{* * *} \\
(0.012)\end{array}$ & $\begin{array}{l}2.303^{* * *} \\
(0.005)\end{array}$ & $\begin{array}{l}2.409^{* * *} \\
(0.040)\end{array}$ & $\begin{array}{l}1.682^{* * *} \\
(0.022)\end{array}$ & $\begin{array}{l}2.111^{* * *} \\
(0.008)\end{array}$ \\
\hline Number of observations & 8230 & 674 & 397 & 2045 & 5114 \\
\hline
\end{tabular}

Notes: The dependent variable in all models is the dietary diversity score of households, including 12 food groups. Models were estimated with a Poisson estimator. Coefficient estimates are shown with robust standard errors in parentheses. ${ }^{*},{ }^{* *},{ }^{* * *}$ Statistically significant at the $10 \%, 5 \%$, and $1 \%$ level, respectively. 
Table A2. 9: Food crop production diversity, market access, and dietary diversity

\begin{tabular}{|c|c|c|c|c|c|}
\hline Explanatory variables & Pooled & Indonesia & Kenya & Ethiopia & Malawi \\
\hline \multirow[t]{2}{*}{ Food crop production diversity } & 0.004 & 0.002 & -0.005 & 0.001 & $0.009^{*}$ \\
\hline & $(0.003)$ & $(0.018)$ & $(0.013)$ & $(0.007)$ & $(0.005)$ \\
\hline \multirow{2}{*}{$\begin{array}{l}\text { Food crop production diversity } \\
\text { squared }\end{array}$} & 2.9E-04 & $-0.009^{* *}$ & $-3.2 \mathrm{E}-04$ & 0.001 & $3.2 \mathrm{E}-04$ \\
\hline & $(2.3 \mathrm{E}-04)$ & $(0.005)$ & $(0.001)$ & $(3.8 \mathrm{E}-04)$ & $(3.1 \mathrm{E}-04)$ \\
\hline \multirow[t]{2}{*}{ Market distance } & $-0.001^{* * *}$ & $-0.002^{* *}$ & -0.008 & $-0.001^{* *}$ & $1.7 \mathrm{E}-04$ \\
\hline & $(2.5 \mathrm{E}-04)$ & $(0.001)$ & $(0.005)$ & $(3.0 \mathrm{E}-04)$ & $(0.001)$ \\
\hline [Food crop production diversity] $\mathrm{x}$ & $8.0 \mathrm{E}-06$ & 0.001 & 0.001 & $7.5 \mathrm{E}-06$ & $-2.1 \mathrm{E}-04$ \\
\hline [Market distance] & $(3.2 \mathrm{E}-05)$ & $(0.001)$ & $(0.001)$ & $(4.1 \mathrm{E}-05)$ & $(3.4 \mathrm{E}-04)$ \\
\hline \multirow[t]{2}{*}{ Off-farm income } & $0.036^{* * * *}$ & -0.003 & -0.001 & $0.083^{* * *}$ & $0.084^{* * *}$ \\
\hline & $(0.007)$ & $(0.020)$ & $(0.026)$ & $(0.029)$ & $(0.012)$ \\
\hline [Food crop production diversity] $\mathrm{x}$ & -0.002 & $0.036^{* * *}$ & $0.007^{* * *}$ & -0.002 & -0.005 \\
\hline [Off-farm income] & $(0.002)$ & $(0.007)$ & $(0.003)$ & $(0.004)$ & $(0.003)$ \\
\hline Indonesia (dummy) & $\begin{array}{c}0.599^{* * * *} \\
(0.014)\end{array}$ & -- & -- & -- & -- \\
\hline Kenya (dummy) & $\begin{array}{l}0.707^{\text {**** }} \\
(0.012)\end{array}$ & -- & -- & -- & -- \\
\hline Malawi (dummy) & $\begin{array}{c}0.428^{* * * *} \\
(0.011)\end{array}$ & -- & -- & -- & -- \\
\hline \multirow[t]{2}{*}{ Model intercept } & $1.692^{* * *}$ & $2.272^{* * *}$ & $2.417^{* * *}$ & $1.688^{* * *}$ & $2.081^{* * *}$ \\
\hline & $(0.014)$ & $(0.016)$ & $(0.038)$ & $(0.029)$ & $(0.013)$ \\
\hline Number of observations & 8230 & 674 & 397 & 2045 & 5114 \\
\hline
\end{tabular}


Table A2. 10: Food production diversity, market participation, and dietary diversity in Ethiopia and Malawi (pooled sample)

Explanatory variables

Food crop production diversity

Food crop production diversity squared

Market distance

[Food crop production diversity] $\mathrm{x}$

[Market distance]

Produce sold to market

[Food crop production diversity] $\mathrm{x}$

[Produce sold]

Off-farm income

[Food crop production diversity] x [Off-

farm income]

Malawi (dummy)

Model intercept

Number of observations

\section{(1)}

Dietary diversity score with respect to all foods

$\begin{array}{cc}0.003 & -0.020^{* * *} \\ (0.003) & (0.005) \\ 0.001^{* *} & 0.002^{* * * *} \\ (2.5 \mathrm{E}-04) & (3.6 \mathrm{E}-04) \\ -0.001^{* * *} & -0.002^{* * *} \\ (2.6 \mathrm{E}-04) & (4.6 \mathrm{E}-04) \\ 2.1 \mathrm{E}-06 & -1.0 \mathrm{E}-04^{*} \\ (3.3 \mathrm{E}-05) & (5.9 \mathrm{E}-05) \\ 0.054^{* * *} & 0.021 \\ (0.015) & (0.020) \\ -0.009^{* * *} & -0.010^{* * *} \\ (0.003) & (0.004) \\ 0.081^{* * *} & 0.106^{* * *} \\ (0.011) & (0.015) \\ -0.003 & -0.001 \\ (0.002) & (0.003) \\ 0.434^{* * *} & 0.562^{* * *} \\ (0.012) & (0.017) \\ 1.664^{* * *} & 1.462^{* * *} \\ (0.016) & (0.023) \\ 7159^{*} & 7159\end{array}$

(2)
Dietary diversity score with respect to purchased foods

Notes: For the calculation of the dietary diversity scores, 12 food groups were included. Models were estimated with a Poisson estimator. Coefficient estimates are shown with robust standard errors in parentheses. ${ }^{*},{ }^{* *},{ }^{* *}$ Statistically significant at the $10 \%, 5 \%$, and $1 \%$ level, respectively. 


\title{
CHAPTER 3
}

\section{Farm Production Diversity and Dietary Quality: Linkages and Measurement Issues}

\begin{abstract}
Recent research has analyzed whether higher levels of farm production diversity contribute to improved dietary quality in smallholder households. We add to this literature by using different indicators, thus testing the robustness of previous findings and helping to better understand the underlying linkages. The analysis builds on data from Indonesia, Kenya, and Uganda. Farm diversity measured through a simple species count has a small positive effect on dietary quality, either expressed in terms of dietary diversity scores or micronutrient consumption levels. However, when measuring production diversity in terms of the number of food groups produced, the effect turns insignificant in most cases. Further analysis suggests that diverse subsistence production contributes less to dietary quality than cash income generated through market sales. Much of the food diversity consumed in farm households is purchased from the market. If farm diversification responds to market incentives and builds on comparative advantage, it can contribute to improved income and nutrition. This may also involve cash crop production. On the other hand, increasing the number of food groups produced on the farm independent of market incentives will foster subsistence, reduce cash incomes, and thus rather worsen dietary quality. We conclude that from a nutrition perspective improving market access is more important than farm diversification as such.
\end{abstract}




\subsection{Introduction}

Agricultural modernization over the last few decades has primarily focused on a few crop species, especially cereals. The resulting production increases have contributed considerably to reducing hunger and improving peoples' access to calorie-dense staple foods (Pingali, 2015; Khoury et al., 2014; Godfray et al., 2010). However, in addition to calories, healthy nutrition requires access to a wide range of nutrients. Micronutrient deficiencies in particular are still widespread, causing multiple serious health problems and significant economic and humanitarian costs (IFPRI, 2015; Horton and Steckel, 2013). To improve nutrition more broadly, stronger emphasis needs to be on promoting dietary quality and diversity.

Many of those people globally affected by nutritional deficiencies live in smallholder farm households in developing countries (Barrett, 2010; Muller, 2009). These households largely depend on agriculture for their livelihoods. Against this background, the question how to make smallholder agriculture more nutrition-sensitive has recently gained significant interest among researchers and policymakers (Pinstrup-Andersen, 2013, Keding et al., 2012; Remans et al., 2011). Often, the promotion of production diversity on smallholder farms is seen as a promising strategy (Powell et al., 2015; Fanzo et al., 2013; Burlingame and Dernini, 2012). As small farm households typically consume a substantial share of what they produce, production diversity could directly translate into consumption diversity and thus improved dietary quality through this subsistence pathway. Several recent studies have empirically analyzed the relationship between farm production and dietary diversity (Sibhatu et al., 2015; Snapp and Fisher, 2015; Jones et al., 2014; Pellegrini and Tasciotti, 2014). Most of these studies suggest that farm production diversity has a positive influence on people's diets, although the magnitude of the estimated effect varies. Sibhatu et al. (2015) used data from various countries and showed that the production diversity effect tends to be small in general, and sometimes insignificant. Results from Sibhatu et al. (2015) and Snapp and Fisher (2015) also suggest that access to markets may be more important for nutrition than increasing farm production diversity. However, various questions remain, especially concerning the indicators used to measure production diversity and nutritional quality. The choice of indicators may possibly affect the relationship in important ways (Luckett et al., 2015; Berti, 2015). 
In order to design policies towards more nutrition-sensitive agriculture, it is important to better understand the role of production diversity for farm household nutrition. Should further diversification of smallholder production systems be promoted, and - if so - what kind of diversification? Here, we contribute to this research direction by using data from different countries and comparing alternative indicators.

On the consumption side, previous studies used the household dietary diversity score (HDDS) or related measures as indicators of dietary quality (Sibhatu et al., 2015; Snapp and Fisher, 2015; Jones et al., 2014). HDDS counts the number of different food groups consumed by the household over a certain period of time. This food group count is generally accepted as a good and easy-to-measure proxy for dietary quality, as it was found to be correlated with various nutrition outcomes in many situations (Headey and Ecker, 2013; Ruel, 2003). However, eventually it is not the number of food groups that matters for healthy nutrition, but the supply of all essential nutrients in sufficient quantities. Hence, in addition to using the HDDS, we also examine how production diversity contributes to consumption levels of various important micronutrients.

On the production side, previous studies used a simple count of all crop and livestock species produced on a farm as the main indicator of production diversity (Sibhatu et al., 2015; Snapp and Fisher, 2015; Jones et al., 2014). However, different species have different nutritional functions, so that the type of farm diversification can matter for effects on household diets (Berti, 2015; Remans et al., 2014; De Clerck et al., 2011). For instance, the dietary quality effect of growing sorghum in addition to maize may be smaller than that of adding a pulse or vegetable crop to a cereal-dominated production system. Hence, in addition to using a simple species count, we also employ an indicator that explicitly considers the nutritional functions of the different commodities produced on a farm. Comparison of results across the different indicators also helps to shed more light on the mechanisms underlying the production and dietary quality link.

The empirical research builds on survey data from Indonesia, Kenya, and Uganda. The data from all three countries were collected in specific regions and are not nationally representative. Nevertheless, the farming and socioeconomic conditions captured in the 
overall sample vary widely, so that the analysis may offer some broader insights that also hold beyond a particular context. For the comparisons, it is advantageous that the relevant data on farm production and household food consumption in all three countries were collected using the same survey format. This also allows us to pool the data for some of the analyses, in addition to looking at each country subsample separately.

\subsection{Materials and Methods}

The main research objective pursued in this study is to better understand the relationship between production diversity and dietary quality in smallholder farm households and the underlying mechanisms. We use different indicators of production diversity and dietary quality that are described in the following, before introducing the statistical approaches and the surveys carried out in Indonesia, Kenya, and Uganda.

\subsubsection{Indicators of dietary quality}

Simple indicators such as household dietary diversity scores (HDDS) are frequently used to measure dietary quality from survey data. HDDS is a categorical measure of the number of different food groups consumed by the household during a specified period of time, like the last 24 hours or the last seven days prior to the survey interviews. Data for calculating HDDS are relatively easy to collect, because no quantity measures of the different food items consumed are required. HDDS are generally considered a useful proxy for dietary quality (Maxwell et al., 2014; Ruel, 2003). The larger the number of different food groups consumed, the more likely it is that household members are supplied with all the nutrients needed for healthy nutrition. HDDS can also be used as an indicator of food security from a calorie perspective (Headey and Ecker, 2013). Poor households usually try to satisfy their calorie needs with cheaper staple foods before diversifying their diets towards higher-value products. Hence, higher levels of dietary diversity indicate that a household is likely already better supplied with calories. 
While there is no international standard on how many food groups to include in the calculation of the HDDS, many studies use 12 different groups (FAO, 2011). We follow this approach and use the following 12 food groups for the calculation of HDDS in this study: cereals; white tubers and roots; legumes, legume products, nuts, and seeds; vegetables and vegetable products; fruits; meat; eggs; fish and fish products; milk and milk products; sweets, sugars, and syrups; oils and fats; and spices, condiments, and beverages.

However, in spite of their usefulness for a first general assessment of dietary quality, HDDS also have a few drawbacks (Hirvonen et al., 2015; Maxwell et al., 2014; Coates, 2013). In particular, not all food groups considered contribute to the supply of essential nutrients in the same way. Moreover, food groups are counted regardless of the actual quantities consumed; very small quantities of certain foods may not add much to healthy nutrition. To address these shortcomings, more comprehensive data about the food quantities and nutrients consumed are required (de Haen et al., 2011). We use detailed food consumption recall data collected during the surveys to calculate the daily quantities of calories and various micronutrients consumed by the household (see below for details). To make the values comparable across households of different size, these quantities are expressed per adult equivalent (AE). In terms of micronutrients, we particularly concentrate on iron, zinc, and vitamin A. Deficiencies in these three micronutrients are responsible for the most important nutritional disorders in large parts of the developing world (Barrett and Bevis, 2015; IFPRI, 2015). Recent studies have used calorie and micronutrient consumption levels to assess nutritional impacts of innovations in African food supply chains (Chiputwa and Qaim, 2016; Chege et al., 2015). We are not aware of any previous research that has used such quantity-based indicators to analyze dietary effects of farm production diversity.

\subsubsection{Indicators of production diversity}

A common indicator of production diversity on a farm is a simple count of the different species produced (Sibhatu et al., 2015). This indicator is taken from the agro-biodiversity literature. Sometimes the area under a crop is used for weighting purposes, although a common weighting scheme is more difficult when livestock production is also involved. We use an unweighted count of all crop and livestock species produced on a farm as one measure 
of production diversity. However, different species have different nutritional functions, which is important to consider when analyzing the production-consumption diversity link. When non-food cash crops are grown, the nutritional value is zero regardless of the number of different species produced. But also when food crops are grown, increasing the number of species within the same food group (e.g., different types of cereals) may have smaller nutritional benefits than when species of a different food group are added to the production portfolio (e.g., adding pulses, vegetables, or fruits). The reason is that products within the same food group tend to provide a similar range of nutrients.

A recent body of literature has developed new diversity scores trying to account for the nutritional functions of different types of food crops produced (Luckett et al., 2015, Remans et al., 2014; DeClerck et al., 2011). The nutritional functional diversity score proposed by Luckett et al. (2015) counts a farm species only as additional when its nutritional profile is sufficiently different from the other species that were already counted on the same farm. Otherwise, the species is considered nutritionally redundant. While this approach has some intuitive appeal, it also has its problems, as judging on the similarity in the nutritional profile always involves some degree of subjectivity. For instance, it depends on the range of different nutrients considered. Even if all common nutrients are taken into account, differences in other nutritionally valuable substances - such as fiber or secondary metabolites - may complicate the concept of nutritional redundancy.

While further work into this interesting line of research is required, we decided to use a simpler and more transparent approach to account for differences in nutritional functions between the species produced on a farm. In particular, we calculate what we call the production diversity score as an alternative measure to the simple species count. The production diversity score builds on the same 12 food groups used for calculating HDDS on the consumption side (see above), hence it is an indicator of the number of different food groups produced on a farm. That is, different species produced on the farm count as one when they all belong to the same food group (e.g., maize, wheat, and sorghum all belong to the group of cereals). On the other hand, one and the same species can count as two when it delivers products that belong to different food groups (e.g., chicken that deliver eggs and meat). 


\subsubsection{Analytical framework}

We want to estimate the effect of farm production diversity on household dietary quality by estimating regression models of the following general form:

$$
D_{i}=\beta_{0}+\beta_{1} P_{i}+\beta_{2} X_{i}+\varepsilon_{i}
$$

where $D_{i}$ is a measure of dietary quality, $P_{i}$ is a measure of production diversity, and $X_{i}$ is a vector of other covariates that may influence dietary quality, all referring to farm household $i$. Variables included in vector $X_{i}$ include farm characteristics such as land area, market access, and sociodemographic characteristics such as household size, age, gender, and education. $\beta_{0}$, $\beta_{1}$, and $\beta_{2}$ are coefficients to be estimated, and $\varepsilon_{i}$ is a random error term.

We estimate different specifications of this model, using the various indicators of dietary quality and production diversity that were introduced above. A comparison of the estimates of $\beta_{1}$ across the specifications helps to test how sensitive the results are to issues of measurement. Comparing the coefficients for the two production diversity indicators can also provide insights into the potential mechanisms underlying the relationship in different situations. For instance, in subsistence settings the coefficient of the production diversity score is expected to be larger than that of the simple species count, because the number of food groups produced will translate more directly into the number of food groups consumed. However, in more market-oriented settings the comparison is less clear and may even be reversed: households that try to produce many of the food groups consumed themselves may forego cash income gains from focusing on those species for which they have a comparative advantage in the market.

\subsubsection{Data sources}

We use data from surveys of smallholder farm households in Indonesia, Kenya, and Uganda. All three surveys were conducted in 2012 and used structured questionnaires with the same format for the production and consumption related aspects of relevance in this study. In all three countries, the surveys are not nationally representative but focus on specific regions in which smallholders produce food and cash crops to varying degrees. Within the selected 
regions, a multistage sampling procedure was used, with random selection of individual farm households at the last stage.

In Indonesia, we surveyed 672 farm households in Jambi Province on Sumatra Island. Farmers in Jambi are often specialized on plantation cash crops, notably rubber and oil palm (Euler et al., 2016). Some of the sample farmers do not grow any food, others have small plots with maize, rice, and horticultural crops, sometimes supplemented with livestock and aquaculture production. In Kenya, the sample comprises 395 farm households from Kiambu County, an important vegetable-growing area in Central Kenya (Chege et al., 2015). Sample farms grow different types of green leafy vegetables (e.g., kale, spinach, black nightshade) in addition to other food crops such as maize and banana and non-food cash crops such as coffee and tea. Some of the farmers are also involved in small-scale livestock production. The data from Uganda were collected in Luwero and Masaka, two districts in the Central Region where a lot of coffee is grown (Chiputwa et al., 2015). The sample comprises 417 farm households that grow coffee in addition to food crops such as plantains, cassava, sweet potatoes, different types of cereals, and legumes such as beans and groundnuts. Some fodder crops are grown as well for the households' small-scale livestock enterprises.

In all three surveys, a wide range of socioeconomic data was captured, including details of agricultural production and food consumption at the household level. To capture dietary patterns we used a 7-day consumption recall, involving quantity data for a large number of food items from own production, market purchases, or any other source. Calculations of calorie and micronutrient consumption levels are based on local and international food composition tables (SMILING, 2013; FAO, 2010; USDA, 2005). In the surveys, we also collected detailed data on agricultural market sales and on total household income, including from farm and off-farm income sources. Consumption and income data are expressed per AE to facilitate comparisons. Cash values were converted from local currencies to US dollars using official exchange rates at the time of the surveys. 


\subsection{Results and Discussion}

\subsubsection{Descriptive statistics}

Table 3.1 shows descriptive statistics of the variables used in this study. The average farm household in the pooled sample, comprising observations from all three countries, cultivates an area of 6.8 acres. Yet, there is considerable heterogeneity in the area cultivated across countries and also within countries. The largest average farm size is observed in Indonesia (11.1 acres), the smallest in Kenya (2.2 acres). Sample farmers in Indonesia primarily grow non-food cash crops such as rubber and oil palm, on average only $6 \%$ of the farm area is cultivated with food crops. In contrast, $74 \%$ of the area of Kenyan sample farms is cultivated with food crops. This does not imply that farms in the Kenyan sample are primarily subsistence-oriented. Vegetables, which we count under food crops, are largely grown for commercial purposes in Kiambu County, as is also reflected in sizeable cash revenues for Kenyan farm households. Sample farms in Uganda are much more subsistence-oriented. Apart from coffee as their main source of agricultural cash revenues, Ugandan farm households produce food and feed crops primarily for domestic use.

In terms of production diversity, farmers in Kenya and Uganda have a much larger species count than their colleagues in Indonesia. Interestingly, farm households in Uganda produce the largest number of species and food groups, but they are performing worst in terms of dietary diversity and calorie consumption. This is a first indication that production diversity is not necessarily a good predictor of consumption diversity and dietary quality. This relationship is analyzed further in the following.

\subsubsection{Production diversity and dietary quality}

We now use the regression models described above to analyze the relationship between production diversity and dietary quality more formally. As explained, we employ different indicators of dietary quality as dependent variable and of production diversity as explanatory variable. The results are summarized in Table 3.2. In this summary table, we only show the estimates for production diversity, as this is the explanatory variable of primary interest. Full 
results of the different models with other covariates included are shown in Tables A3.1 to A3.8 in Appendix A3.

Table 3. 1: Descriptive statistics by country

\begin{tabular}{|c|c|c|c|c|}
\hline Explanatory variables & Pooled & Indonesia & Kenya & Uganda \\
\hline \multicolumn{5}{|l|}{ Farm characteristics } \\
\hline \multirow[t]{2}{*}{ Cultivated land area (acres) } & 6.83 & 11.14 & 2.16 & 4.30 \\
\hline & $(13.17)$ & $(18.35)$ & $(2.93)$ & $(3.06)$ \\
\hline \multirow[t]{2}{*}{ Share of land under food crops $(\%)$} & 35.94 & 5.99 & 74.12 & 48.04 \\
\hline & $(37.55)$ & $(19.71)$ & $(30.14)$ & $(23.67)$ \\
\hline \multirow[t]{2}{*}{ Agricultural cash revenues per year (US\$/AE) } & 1468.22 & 2537.74 & 1017.06 & 172.03 \\
\hline & $(3819.48)$ & $(5208.99)$ & $(2166.42)$ & $(264.82)$ \\
\hline \multirow[t]{2}{*}{ Species count on farm (crop + livestock) } & 5.16 & 1.73 & 7.83 & 7.99 \\
\hline & $(3.53)$ & $(0.91)$ & $(2.59)$ & $(2.01)$ \\
\hline \multirow[t]{2}{*}{ Production diversity score (12 food groups) } & 2.91 & 0.46 & 4.36 & 5.52 \\
\hline & $(2.60)$ & $(1.15)$ & $(1.62)$ & $(1.00)$ \\
\hline \multicolumn{5}{|l|}{ Dietary quality characteristics } \\
\hline \multirow[t]{2}{*}{ Household dietary diversity score (HDDS) } & 10.19 & 10.01 & 11.39 & 9.33 \\
\hline & $(1.53)$ & $(1.29)$ & $(0.97)$ & $(1.63)$ \\
\hline \multirow[t]{2}{*}{ Calorie consumption per day (kcal/AE) } & 3148.72 & 3124.08 & 3297.86 & 3047.28 \\
\hline & $(1373.36)$ & $(1475.34)$ & $(1171.24)$ & $(1371.08)$ \\
\hline \multirow[t]{2}{*}{ Iron consumption per day (mg/AE) } & 19.64 & 19.61 & 16.86 & 22.33 \\
\hline & (11.04) & $(12.29)$ & $(7.41)$ & $(11.14)$ \\
\hline \multirow{2}{*}{ Zinc consumption per day (mg/AE) } & 13.94 & 11.07 & 21.20 & 11.69 \\
\hline & $(7.84)$ & $(5.52)$ & $(8.10)$ & $(6.29)$ \\
\hline \multirow[t]{2}{*}{ Vitamin A consumption per day ( $\mu \mathrm{g}$ RE/AE) } & 1227.55 & 1127.00 & 1389.73 & 1236.46 \\
\hline & $(1358.68)$ & $(1633.52)$ & $(965.51)$ & $(1161.25)$ \\
\hline \multicolumn{5}{|l|}{ Other household characteristics } \\
\hline \multirow[t]{2}{*}{ Total household income per year (US\$/AE) } & 3384.42 & 3460.11 & 2286.00 & 4302.89 \\
\hline & $(77140)$ & $(6789.35)$ & $(3542.06)$ & $(9670.22)$ \\
\hline \multirow[t]{2}{*}{ Distance to market $(\mathrm{km})$} & 4.85 & 6.56 & 3.11 & 3.74 \\
\hline & $(6.02)$ & $(7.41)$ & $(3.59)$ & $(4.42)$ \\
\hline \multirow[t]{2}{*}{ Household size (number of members) } & 4.93 & 4.20 & 4.67 & 6.60 \\
\hline & $(2.40)$ & $(1.52)$ & $(1.71)$ & $(3.20)$ \\
\hline \multirow[t]{2}{*}{ Age of household head (years) } & 49.32 & 45.72 & 52.05 & 52.54 \\
\hline & $(13.59)$ & $(12.18)$ & $(13.65)$ & $(14.29)$ \\
\hline \multirow[t]{2}{*}{ Education level of household head (years) } & 7.81 & 7.50 & 9.63 & 6.57 \\
\hline & $(3.82)$ & $(3.63)$ & $(3.71)$ & $(3.63)$ \\
\hline Male household head (dummy) & 0.88 & 0.95 & 0.88 & 0.76 \\
\hline Number of observations & 1484 & 672 & 395 & 417 \\
\hline
\end{tabular}

Notes: Mean values are shown with standard deviations in parentheses. AE stands for adult equivalent. RE stands for retinol equivalent.

We estimated models for the individual countries, as well as pooled models with all observations combined. The pooled data models include country dummies to account for country fixed effects, in addition to the other explanatory variables. In column (1) of Table 3.2 , we use the household dietary diversity score (HDDS) as dependent variable. Since this is 
a count variable, the underlying models were estimated with a Poisson estimator. In Poisson models, the estimated coefficients can be interpreted as semi-elasticities. In columns (2) to (5), with calorie and micronutrient consumption levels as dependent variables, the models were estimated with ordinary least squares (OLS), hence the estimates can be interpreted as marginal effects. All models were estimated with robust standard errors to account for heteroscedasticity.

Table 3. 2: Effect of farm production diversity on dietary quality

\begin{tabular}{|c|c|c|c|c|c|}
\hline Explanatory variables & $\begin{array}{c}\text { (1) } \\
\text { HDDS }\end{array}$ & $\begin{array}{c}(2) \\
\text { Calories } \\
\text { (kcal/AE) }\end{array}$ & $\begin{array}{c}(3) \\
\text { Iron } \\
(\mathrm{mg} / \mathrm{AE})\end{array}$ & $\begin{array}{c}\text { (4) } \\
\text { Zinc } \\
(\mathrm{mg} / \mathrm{AE})\end{array}$ & $\begin{array}{c}(5) \\
\text { Vitamin A } \\
(\mu \mathrm{g} / \mathrm{AE})\end{array}$ \\
\hline \multicolumn{6}{|c|}{ Species count (crop + livestock) } \\
\hline Pooled & $\begin{array}{c}0.010^{* * *} \\
(0.002)\end{array}$ & $\begin{array}{c}67.499^{* * *} \\
(19.095)\end{array}$ & $\begin{array}{c}0.506^{* * *} \\
(0.142)\end{array}$ & $\begin{array}{l}0.251^{* *} \\
(0.101)\end{array}$ & $\begin{array}{c}30.965 \\
(19.517)\end{array}$ \\
\hline Indonesia & $\begin{array}{l}0.015^{* * *} \\
(0.005)\end{array}$ & $\begin{array}{c}300.402^{* * * *} \\
(66.202)\end{array}$ & $\begin{array}{l}2.499^{* * * *} \\
(0.546)\end{array}$ & $\begin{array}{l}1.006^{* * * *} \\
(0.249)\end{array}$ & $\begin{array}{c}204.475^{* *} \\
(84.544)\end{array}$ \\
\hline Kenya & $\begin{array}{l}0.004^{\text {** }} \\
(0.002)\end{array}$ & $\begin{array}{c}-2.972 \\
(25.358)\end{array}$ & $\begin{array}{c}0.028 \\
(0.165)\end{array}$ & $\begin{array}{c}0.046 \\
(0.173)\end{array}$ & $\begin{array}{l}-31.527 \\
(21.179)\end{array}$ \\
\hline Uganda & $\begin{array}{l}0.021^{* * *} \\
(0.004)\end{array}$ & $\begin{array}{l}83.035^{* *} \\
(33.648)\end{array}$ & $\begin{array}{l}0.470^{*} \\
(0.255)\end{array}$ & $\begin{array}{l}0.301^{* *} \\
(0.152)\end{array}$ & $\begin{array}{c}35.618 \\
(30.738)\end{array}$ \\
\hline \multicolumn{6}{|c|}{ Production diversity score (food groups) } \\
\hline Pooled & $\begin{array}{c}0.008^{* * *} \\
(0.003)\end{array}$ & $\begin{array}{c}30.382 \\
(28.238)\end{array}$ & $\begin{array}{c}0.140 \\
(0.212)\end{array}$ & $\begin{array}{c}0.157 \\
(0.145)\end{array}$ & $\begin{array}{l}-31.662 \\
(23.545)\end{array}$ \\
\hline Indonesia & $\begin{array}{c}0.002 \\
(0.005)\end{array}$ & $\begin{array}{c}12.793 \\
(48.037)\end{array}$ & $\begin{array}{c}0.088 \\
(0.410)\end{array}$ & $\begin{array}{l}-0.019 \\
(0.179)\end{array}$ & $\begin{array}{l}-33.383 \\
(40.762)\end{array}$ \\
\hline Kenya & $\begin{array}{c}0.004 \\
(0.003)\end{array}$ & $\begin{array}{c}37.246 \\
(46.244)\end{array}$ & $\begin{array}{c}0.088 \\
(0.297)\end{array}$ & $\begin{array}{c}0.308 \\
(0.294)\end{array}$ & $\begin{array}{c}-69.592^{* *} \\
(33.458)\end{array}$ \\
\hline Uganda & $\begin{array}{c}0.033^{* * * *} \\
(0.009)\end{array}$ & $\begin{array}{l}108.229 \\
(70.622)\end{array}$ & $\begin{array}{c}0.835 \\
(0.547)\end{array}$ & $\begin{array}{c}0.599^{*} \\
(0.321)\end{array}$ & $\begin{array}{c}49.277 \\
(55.715)\end{array}$ \\
\hline
\end{tabular}

Notes: The coefficient estimates are based on regression models as shown in Tables A3.1 to A3.8 in Appendix A3. Robust standard errors are given in parentheses. Coefficients in column (1) were estimated with Poisson models. Coefficients in columns (2) to (5) were estimated with OLS models. ${ }^{*},{ }^{* *},{ }^{* * *}$ denote significance at the $10 \%, 5 \%$, and $1 \%$ level, respectively. HDDS stands for household dietary diversity score. AE stands for adult equivalent.

In the upper part of Table 3.2, we use the simple species count as the indicator of production diversity. The positive and significant coefficients in column (1) suggest that household dietary diversity increases with the number of different species produced on the farm. Yet the effect is relatively small. After controlling for other factors, producing one additional crop or livestock species increases the number of food groups consumed by only $1 \%$ in the pooled sample. In other words, diverse and balanced diets would require extremely diverse production patterns when relying on own farm production alone. The individual country 
models reveal that the magnitude of the estimates varies. But even the effect of $2.1 \%$ in Uganda is relatively small. Small positive effects of production diversity on dietary diversity are consistent with findings by Sibhatu et al. (2015).

In columns (2) to (5) of the upper part of Table 3.2, where we use different indicators of dietary quality as dependent variables, we also see predominantly positive effects. Many of these effects are statistically significant. We infer that the number of species produced on the farm also contributes to higher calorie and micronutrient consumption. For instance, the pooled model results suggest that one additional crop or livestock species produced increases daily calorie consumption per $\mathrm{AE}$ by $67.6 \mathrm{kcal}$, iron consumption by $0.51 \mathrm{mg}$, and zinc consumption by $0.25 \mathrm{mg}$. Comparing with sample mean consumption levels, these estimated marginal effects correspond to changes of less than 3\%, again with some differences observed between countries. With the exception of Indonesia, the effects of species diversity on vitamin A consumption are not statistically significant.

We conclude that - even though effects are relatively small - farm species diversity can contribute to dietary quality, measured either in terms of HDDS or calorie and micronutrient consumption levels. But the underlying mechanisms are still unclear. The lower part of Table 3.2, where we measure farm diversity in terms of production diversity scores helps to gain further insights. As explained, instead of a simple species count, production diversity scores count the number of different food groups produced. That is, the production of non-food crops or of several food crops within the same food group does not influence this measure. If subsistence production is an important source of food in the household, we would expect a strong association between the numbers of food groups produced and consumed. In that case, switching from the simple species count to production diversity scores should lead to larger coefficient estimates. However, the results in Table 3.2 indicate that the opposite is true. In most cases, the effects in the lower part Table 3.2 are smaller than those in the upper part. Many of the estimates also turn insignificant, especially when looking at dietary quality in terms of calorie and micronutrient consumption. These results suggest that the subsistence pathway is not of major importance. 
A more likely mechanism to explain the positive association between production diversity and dietary quality is the cash income pathway. Farm diversification may add to cash incomes, when farmers respond to market price incentives. Rather than trying to maximize the number of food groups produced it is economically more rational to diversify following the principles of comparative advantage. This may include diversifying into non-food cash crops. A case in point is Indonesia, where many farmers could increase their cash incomes by adding oil palm to their production portfolio (Krishna et al., 2015). Among other things, the higher cash income is used to improve dietary quality through the purchase of more diverse and nutritious foods from the market. Adding additional food groups to the production portfolio instead would not have the same nutritional effect, which is why the significantly positive effects in the upper part of Table 3.2 turn insignificant in the lower part. One exception is Uganda, where the role of subsistence is still more pronounced and cash revenues are relatively small.

Table 3. 3: Association between agricultural cash revenues and dietary quality

\begin{tabular}{lccccc}
\hline Explanatory variables & $\begin{array}{c}(1) \\
\text { HDDS }\end{array}$ & $\begin{array}{c}(2) \\
\text { Calories } \\
(\mathrm{kcal} / \mathrm{AE})\end{array}$ & $\begin{array}{c}(3) \\
\text { Iron } \\
(\mathrm{mg} / \mathrm{AE})\end{array}$ & $\begin{array}{c}(4) \\
\text { Zinc } \\
(\mathrm{mg} / \mathrm{AE})\end{array}$ & $\begin{array}{c}(5) \\
\text { Vitamin A } \\
(\mu \mathrm{g} / \mathrm{AE})\end{array}$ \\
\hline Pooled & $3.8 \mathrm{E}-06^{* * * *}$ & $0.093^{* * * *}$ & $0.001^{* * * *}$ & $3.4 \mathrm{E}-04^{* * * *}$ & $0.070^{* * * *}$ \\
& $(5.5 \mathrm{E}-07)$ & $(0.021)$ & $(1.5 \mathrm{E}-04)$ & $(8.7 \mathrm{E}-05)$ & $(0.016)$ \\
Indonesia & $3.7 \mathrm{E}-06^{* * *}$ & $0.095^{* * *}$ & $0.001^{* * *}$ & $3.4 \mathrm{E}-04^{* * *}$ & $0.074^{* * * *}$ \\
& $(5.8 \mathrm{E}-07)$ & $(0.022)$ & $(1.6 \mathrm{E}-04)$ & $(9.4 \mathrm{E}-05)$ & $(0.017)$ \\
Kenya & $3.6 \mathrm{E}-06^{* *}$ & $0.052^{* * * *}$ & $2.6 \mathrm{E}-04^{* *}$ & $2.7 \mathrm{E}-04$ & 0.035 \\
& $(1.4 \mathrm{E}-06)$ & $(0.016)$ & $(1.2 \mathrm{E}-04)$ & $(1.6 \mathrm{E}-04)$ & $(0.024)$ \\
Uganda & $3.5 \mathrm{E}-05$ & $1.072^{* * *}$ & $0.005^{* * *}$ & $0.004^{* * *}$ & 0.144 \\
& $(2.5 \mathrm{E}-05)$ & $(0.240)$ & $(0.002)$ & $(0.001)$ & $(0.194)$ \\
\hline
\end{tabular}

Notes: The coefficient estimates are based on regression models as shown in Table A3.9 in Appendix A3. Robust standard errors are given in parentheses. Coefficients in column (1) were estimated with Poisson models. Coefficients in columns (2) to (5) were estimated with OLS models. " , ** , *** denote significance at the $10 \%, 5 \%$, and $1 \%$ level, respectively. HDDS stands for household dietary diversity score. AE stands for adult equivalent.

The important role of markets and cash incomes for household dietary quality is also underlined by some of the other covariates included in the different models, which are shown in Tables A3.1 to A3.8 in Appendix A3. Market distance has a negative effect on dietary diversity and nutrient consumption in most of the models. Interestingly, the share of land under food crops also has negative effects in some cases. In other words, cash crop production and market sales are sometimes more important for household nutrition than food crop 
production. On the other hand, total farm size and educational levels contribute to higher dietary quality, as one would expect.

\subsubsection{Role of agricultural cash revenues}

The above analysis suggests that cash incomes may play a more important role for farm household dietary quality than diverse subsistence production. This is now analyzed further by regressing the different dietary quality indicators on agricultural cash revenues. Cash revenues are endogenous, so the estimation results should not be interpreted as causal. We are primarily interested in the association, which is also why we do not control for other factors in these models. Several other factors are correlated with cash revenues, so their inclusion would make interpretation of the association less straightforward. Results are shown in Table 3.3. Agricultural cash revenues are positively associated with all dietary quality indicators, and most of these associations are statistically significant. The magnitude of the coefficients may seem small, but this is due to the fact that cash revenues are expressed in US dollars per year. Scaling this variable changes the picture. For instance, in the pooled model 1000 dollars of additional cash revenues per year would be associated with $3-6 \%$ higher calorie and micronutrient consumption. These results support our hypothesis that market transactions and cash revenues matter for household dietary quality.

Farm diversification and increasing cash revenues are not necessarily contradictory strategies. As discussed above, it much depends on whether or not diversification is a response to market incentives. In Table 3.4, we correlate the two different production diversity indicators with agricultural cash revenues and total household incomes. In the pooled sample, the species count and the production diversity score are both uncorrelated with total household income, but negatively correlated with agricultural cash revenues. This suggests that diverse production systems are typically associated with lower market sales and higher subsistence orientation. However, the subsample from Kenya with positive correlation coefficients indicates that this is not always the case. Farmers in Kenya have diversified into different horticultural crops, which are in high demand in the market and therefore help to increase market sales and household incomes. 
Table 3. 4: Correlation between production diversity, agricultural cash revenues, and household income

\begin{tabular}{|c|c|c|c|c|}
\hline Explanatory variables & Pooled & Indonesia & Kenya & Uganda \\
\hline \multicolumn{5}{|l|}{ Species count (crop + livestock) } \\
\hline Agricultural cash revenues (US\$/AE) & $-0.173^{* * *}$ & $0.132^{* * *}$ & $0.199^{* * *}$ & -0.004 \\
\hline Total household income (US\$/AE) & 0.030 & 0.036 & $0.129^{* *}$ & $0.091^{*}$ \\
\hline \multicolumn{5}{|l|}{ Production diversity score (food groups) } \\
\hline Agricultural cash revenues (US\$/AE) & $-0.232^{* * *}$ & $-0.073^{*}$ & $0.22^{* * *}$ & 0.028 \\
\hline Total household income (US\$/AE) & 0.012 & $-0.100^{* * *}$ & $0.18^{* * *}$ & 0.049 \\
\hline
\end{tabular}

Notes: ${ }^{*},{ }^{* *}$, and ${ }^{* * *}$ denote significance at the $10 \%, 5 \%$, and $1 \%$ level, respectively. AE stands for adult equivalent.

Of particular interest is the analysis for Indonesia, where agricultural cash revenues are positively and negatively associated with the farm species count and the production diversity score, respectively. The reason for this switch in the sign is that cash crop diversification helps to increase farm revenues and incomes, whereas growing additional food groups is against comparative advantage in this context and hence associated with income losses.

\subsubsection{Further discussion}

The analysis suggests that farm diversification can be positively associated with household dietary quality, but that fostering market access and cash revenues are more promising avenues. The important role of markets for household nutrition can also be seen in Figure 3.1, which compares mean dietary diversity scores and production diversity scores across the different study countries. In the pooled sample, households consume 10.2 food groups, while only producing 2.9 food groups on average. In other words, own farm production accounts for less than $30 \%$ of the dietary diversity consumed in the households. Depending on climatic conditions, this number may vary seasonally. In the dry season, the contribution of own production may be lower still; especially fresh horticultural produce cannot be easily stored at home over longer periods of time. 


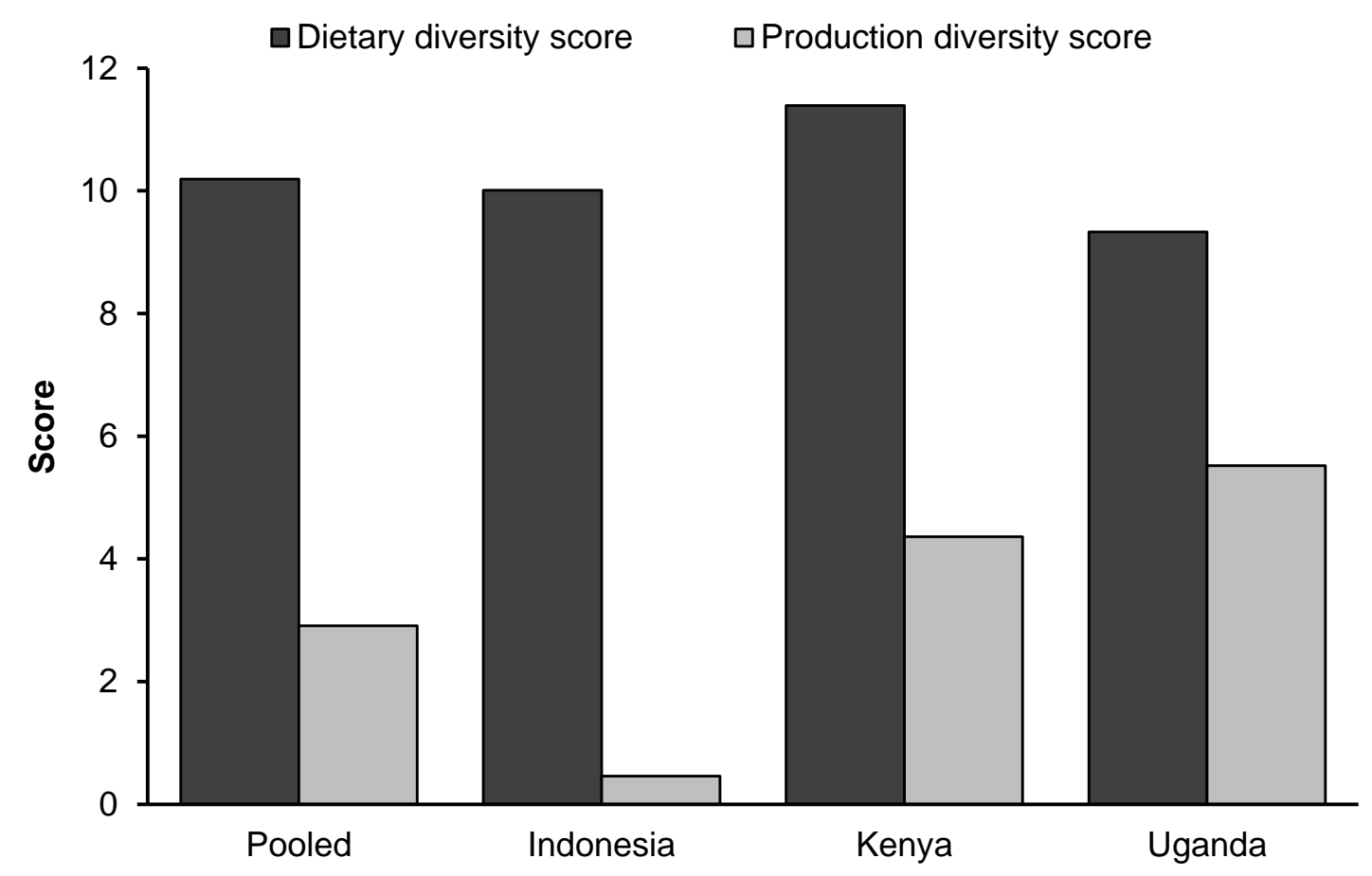

Figure 3. 1: Mean diversity scores and production diversity scores in farm households

Against this background it is unrealistic to assume that own production diversity could be the core element of dietary diversity in smallholder farm households. Uganda, where own production diversity accounts for $60 \%$ of household dietary diversity (Figure 3.1), almost looks like an exception. However, even in Uganda fostering market access and commercialization may be a better strategy to improve nutrition than promoting the cultivation of additional food groups. As we also showed, a high production diversity score can be associated with lower cash incomes, which would rather be counterproductive for household dietary quality.

\subsection{Conclusion}

We have analyzed the relationship between farm production diversity and household dietary quality using micro-level data from Indonesia, Kenya, and Uganda. We have contributed to the existing literature by using different indicators and comparing results, thus shedding light 
on the robustness of previous findings and also helping to better understand some of the underlying linkages. When measuring farm diversity in terms of a simple count of crop and livestock species produced, we found a positive relationship with household dietary diversity. This is consistent with previous findings (Sibhatu et al., 2015; Jones et al., 2014; Pellegrini and Tasciotti, 2014; Keding et al., 2012). However, as was also reported by Sibhatu et al. (2015), this effect of production diversity on consumption diversity is relatively small.

The small positive effect also remains when using other indicators of dietary quality, such as household consumption levels of calories and micronutrients. We conclude that the results are not driven by the way dietary quality is measured. While dietary diversity scores are not a perfect predictor of specific nutritional deficiencies, they seem to work well in terms of capturing broader aspects of dietary quality in farm households. This is a welcome finding, because the calculation of dietary diversity scores requires less data than the calculation of nutrient consumption levels.

We also tested the sensitivity of results with respect to changes in the production diversity indicator. When using production diversity scores instead of a simple species count, the effect on dietary quality gets smaller, in many cases it turns insignificant. This is an interesting finding. The production diversity score measures the number of different food groups produced on a farm, so one could have expected the effect on the number of food groups consumed in the farm household to be stronger. The fact that this is not the case reveals that the subsistence pathway is not the main mechanism underlying the production-consumption relationship. Cash income generated from agricultural sales seems to be a more important pathway contributing to improved dietary quality. Additional model estimates confirmed a significant positive association between agricultural cash revenues and dietary quality, measured either in terms of dietary diversity scores or nutrient consumption levels.

These results suggest that market access is more important for farm household nutrition than production diversity per se. Our data show that own production typically accounts for less than $30 \%$ of the different food groups consumed in farm households; the rest is purchased from the market. Diversifying the farm production portfolio such that more food groups were produced would foster subsistence, reduce cash incomes, and thus rather worsen dietary 
quality. Indeed, we showed that a larger number of food groups produced on a farm is often negatively associated with agricultural cash revenues. This does not mean that farm diversity is bad. But the type of diversification should follow market incentives, building on farmer's comparative advantage, rather than trying to maximize the number of food groups produced. Our results clearly suggest that diversifying into cash crops can help improve diets through the income pathway.

It needs to be stressed that the data used in this study mainly refer to situations where farmers have relatively good access to markets. Results for Uganda suggest that in less commercialized settings the subsistence pathway still plays a more important role. However, even in situations where farmers primarily produce for subsistence, a large share of the food consumed is purchased from the market (Luckett et al., 2015; Sibhatu et al., 2015). Hence, also in such situations policy initiatives should not foster subsistence but improve farmers' access to markets through strengthening infrastructure and institutions. Farmers' subsistence orientation is primarily a response to risk and various other market failures. Reducing these failures and supporting a higher level of market integration can contribute to higher incomes and better nutrition in smallholder households.

We conclude that farm diversification should not be considered a goal in itself. If diversification helps to increase household income, it will contribute to better nutrition. Otherwise, diversification can also be counterproductive from a dietary quality perspective. It should be stressed that diversity may also have environmental benefits, which we did not analyze here. Furthermore, it should be stressed that our results refer to the individual farm level. At higher scales (villages, districts, provinces, countries etc.) sufficient diversity is important, because affordable access to diverse foods from the market certainly requires that somebody produces these foods. This means that policy biases towards only a small number of staple foods - as often observed in the past - need to be rectified. If markets and technologies for a wide range of products exist, food systems will become more diverse, even without every farmer having to maximize diversity on her own farm. 


\section{Appendix A3: Additional Tables}

Table A3. 1: Effect of farm species count on dietary quality (pooled sample)

\begin{tabular}{|c|c|c|c|c|c|}
\hline Explanatory variables & $\begin{array}{l}(1) \\
\text { HDDS }\end{array}$ & $\begin{array}{c}(2) \\
\text { Calories } \\
\text { (kcal/AE) }\end{array}$ & $\begin{array}{c}(3) \\
\text { Iron } \\
(\mathrm{mg} / \mathrm{AE})\end{array}$ & $\begin{array}{c}(4) \\
\text { Zinc } \\
(\mathrm{mg} / \mathrm{AE})\end{array}$ & $\begin{array}{c}(5) \\
\text { Vitamin A } \\
(\mu \mathrm{g} / \mathrm{AE})\end{array}$ \\
\hline Species count (crop + & $0.010^{* * * *}$ & $67.499^{\text {***** }}$ & $0.506^{* * *}$ & $0.251^{\text {*** }}$ & 30.965 \\
\hline livestock) & $(0.002)$ & $(19.095)$ & $(0.142)$ & $(0.101)$ & $(19.517)$ \\
\hline \multirow[t]{2}{*}{ Distance to market $(\mathrm{km})$} & $-0.001^{*}$ & $-9.265^{*}$ & -0.033 & -0.013 & 0.154 \\
\hline & $(0.001)$ & $(5.625)$ & $(0.047)$ & $(0.024)$ & $(6.735)$ \\
\hline \multirow[t]{2}{*}{ Cultivated land area (acres) } & $0.001^{* * *}$ & 10.192 & $0.095^{*}$ & 0.045 & $9.231^{*}$ \\
\hline & $(1.9 \mathrm{E}-04)$ & $(7.315)$ & $(0.049)$ & $(0.030)$ & $(5.159)$ \\
\hline \multirow{2}{*}{$\begin{array}{l}\text { Share of land under food crops } \\
(\%)\end{array}$} & $-2.5 \mathrm{E}-04^{*}$ & 0.618 & 0.018 & 0.005 & $2.650^{* *}$ \\
\hline & $(1.4 \mathrm{E}-04)$ & $(1.514)$ & $(0.012)$ & $(0.008)$ & $(1.201)$ \\
\hline \multirow{2}{*}{$\begin{array}{l}\text { Male household head } \\
\text { (dummy) }\end{array}$} & $0.041^{* * *}$ & -43.835 & 0.173 & -0.992 & -150.992 \\
\hline & $(0.011)$ & $(115.275)$ & $(0.894)$ & $(0.605)$ & $(101.040)$ \\
\hline \multirow[t]{2}{*}{ Age of household head (years) } & $-0.001^{* *}$ & $7.894^{* * *}$ & $0.051^{* *}$ & 0.009 & 3.266 \\
\hline & $(2.9 \mathrm{E}-04)$ & $(2.962)$ & $(0.023)$ & $(0.014)$ & $(3.052)$ \\
\hline \multirow{2}{*}{$\begin{array}{l}\text { Education of household head } \\
\text { (years) }\end{array}$} & $0.005^{* * *}$ & 7.487 & 0.124 & 0.032 & $27.024^{* *}$ \\
\hline & $(0.001)$ & $(11.005)$ & $(0.091)$ & $(0.054)$ & $(12.731)$ \\
\hline \multirow[t]{2}{*}{ Household size (number) } & $0.005^{* * *}$ & $-159.393^{* * *}$ & $-1.043^{* * *}$ & $-0.614^{* * *}$ & $-25.300^{*}$ \\
\hline & $(0.002)$ & $(17.282)$ & $(0.131)$ & $(0.082)$ & $(14.689)$ \\
\hline \multirow[t]{2}{*}{ Indonesia (dummy) } & $0.119^{* * *}$ & 152.026 & -1.702 & -0.361 & 96.974 \\
\hline & $(0.018)$ & $(169.145)$ & $(1.322)$ & $(0.791)$ & (153.196) \\
\hline \multirow{2}{*}{ Uganda (dummy) } & $0.197^{* * *}$ & -87.904 & $-8.228^{* * *}$ & $8.247^{* * *}$ & -5.457 \\
\hline & $(0.011)$ & $(112.243)$ & $(0.857)$ & $(0.621)$ & $(96.595)$ \\
\hline \multirow[t]{2}{*}{ Constant } & $2.095^{* * *}$ & $3085.113^{* * *}$ & $20.397^{* * *}$ & $13.382^{* * *}$ & $752.306^{\text {***** }}$ \\
\hline & $(0.028)$ & $(258.310)$ & $(1.998)$ & $(1.276)$ & $(290.853)$ \\
\hline Number of observations & 1484 & 1484 & 1484 & 1484 & 1484 \\
\hline Pseudo $\mathrm{R}^{2} / \mathrm{R}^{2}$ & 0.017 & 0.088 & 0.095 & 0.351 & 0.024 \\
\hline
\end{tabular}

Notes: Column (1) was estimated with a Poisson estimator. Columns (2)-(5) were estimated with OLS. Coefficient estimates are shown with robust standard errors in parentheses. ${ }^{*},{ }^{* *},{ }^{* * *}$ denote significance at the $10 \%, 5 \%$, and $1 \%$ level, respectively. HDDS stands for household dietary diversity score. AE stands for adult equivalent. 
Table A3. 2: Effect of farm species count on dietary quality (Indonesian sample)

\begin{tabular}{|c|c|c|c|c|c|}
\hline Explanatory variables & $\begin{array}{l}(1) \\
\text { HDDS }\end{array}$ & $\begin{array}{c}(2) \\
\text { Calories } \\
\text { (kcal/AE) }\end{array}$ & $\begin{array}{c}(3) \\
\text { Iron } \\
(\mathrm{mg} / \mathrm{AE})\end{array}$ & $\begin{array}{c}(4) \\
\text { Zinc } \\
(\mathrm{mg} / \mathrm{AE})\end{array}$ & $\begin{array}{c}(5) \\
\text { Vitamin A } \\
(\mu \mathrm{g} / \mathrm{AE})\end{array}$ \\
\hline Species count (crop + & $0.015^{\text {*** }}$ & $300.402^{* * *}$ & $2.499^{* * * *}$ & $1.006^{* * * *}$ & $204.475^{* * 4}$ \\
\hline livestock) & $(0.005)$ & $(66.202)$ & $(0.546)$ & $(0.249)$ & $(84.544)$ \\
\hline \multirow[t]{2}{*}{ Distance to market $(\mathrm{km})$} & -0.001 & $-13.188^{*}$ & -0.033 & -0.024 & 3.759 \\
\hline & $(0.001)$ & $(6.747)$ & $(0.057)$ & $(0.028)$ & $(8.514)$ \\
\hline \multirow[t]{2}{*}{ Cultivated land area (acres) } & $4.3 \mathrm{E}-04^{* *}$ & 8.915 & $0.084^{*}$ & 0.039 & 7.573 \\
\hline & $(1.9 \mathrm{E}-04)$ & $(7.194)$ & $(0.047)$ & $(0.029)$ & $(4.969)$ \\
\hline \multirow{2}{*}{$\begin{array}{l}\text { Share of land under food crops } \\
(\%)\end{array}$} & $-0.001^{* * *}$ & -1.593 & -0.011 & -0.007 & -3.272 \\
\hline & $(2.7 \mathrm{E}-04)$ & $(3.336)$ & $(0.028)$ & $(0.015)$ & $(2.510)$ \\
\hline \multirow{2}{*}{$\begin{array}{l}\text { Male household head } \\
\text { (dummy) }\end{array}$} & 0.028 & 178.446 & 1.670 & 0.833 & 138.395 \\
\hline & $(0.020)$ & $(231.696)$ & $(1.900)$ & $(0.809)$ & $(185.315)$ \\
\hline \multirow{2}{*}{ Age of household head (years) } & $3.4 \mathrm{E}-04$ & $8.535^{*}$ & $0.074^{*}$ & 0.011 & 7.890 \\
\hline & $(4.3 \mathrm{E}-04)$ & $(5.142)$ & $(0.044)$ & $(0.019)$ & $(6.165)$ \\
\hline \multirow{2}{*}{$\begin{array}{l}\text { Education of household head } \\
\text { (years) }\end{array}$} & $0.007^{* * *}$ & 24.072 & $0.322^{* *}$ & 0.066 & $62.071^{* *}$ \\
\hline & $(0.001)$ & $(17.153)$ & $(0.152)$ & $(0.068)$ & $(25.285)$ \\
\hline \multirow[t]{2}{*}{ Household size (number) } & $0.008^{* *}$ & $-196.305^{* * *}$ & $-1.565^{* * *}$ & $-0.641^{* * *}$ & -60.989 \\
\hline & $(0.004)$ & $(33.081)$ & $(0.295)$ & $(0.114)$ & $(38.134)$ \\
\hline \multirow{2}{*}{ Constant } & $2.154^{* * *}$ & $2651.500^{* * * *}$ & $13.534^{* * *}$ & $9.885^{* * *}$ & -39.350 \\
\hline & $(0.035)$ & $(390.809)$ & $(2.982)$ & $(1.466)$ & $(457.519)$ \\
\hline Number of observations & 672 & 672 & 672 & 672 & 672 \\
\hline Pseudo $R^{2} / R^{2}$ & 0.004 & 0.110 & 0.113 & 0.090 & 0.050 \\
\hline
\end{tabular}

Notes: Column (1) was estimated with a Poisson estimator. Columns (2)-(5) were estimated with OLS. Coefficient estimates are shown with robust standard errors in parentheses. ${ }^{*},{ }^{* *},{ }^{* * *}$ denote significance at the $10 \%, 5 \%$, and $1 \%$ level, respectively. HDDS stands for household dietary diversity score. AE stands for adult equivalent. 
Table A3. 3: Effects of farm species count on dietary quality (Kenyan sample)

\begin{tabular}{|c|c|c|c|c|c|}
\hline Explanatory variables & $\begin{array}{c}(1) \\
\text { HDDS }\end{array}$ & $\begin{array}{c}(2) \\
\text { Calories } \\
\text { (kcal/AE) }\end{array}$ & $\begin{array}{c}(3) \\
\text { Iron } \\
(\mathrm{mg} / \mathrm{AE})\end{array}$ & $\begin{array}{c}(4) \\
\text { Zinc } \\
(\mathrm{mg} / \mathrm{AE})\end{array}$ & $\begin{array}{c}(5) \\
\text { Vitamin A } \\
(\mu \mathrm{g} / \mathrm{AE})\end{array}$ \\
\hline Species count (crop + & $0.004^{* * *}$ & -2.972 & 0.028 & 0.046 & -31.527 \\
\hline livestock) & $(0.002)$ & $(25.358)$ & $(0.165)$ & $(0.173)$ & $(21.179)$ \\
\hline Distance to market $(\mathrm{km})$ & $-0.002^{*}$ & 16.987 & 0.029 & 0.105 & -7.074 \\
\hline & $(0.001)$ & $(10.328)$ & $(0.071)$ & $(0.076)$ & $(9.347)$ \\
\hline Cultivated land area (acres) & $\begin{array}{l}0.003^{* * *} \\
(0.001)\end{array}$ & $\begin{array}{c}-2.364 \\
(16.436)\end{array}$ & $\begin{array}{l}1.5 \mathrm{E}-04 \\
(0.135)\end{array}$ & $\begin{array}{c}0.044 \\
(0.113)\end{array}$ & $\begin{array}{l}38.648^{* *} \\
(17.845)\end{array}$ \\
\hline $\begin{array}{l}\text { Share of land under food crops } \\
(\%)\end{array}$ & $\begin{array}{l}-7.1 \mathrm{E}-05 \\
(1.6 \mathrm{E}-04)\end{array}$ & $\begin{array}{l}-0.894 \\
(2.139)\end{array}$ & $\begin{array}{l}-0.003 \\
(0.013)\end{array}$ & $\begin{array}{l}-0.003 \\
(0.015)\end{array}$ & $\begin{array}{c}1.048 \\
(1.700)\end{array}$ \\
\hline $\begin{array}{l}\text { Male household head } \\
\text { (dummy) }\end{array}$ & $0.026^{*}$ & 136.589 & $4.144^{* * *}$ & -2.311 & -122.358 \\
\hline & $(0.014)$ & $(182.447)$ & $(0.957)$ & $(1.470)$ & $(169.735)$ \\
\hline Age of household head (years) & $\begin{array}{c}-0.001 \\
(4.3 \mathrm{E}-04)\end{array}$ & $\begin{array}{c}4.530 \\
(5.659)\end{array}$ & $\begin{array}{l}-0.015 \\
(0.036)\end{array}$ & $\begin{array}{l}-0.045 \\
(0.036)\end{array}$ & $\begin{array}{l}-0.171 \\
(4.398)\end{array}$ \\
\hline $\begin{array}{l}\text { Education of household head } \\
\text { (years) }\end{array}$ & $\begin{array}{l}0.004^{* * *} \\
(0.001)\end{array}$ & $\begin{array}{c}13.361 \\
(17.916)\end{array}$ & $\begin{array}{l}0.207^{*} \\
(0.114)\end{array}$ & $\begin{array}{c}0.119 \\
(0.127)\end{array}$ & $\begin{array}{l}29.339^{* *} \\
(12.649)\end{array}$ \\
\hline Household size (number) & $\begin{array}{c}0.001 \\
(0.003)\end{array}$ & $\begin{array}{c}-248.816^{* * *} \\
(39.987)\end{array}$ & $\begin{array}{c}-1.326^{* * *} \\
(0.239)\end{array}$ & $\begin{array}{c}-1.292^{* * *} \\
(0.256)\end{array}$ & $\begin{array}{c}-104.862^{* * * *} \\
(24.007)\end{array}$ \\
\hline Constant & $\begin{array}{l}2.366^{* * *} \\
(0.039)\end{array}$ & $\begin{array}{c}3964.714^{* * *} \\
(448.199)\end{array}$ & $\begin{array}{c}17.800^{* * *} \\
(3.182)\end{array}$ & $\begin{array}{c}29.632^{* * *} \\
(3.270)\end{array}$ & $\begin{array}{c}1800.099^{\text {**** }} \\
(380.319)\end{array}$ \\
\hline Number of observations & 395 & 395 & 395 & 395 & 395 \\
\hline Pseudo $\mathrm{R}^{2} / \mathrm{R}^{2}$ & 0.002 & 0.131 & 0.119 & 0.100 & 0.073 \\
\hline
\end{tabular}

Notes: Column (1) was estimated with a Poisson estimator. Columns (2)-(5) were estimated with OLS. Coefficient estimates are shown with robust standard errors in parentheses. ${ }^{*},{ }^{* *},{ }^{* * *}$ denote significance at the $10 \%, 5 \%$, and $1 \%$ level, respectively. HDDS stands for household dietary diversity score. AE stands for adult equivalent. 
Table A3. 4: Effects of farm species count on dietary quality (Ugandan sample)

\begin{tabular}{|c|c|c|c|c|c|}
\hline Explanatory variables & $\begin{array}{c}\text { (1) } \\
\text { HDDS }\end{array}$ & $\begin{array}{c}(2) \\
\text { Calories } \\
\text { (kcal/AE) }\end{array}$ & $\begin{array}{c}(3) \\
\text { Iron } \\
(\mathrm{mg} / \mathrm{AE})\end{array}$ & $\begin{array}{c}(4) \\
\text { Zinc } \\
(\mathrm{mg} / \mathrm{AE})\end{array}$ & $\begin{array}{c}(5) \\
\text { Vitamin A } \\
(\mu \mathrm{g} / \mathrm{AE})\end{array}$ \\
\hline Species count (crop + & $0.021^{* * * 2}$ & $83.035^{\text {*** }}$ & $0.470^{*}$ & $0.301^{* * * 4}$ & 35.618 \\
\hline livestock) & $(0.004)$ & $(33.648)$ & $(0.255)$ & $(0.152)$ & $(30.738)$ \\
\hline Distance to market $(\mathrm{km})$ & -0.001 & -14.381 & -0.109 & -0.057 & -7.171 \\
\hline & $(0.002)$ & $(13.643)$ & $(0.104)$ & $(0.052)$ & $(11.823)$ \\
\hline Cultivated land area (acres) & -0.001 & 26.701 & 0.123 & 0.162 & -11.130 \\
\hline & $(0.003)$ & $(20.905)$ & $(0.164)$ & $(0.111)$ & $(17.030)$ \\
\hline Share of land under food crops & $-3.6 \mathrm{E}-04$ & -1.522 & 0.017 & 0.007 & $6.271^{* *}$ \\
\hline$(\%)$ & $(3.5 \mathrm{E}-04)$ & $(2.797)$ & $(0.022)$ & $(0.013)$ & $(2.454)$ \\
\hline $\begin{array}{l}\text { Male household head } \\
\text { (dummy) }\end{array}$ & $0.052^{* *}$ & -176.676 & -1.872 & -0.387 & -169.442 \\
\hline & $(0.021)$ & $(176.997)$ & $(1.405)$ & $(0.788)$ & $(154.543)$ \\
\hline Age of household head (years) & $\begin{array}{l}-0.002^{* *} \\
(0.001)\end{array}$ & $\begin{array}{l}11.271^{* * *} \\
(4.620)\end{array}$ & $\begin{array}{l}0.091^{* * *} \\
(0.037)\end{array}$ & $\begin{array}{l}0.054^{* *} \\
(0.022)\end{array}$ & $\begin{array}{c}3.926 \\
(4.419)\end{array}$ \\
\hline $\begin{array}{l}\text { Education of household head } \\
\text { (years) }\end{array}$ & $\begin{array}{l}0.006^{* * *} \\
(0.002)\end{array}$ & $\begin{array}{l}-32.411 \\
(20.458)\end{array}$ & $\begin{array}{l}-0.312^{*} \\
(0.180)\end{array}$ & $\begin{array}{l}-0.201^{*} \\
(0.107)\end{array}$ & $\begin{array}{l}-27.582^{*} \\
(15.528)\end{array}$ \\
\hline Household size (number) & $\begin{array}{l}0.003 \\
(0.003)\end{array}$ & $\begin{array}{c}-130.325^{* * *} \\
(22.348)\end{array}$ & $\begin{array}{l}-0.780^{* * *} \\
(0.169)\end{array}$ & $\begin{array}{c}-0.476^{* * * *} \\
(0.104)\end{array}$ & $\begin{array}{c}11.989 \\
(17.015)\end{array}$ \\
\hline Constant & $\begin{array}{l}2.063^{* * *} \\
(0.056)\end{array}$ & $\begin{array}{c}3007.942^{* * *} \\
(403.447)\end{array}$ & $\begin{array}{c}21.492^{* * *} \\
(3.132)\end{array}$ & $\begin{array}{c}10.339^{* * *} \\
(1.762)\end{array}$ & $\begin{array}{c}751.280^{*} \\
(421.745)\end{array}$ \\
\hline No. of observations & 417 & 417 & 417 & 417 & 417 \\
\hline Pseudo $\mathrm{R}^{2} / \mathrm{R}^{2}$ & 0.010 & 0.119 & 0.093 & 0.094 & 0.044 \\
\hline
\end{tabular}

Notes: Column (1) was estimated with a Poisson estimator. Columns (2)-(5) were estimated with OLS. Coefficient estimates are shown with robust standard errors in parentheses. ${ }^{*},{ }^{* *},{ }^{* * *}$ denote significance at the $10 \%, 5 \%$, and $1 \%$ level, respectively. HDDS stands for household dietary diversity score. AE stands for adult equivalent. 
Table A3. 5: Effect of production diversity score on dietary quality (pooled sample)

\begin{tabular}{|c|c|c|c|c|c|}
\hline Explanatory variables & $\begin{array}{c}(1) \\
\text { HDDS }\end{array}$ & $\begin{array}{c}(2) \\
\text { Calories } \\
\text { (kcal/AE) }\end{array}$ & $\begin{array}{c}(3) \\
\text { Iron } \\
(\mathrm{mg} / \mathrm{AE})\end{array}$ & $\begin{array}{c}\text { (4) } \\
\text { Zinc } \\
\text { (mg/AE) }\end{array}$ & $\begin{array}{c}(5) \\
\text { Vitamin A } \\
(\mu \mathrm{g} / \mathrm{AE})\end{array}$ \\
\hline Production diversity score & $0.008^{\text {***** }}$ & 30.382 & 0.140 & 0.157 & -31.662 \\
\hline (food groups) & $(0.003)$ & $(28.238)$ & $(0.212)$ & $(0.145)$ & $(23.545)$ \\
\hline \multirow[t]{2}{*}{ Distance to market $(\mathrm{km})$} & $-0.001^{* *}$ & -9.443 & -0.032 & -0.015 & 1.433 \\
\hline & $(0.001)$ & $(5.790)$ & $(0.049)$ & $(0.025)$ & $(6.837)$ \\
\hline \multirow[t]{2}{*}{ Cultivated land area (acres) } & $0.001^{* * *}$ & 10.538 & $0.097^{* *}$ & 0.046 & $9.316^{*}$ \\
\hline & $(2.0 \mathrm{E}-04)$ & $(7.418)$ & $(0.049)$ & $(0.030)$ & $(5.203)$ \\
\hline \multirow{2}{*}{$\begin{array}{l}\text { Share of land under food crops } \\
(\%)\end{array}$} & $-3.4 \mathrm{E}-04^{* *}$ & 0.018 & 0.013 & 0.003 & $2.316^{* *}$ \\
\hline & $(1.4 \mathrm{E}-04)$ & $(1.487)$ & $(0.012)$ & $(0.008)$ & $(1.173)$ \\
\hline \multirow{2}{*}{$\begin{array}{l}\text { Male household head } \\
\text { (dummy) }\end{array}$} & $0.043^{* * *}$ & -33.726 & 0.237 & -0.948 & -152.233 \\
\hline & $(0.012)$ & $(114.936)$ & $(0.890)$ & $(0.606)$ & $(100.502)$ \\
\hline \multirow{2}{*}{ Age of household head (years) } & $-4.5 \mathrm{E}-04$ & $9.183^{* * *}$ & $0.062^{* * *}$ & 0.013 & 4.572 \\
\hline & $(2.9 \mathrm{E}-04)$ & $(2.963)$ & $(0.023)$ & $(0.014)$ & $(3.079)$ \\
\hline \multirow{2}{*}{$\begin{array}{l}\text { Education of household head } \\
\text { (years) }\end{array}$} & $0.006^{* * *}$ & 9.938 & 0.146 & 0.039 & $30.109^{* *}$ \\
\hline & $(0.001)$ & $(11.015)$ & $(0.091)$ & $(0.054)$ & $(12.876)$ \\
\hline \multirow[t]{2}{*}{ Household size (number) } & $0.006^{* * *}$ & $-150.898^{* * *}$ & $-0.971^{* * *}$ & $-0.586^{* * *}$ & -17.368 \\
\hline & $(0.002)$ & $(16.916)$ & $(0.129)$ & $(0.080)$ & $(14.230)$ \\
\hline \multirow[t]{2}{*}{ Indonesia (dummy) } & $0.094^{* * * *}$ & -110.792 & $-4.100^{* * *}$ & -1.125 & $-246.359^{*}$ \\
\hline & $(0.019)$ & $(184.301)$ & $(1.435)$ & $(0.847)$ & $(144.422)$ \\
\hline \multirow[t]{2}{*}{ Uganda (dummy) } & $0.208^{* * * *}$ & -36.673 & $-7.935^{* * *}$ & $8.483^{* * *}$ & -28.744 \\
\hline & $(0.012)$ & (116.819) & $(0.874)$ & $(0.648)$ & $(94.013)$ \\
\hline \multirow[t]{2}{*}{ Constant } & $2.121^{* * * *}$ & $3336.638^{* * * *}$ & $22.622^{* * * *}$ & $14.148^{* * * *}$ & $1044.834^{\text {*** }}$ \\
\hline & $(0.028)$ & $(262.419)$ & $(2.030)$ & $(1.293)$ & $(275.266)$ \\
\hline Number of observations & 1484 & 1484 & 1484 & 1484 & 1484 \\
\hline Pseudo $\mathrm{R}^{2} / \mathrm{R}^{2}$ & 0.017 & 0.081 & 0.089 & 0.348 & 0.024 \\
\hline
\end{tabular}

Notes: Column (1) was estimated with a Poisson estimator. Columns (2)-(5) were estimated with OLS. Coefficient estimates are shown with robust standard errors in parentheses. ${ }^{*},{ }^{* *},{ }^{* *}$ denote significance at the $10 \%, 5 \%$, and $1 \%$ level, respectively. HDDS stands for household dietary diversity score. AE stands for adult equivalent. 
Table A3. 6: Effects of production diversity score on dietary quality (Indonesian sample)

\begin{tabular}{|c|c|c|c|c|c|}
\hline Explanatory variables & $\begin{array}{c}(1) \\
\text { HDDS }\end{array}$ & $\begin{array}{c}(2) \\
\text { Calories } \\
\text { (kcal/AE) }\end{array}$ & $\begin{array}{c}\text { (3) } \\
\text { Iron } \\
\text { (mg/AE) } \\
\end{array}$ & $\begin{array}{c}(4) \\
\text { Zinc } \\
\text { (mg/AE) }\end{array}$ & $\begin{array}{c}(5) \\
\text { Vitamin A } \\
(\mu \mathrm{g} / \mathrm{AE})\end{array}$ \\
\hline $\begin{array}{l}\text { Production diversity score (food } \\
\text { groups) }\end{array}$ & $\begin{array}{c}0.002 \\
(0.005)\end{array}$ & $\begin{array}{c}12.793 \\
(48.037)\end{array}$ & $\begin{array}{c}0.088 \\
(0.410)\end{array}$ & $\begin{array}{l}-0.019 \\
(0.179)\end{array}$ & $\begin{array}{l}-33.383 \\
(40.762)\end{array}$ \\
\hline Distance to market $(\mathrm{km})$ & $\begin{array}{l}-0.001 \\
(0.001)\end{array}$ & $\begin{array}{l}-10.461 \\
(7.001)\end{array}$ & $\begin{array}{l}-0.009 \\
(0.061)\end{array}$ & $\begin{array}{l}-0.014 \\
(0.029)\end{array}$ & $\begin{array}{c}6.707 \\
(8.804)\end{array}$ \\
\hline Cultivated land area (acres) & $\begin{array}{l}4.8 \mathrm{E}-04^{* *} \\
(2.1 \mathrm{E}-04)\end{array}$ & $\begin{array}{c}9.879 \\
(7.668)\end{array}$ & $\begin{array}{c}0.092^{*} \\
(0.051)\end{array}$ & $\begin{array}{c}0.042 \\
(0.031)\end{array}$ & $\begin{array}{c}8.155 \\
(5.253)\end{array}$ \\
\hline $\begin{array}{l}\text { Share of land under food crops } \\
(\%)\end{array}$ & $\begin{array}{l}-0.001^{* * *} \\
(2.7 \mathrm{E}-04)\end{array}$ & $\begin{array}{c}0.151 \\
(3.254)\end{array}$ & $\begin{array}{c}0.004 \\
(0.028)\end{array}$ & $\begin{array}{l}1.9 \mathrm{E}-04 \\
(0.015)\end{array}$ & $\begin{array}{l}-1.468 \\
(2.176)\end{array}$ \\
\hline Male household head (dummy) & $\begin{array}{l}0.034^{*} \\
(0.019)\end{array}$ & $\begin{array}{l}280.023 \\
(237.396)\end{array}$ & $\begin{array}{c}2.511 \\
(1.896)\end{array}$ & $\begin{array}{c}1.160 \\
(0.808)\end{array}$ & $\begin{array}{c}198.291 \\
(187.363)\end{array}$ \\
\hline Age of household head (years) & $\begin{array}{c}0.001 \\
(4.2 \mathrm{E}-04)\end{array}$ & $\begin{array}{c}12.169^{* *} \\
(5.270)\end{array}$ & $\begin{array}{l}0.104^{\text {** }} \\
(0.045)\end{array}$ & $\begin{array}{c}0.024 \\
(0.020)\end{array}$ & $\begin{array}{l}10.963^{*} \\
(6.390)\end{array}$ \\
\hline $\begin{array}{l}\text { Education of household head } \\
\text { (years) }\end{array}$ & $\begin{array}{l}0.007^{* * *} \\
(0.001)\end{array}$ & $\begin{array}{l}31.050^{*} \\
(17.317)\end{array}$ & $\begin{array}{l}0.381^{* *} \\
(0.153)\end{array}$ & $\begin{array}{c}0.090 \\
(0.069)\end{array}$ & $\begin{array}{l}67.837^{* *} \\
(26.406)\end{array}$ \\
\hline Household size (number) & $\begin{array}{l}0.008^{* *} \\
(0.004)\end{array}$ & $\begin{array}{l}-186.797^{* * * *} \\
(33.447)\end{array}$ & $\begin{array}{l}-1.485^{* * * *} \\
(0.298)\end{array}$ & $\begin{array}{l}-0.604^{* * * *} \\
(0.115)\end{array}$ & $\begin{array}{l}-51.405 \\
(38.322)\end{array}$ \\
\hline Constant & $\begin{array}{l}2.163^{* * *} \\
(0.035)\end{array}$ & $\begin{array}{l}2805.095^{* * * *} \\
(405.753)\end{array}$ & $\begin{array}{c}14.799^{* * *} \\
(3.036)\end{array}$ & $\begin{array}{c}10.356^{* * *} \\
(1.520)\end{array}$ & $\begin{array}{c}35.092 \\
(450.734)\end{array}$ \\
\hline Number of observations & 672 & 672 & 672 & 672 & 672 \\
\hline Pseudo $\mathrm{R}^{2} / \mathrm{R}^{2}$ & 0.003 & 0.068 & 0.071 & 0.056 & 0.035 \\
\hline
\end{tabular}

Notes: Column (1) was estimated with a Poisson estimator. Columns (2)-(5) were estimated with OLS. Coefficient estimates are shown with robust standard errors in parentheses. ${ }^{*},{ }^{* *},{ }^{* * *}$ denote significance at the $10 \%, 5 \%$, and $1 \%$ level, respectively. HDDS stands for household dietary diversity score. AE stands for adult equivalent. 
Table A3. 7: Effect of production diversity score on dietary quality (Kenyan sample)

\begin{tabular}{lccccc}
\hline & $\begin{array}{c}(1) \\
\text { Explanatory variables }\end{array}$ & $\begin{array}{c}(2) \\
\text { Calories } \\
\text { (kcal/AE) }\end{array}$ & $\begin{array}{c}(3) \\
\text { Iron } \\
(\mathrm{mg} / \mathrm{AE})\end{array}$ & $\begin{array}{c}\text { Zinc } \\
(\mathrm{mg} / \mathrm{AE})\end{array}$ & $\begin{array}{c}\text { Vitamin A } \\
(\mu \mathrm{g} / \mathrm{AE})\end{array}$ \\
\hline Production diversity score (food & 0.004 & 37.246 & 0.088 & 0.308 & $-69.592^{* *}$ \\
groups) & $(0.003)$ & $(46.244)$ & $(0.297)$ & $(0.294)$ & $(33.458)$ \\
Distance to market (km) & $-0.003^{*}$ & 15.736 & 0.025 & 0.092 & -3.619 \\
& $(0.001)$ & $(10.426)$ & $(0.070)$ & $(0.078)$ & $(9.524)$ \\
Cultivated land area (acres) & $0.003^{* * *}$ & -7.083 & -0.006 & 0.015 & $41.990^{* * *}$ \\
& $(0.001)$ & $(16.912)$ & $(0.134)$ & $(0.115)$ & $(17.787)$ \\
Share of land under food crops & $-1.1 \mathrm{E}-04$ & -0.300 & -0.002 & 0.001 & 0.885 \\
(\%) & $(1.6 \mathrm{E}-04)$ & $(2.105)$ & $(0.013)$ & $(0.015)$ & $(1.641)$ \\
Male household head (dummy) & $0.025^{*}$ & 136.790 & $4.140^{* * *}$ & -2.319 & -117.946 \\
& $(0.014)$ & $(182.834)$ & $(0.960)$ & $(1.472)$ & $(169.746)$ \\
Age of household head (years) & $-4.2 \mathrm{E}-04$ & 3.384 & -0.016 & -0.051 & 0.133 \\
& $(4.3 \mathrm{E}-04)$ & $(5.600)$ & $(0.036)$ & $(0.035)$ & $(4.310)$ \\
Education of household (years) & $0.004^{* * *}$ & 10.905 & $0.204^{*}$ & 0.104 & $30.946^{* *}$ \\
& $(0.002)$ & $(17.876)$ & $(0.114)$ & $(0.126)$ & $(12.650)$ \\
Household size (number) & 0.001 & $-251.965^{* * *}$ & $-1.328^{* * *}$ & $-1.308^{* * *}$ & $-104.471^{* * *}$ \\
& $(0.003)$ & $(39.855)$ & $(0.238)$ & $(0.254)$ & $(23.600)$ \\
Constant & $2.375^{* * *}$ & $3846.098^{* * *}$ & $17.717^{* * *}$ & $29.047^{* * *}$ & $1814.003^{* * *}$ \\
& $(0.037)$ & $(449.830)$ & $(3.176)$ & $(3.289)$ & $(372.653)$ \\
Number of observations & 395 & 395 & 395 & 395 & 395 \\
Pseudo R ${ }^{2} / \mathrm{R}^{2}$ & 0.002 & 0.133 & 0.119 & 0.102 & 0.078 \\
\hline
\end{tabular}

Notes: Column (1) was estimated with a Poisson estimator. Columns (2)-(5) were estimated with OLS. Coefficient estimates are shown with robust standard errors in parentheses. ${ }^{*},{ }^{* *},{ }^{* * *}$ denote significance at the $10 \%, 5 \%$, and $1 \%$ level, respectively. HDDS stands for household dietary diversity score. AE stands for adult equivalent. 
Table A3. 8: Effects of production diversity score on dietary quality (Ugandan sample)

\begin{tabular}{|c|c|c|c|c|c|}
\hline Explanatory variables & $\begin{array}{l}(1) \\
\text { HDDS }\end{array}$ & $\begin{array}{c}(2) \\
\text { Calories } \\
\text { (kcal/AE) }\end{array}$ & $\begin{array}{c}\text { (3) } \\
\text { Iron } \\
\text { (mg/AE) } \\
\end{array}$ & $\begin{array}{c}(4) \\
\text { Zinc } \\
\text { (mg/AE) }\end{array}$ & $\begin{array}{c}(5) \\
\text { Vitamin A } \\
(\mu \mathrm{g} / \mathrm{AE})\end{array}$ \\
\hline $\begin{array}{l}\text { Production diversity score (food } \\
\text { groups) }\end{array}$ & $\begin{array}{l}0.033^{* * * *} \\
(0.009)\end{array}$ & $\begin{array}{l}108.229 \\
(70.622)\end{array}$ & $\begin{array}{c}0.835 \\
(0.547)\end{array}$ & $\begin{array}{l}0.599^{*} \\
(0.321)\end{array}$ & $\begin{array}{c}49.277 \\
(55.715)\end{array}$ \\
\hline Distance to market $(\mathrm{km})$ & $\begin{array}{l}-0.001 \\
(0.002)\end{array}$ & $\begin{array}{l}-15.457 \\
(13.966)\end{array}$ & $\begin{array}{l}-0.118 \\
(0.105)\end{array}$ & $\begin{array}{l}-0.063 \\
(0.053)\end{array}$ & $\begin{array}{c}-7.661 \\
(11.896)\end{array}$ \\
\hline Cultivated land area (acres) & $\begin{array}{l}-4.5 \mathrm{E}-04 \\
(0.003)\end{array}$ & $\begin{array}{c}27.355 \\
(21.307)\end{array}$ & $\begin{array}{c}0.124 \\
(0.167)\end{array}$ & $\begin{array}{c}0.162 \\
(0.112)\end{array}$ & $\begin{array}{l}-10.883 \\
(16.796)\end{array}$ \\
\hline $\begin{array}{l}\text { Share of land under food crops } \\
(\%)\end{array}$ & $\begin{array}{l}-4.0 \mathrm{E}-04 \\
(3.6 \mathrm{E}-04)\end{array}$ & $\begin{array}{l}-1.616 \\
(2.792)\end{array}$ & $\begin{array}{c}0.015 \\
(0.022)\end{array}$ & $\begin{array}{c}0.006 \\
(0.013)\end{array}$ & $\begin{array}{l}6.220^{* *} \\
(2.475)\end{array}$ \\
\hline Male household head (dummy) & $\begin{array}{l}0.058^{* * *} \\
(0.022)\end{array}$ & $\begin{array}{l}-154.607 \\
(175.568)\end{array}$ & $\begin{array}{l}-1.719 \\
(1.400)\end{array}$ & $\begin{array}{l}-0.281 \\
(0.786)\end{array}$ & $\begin{array}{l}-159.617 \\
(155.215)\end{array}$ \\
\hline Age of household head (years) & $\begin{array}{l}-0.001^{*} \\
(0.001)\end{array}$ & $\begin{array}{l}12.419^{* * *} \\
(4.681)\end{array}$ & $\begin{array}{l}0.098^{* * *} \\
(0.038)\end{array}$ & $\begin{array}{l}0.060^{* * *} \\
(0.022)\end{array}$ & $\begin{array}{c}4.435 \\
(4.342)\end{array}$ \\
\hline $\begin{array}{l}\text { Education of household head } \\
\text { (years) }\end{array}$ & $\begin{array}{l}0.006^{* *} \\
(0.002)\end{array}$ & $\begin{array}{l}-31.594 \\
(20.885)\end{array}$ & $\begin{array}{l}-0.313^{*} \\
(0.183)\end{array}$ & $\begin{array}{l}-0.203^{*} \\
(0.108)\end{array}$ & $\begin{array}{l}-27.297^{*} \\
(15.897)\end{array}$ \\
\hline Household size (number) & $\begin{array}{l}0.005^{*} \\
(0.003)\end{array}$ & $\begin{array}{l}-122.336^{* * *} \\
(21.459)\end{array}$ & $\begin{array}{c}-0.757^{* * *} \\
(0.166)\end{array}$ & $\begin{array}{l}-0.467^{* * * *} \\
(0.102)\end{array}$ & $\begin{array}{c}15.135 \\
(17.106)\end{array}$ \\
\hline Constant & $\begin{array}{l}2.023^{* * * *} \\
(0.067)\end{array}$ & $\begin{array}{l}2944.099^{* * *} \\
(492.010)\end{array}$ & $\begin{array}{l}20.046^{* * * *} \\
(3.820)\end{array}$ & $\begin{array}{l}9.105^{* * *} \\
(2.219)\end{array}$ & $\begin{array}{c}709.994 \\
(433.212)\end{array}$ \\
\hline Number of observations & 417 & 417 & 417 & 417 & 417 \\
\hline Pseudo $\mathrm{R}^{2} / \mathrm{R}^{2}$ & 0.009 & 0.112 & 0.092 & 0.094 & 0.043 \\
\hline
\end{tabular}

Notes: Column (1) was estimated with a Poisson estimator. Columns (2)-(5) were estimated with OLS. Coefficient estimates are shown with robust standard errors in parentheses. ${ }^{*},{ }^{* *},{ }^{* * *}$ denote significance at the $10 \%, 5 \%$, and $1 \%$ level, respectively. HDDS stands for household dietary diversity score. AE stands for adult equivalent. 
Table A3. 9: Association between agricultural cash revenues and dietary quality

\begin{tabular}{|c|c|c|c|c|c|}
\hline $\begin{array}{l}\text { Explanatory variables by } \\
\text { country }\end{array}$ & $\begin{array}{c}(1) \\
\text { HDDS }\end{array}$ & $\begin{array}{c}(2) \\
\text { Calories } \\
\text { (kcal/AE) } \\
\end{array}$ & $\begin{array}{c}(3) \\
\text { Iron } \\
(\mathrm{mg} / \mathrm{AE})\end{array}$ & $\begin{array}{c}(4) \\
\text { Zinc } \\
(\mathrm{mg} / \mathrm{AE})\end{array}$ & $\begin{array}{c}(5) \\
\text { Vitamin A } \\
(\mu \mathrm{g} / \mathrm{AE})\end{array}$ \\
\hline \multicolumn{6}{|l|}{ Pooled } \\
\hline Agricultural cash revenues & $3.8 \mathrm{E}-06^{* * *}$ & $0.093^{* * *}$ & $0.001^{* * *}$ & $3.4 \mathrm{E}-04^{* * *}$ & $0.070^{* * *}$ \\
\hline (US\$/AE) & $(5.5 \mathrm{E}-07)$ & $(0.021)$ & $(1.5 \mathrm{E}-04)$ & $(8.7 \mathrm{E}-05)$ & $(0.016)$ \\
\hline \multirow[t]{2}{*}{ Indonesia (dummy) } & $0.061^{* * *}$ & -142.310 & $-4.368^{* * *}$ & $-1.426^{* * *}$ & $-274.297^{\text {*** }}$ \\
\hline & $(0.010)$ & $(92.970)$ & $(0.745)$ & $(0.400)$ & $(83.738)$ \\
\hline \multirow[t]{2}{*}{ Uganda (dummy) } & $0.196^{* * * *}$ & $172.288^{*}$ & $-6.053^{* * * *}$ & $9.229^{* * *}$ & 93.876 \\
\hline & $(0.010)$ & $(90.668)$ & $(0.672)$ & $(0.515)$ & $(75.884)$ \\
\hline \multirow[t]{2}{*}{ Constant } & $2.233^{* * *}$ & $3031.343^{* * *}$ & $22.207^{* * * *}$ & $11.632^{* * * *}$ & $1224.370^{\text {*** }}$ \\
\hline & $(0.009)$ & $(66.997)$ & $(0.545)$ & $(0.308)$ & $(56.928)$ \\
\hline Number of observations & 1484 & 1484 & 1484 & 1484 & 1484 \\
\hline Pseudo $R^{2} / R^{2}$ & $0.014^{+}$ & 0.066 & 0.087 & 0.338 & 0.042 \\
\hline \multicolumn{6}{|l|}{ Indonesia } \\
\hline Agricultural cash revenues & $3.7 \mathrm{E}-06^{* * * *}$ & $0.095^{* * *}$ & $0.001^{* * *}$ & $3.4 \mathrm{E}-04^{* * *}$ & $0.074^{* * *}$ \\
\hline (US\$/AE) & $(5.8 \mathrm{E}-07)$ & $(0.022)$ & $(1.6 \mathrm{E}-04)$ & $(9.4 \mathrm{E}-05)$ & $(0.017)$ \\
\hline \multirow[t]{2}{*}{ Constant } & $2.294^{* * *}$ & $2882.418^{* * * *}$ & $17.744^{* * * *}$ & $10.205^{* * *}$ & $941.235^{* * * *}$ \\
\hline & $(0.005)$ & $(69.511)$ & $(0.542)$ & $(0.276)$ & $(63.563)$ \\
\hline Number of observations & 672 & 672 & 672 & 672 & 672 \\
\hline Pseudo $R^{2} / R^{2}$ & $0.001^{+}$ & 0.113 & 0.096 & 0.103 & 0.055 \\
\hline \multicolumn{6}{|l|}{ Kenya } \\
\hline Agricultural cash revenues & $3.6 \mathrm{E}-06^{* *}$ & $0.052^{* * *}$ & $2.6 \mathrm{E}-04^{* *}$ & 2.7E-04 & 0.035 \\
\hline (US\$/AE) & $(1.4 \mathrm{E}-06)$ & $(0.016)$ & $(1.2 \mathrm{E}-04)$ & $(1.6 \mathrm{E}-04)$ & $(0.024)$ \\
\hline \multirow[t]{2}{*}{ Constant } & $2.429^{* * *}$ & $3245.445^{* * *}$ & $16.593^{* * *}$ & $20.933^{* * * *}$ & $1354.308^{* * *}$ \\
\hline & $(0.005)$ & $(61.180)$ & $(0.405)$ & $(0.439)$ & $(54.779)$ \\
\hline Number of observations & 395 & 395 & 395 & 395 & 395 \\
\hline Pseudo $\mathrm{R}^{2} / \mathrm{R}^{2}$ & $0.0002^{+}$ & 0.009 & 0.006 & 0.005 & 0.006 \\
\hline \multicolumn{6}{|l|}{ Uganda } \\
\hline Agricultural cash revenues & $3.5 \mathrm{E}-05$ & $1.072^{* * *}$ & $0.005^{* * *}$ & $0.004^{* * *}$ & 0.144 \\
\hline (US\$/AE) & $(2.5 \mathrm{E}-05)$ & $(0.240)$ & $(0.002)$ & $(0.001)$ & $(0.194)$ \\
\hline \multirow[t]{2}{*}{ Constant } & $2.227^{* * *}$ & $2862.870^{* * * *}$ & $21.467^{* * * *}$ & $10.936^{* * * *}$ & $1211.644^{* * * *}$ \\
\hline & $(0.010)$ & $(77.754)$ & $(0.648)$ & $(0.378)$ & $(72.216)$ \\
\hline Number of observations & 417 & 417 & 417 & 417 & 417 \\
\hline Pseudo $R^{2} / \mathrm{R}^{2}$ & $0.0002^{+}$ & 0.043 & 0.014 & 0.034 & 0.001 \\
\hline
\end{tabular}

Notes: The models in column (1) were estimated with a Poisson estimator. The models in columns (2)-(5) were estimated with OLS. Coefficient estimates are shown with robust standard errors in parentheses. ${ }^{*},{ }^{* *},{ }^{* * *}$ denote significance at the $10 \%, 5 \%$, and $1 \%$ level, respectively. HDDS stands for household dietary diversity score. AE stands for adult equivalent. 


\title{
CHAPTER 4
}

\section{Contributions of Market Purchases and Home Production to Seasonal Food Availability in Farm Households: Insights from Ethiopia}

\begin{abstract}
In this study, we contribute to the food security literature by investigating the relative contribution of market purchases and own production to seasonal food availability in farm households. We use nationally representative survey data from Ethiopia and calculated daily per capita calorie consumption and household dietary diversity scores as indicators of food availability and dietary quality for each month in a full calendar year. We find that Ethiopian farmers extensively engage in selling and buying foods; most of them are net buyers of food commodities. A large number of farms lack food and could not cover their regular food needs from what is produced on-farm. Food purchases using money earned through agricultural sales and off-farm activities clearly stand out as the major source of food throughout all seasons. Households with insufficient food available rely more on own production as a source of food, while households with enough food available mostly rely on food purchases. We conclude that - in most cases - subsistence production cannot be the main or only source of food in smallholder farm households. Improving market access seems to be more important for improving nutrition. Hence, policies aimed at strengthening markets and improving offfarm income opportunities for the rural poor should have high priority.
\end{abstract}




\subsection{Introduction}

Despite significant progress in food production, providing healthy and sufficient food for all remains a big challenge (Foley et al., 2011). Today, the global scale of hunger and malnutrition is staggering: one in nine people continue to go chronically underfed every day meaning that she does not have access to sufficient calorie, and nearly one third of the world population is classified micronutrient malnourished which means that the intake of minerals and vitamins is too low to support a healthy life (IFPRI, 2016; FAO et al., 2015). In the subSaharan Africa, majority of the undernourished people are smallholder farmers living in the rural areas of those countries (Barrett, 2010; Muller, 2009), most of whom are women and children. Although those farmers produce majority of the food supply, paradoxically they are the most undernourished rural people who are suffering from different facets of nutrition deficiencies (FAO, 2014; Herrero et al., 2010). Thus, it might not be astonishing that policy intervention against poverty and food insecurity in most developing countries primarily attempt to enhance the agricultural sector. Nevertheless, those policy interventions often fail (Erickson et al., 2009). The unsuccessful policy interventions generally underscore the fundamental role of agriculture in delivering sufficiently diverse food to the people who count on it the most. Achieving sustainable food access for all is a fundamental part of the post2015 United Nations Sustainable Development Goals (SDGs) (United Nations, 2015).

So how can sustainable and adequately diverse food provisioning in farm households be realized? A complex question to answer, particularly as the disadvantaged smallholder farmers reside in remote and environmentally fragile areas of the developing world (FAO, 2014). Recently, there are two main food provisioning strategies believed to directly benefit smallholder farmers and getting more research attention: more diverse on-farm food production for home use and market simulated food provisioning. Introducing additional crops and livestock species on smallholder farms is perceived as potentially promising strategy (Powell et al., 2015; Fanzo et al., 2013; Burlingame and Dernini, 2012). This is due to the fact that smallholder farmers consume a significant part of what they produce and hence farm diversity could boost diversity of food available from own production. Farm diversity is also acknowledged as environmental friendly and could enhance agroecological 
sustainability (Luckett et al., 2015; Burlingame and Dernini, 2012; Frison et al., 2006; Deckelbaum et al., 2006). At the same time, others argue that strengthening markets might be more promising strategy to achieve sustainable food security in farm households (Sibhatu et al., 2015; Stifel and Minten, 2015; Hirvonen and Hoddinott, 2014). They argue that smallholder farmers, particularly in the sub-Saharan Africa, are already highly diversified and adding more species on top of it could be economically negative (Sibhatu et al., 2015; Sibhatu and Qaim, 2016); most smallholder farmers engage in market transaction (even in remote settings; Luckett et al., 2015) and are net buyers of food items (World Bank, 2007b); and the food markets and diets in those countries are transforming very fast (Qaim, 2016b; Tschirley et al., 2015), which calls for caution so that smallholder farmers not to be marginalized further.

Moreover, recent findings suggest that several factors such as off-farm income and improved market access are essential for food availability in farm households (Frelat et al., 2016; Sibhatu et al., 2015). However, those studies are based on cross-sectional datasets and availability of food is not stable over time; it varies across agricultural seasons for example (Hassen et al., 2016; Hirvonen et al., 2015; Kearney, 2010). Evidences suggest that dietary diversity and calorie consumption vary across agricultural seasons (Hirvonen et al., 2015), and food purchases play an essential role in providing food to farm households (Luckett et al., 2015). Nonetheless, we are not aware of a study on the seasonal variation and contribution of own production and market purchases from farm and off-farm incomes to seasonal food availability in farm households. Here, we aim to address this research gap by using unique seasonal data available from Ethiopia. Understanding how food sources and food availability vary across agricultural seasons could help to design sound policies that aim to improve food and nutrition security in developing countries.

In particular, the objectives of this study are twofold. First, we examine how food purchases and own production in smallholder farm households vary across agricultural seasons. Second we assess the relative contribution of market purchases and on-farm food production to sufficient food availability and further analysis whether this effect varies across agroecological zones. Ethiopia was chosen because unique and nationally representative data collected in each month over a calendar year and suitable for the analysis is available. 
Ethiopia is also uniquely interesting country that more than $80 \%$ of its population live in rural areas and practice seasonal rain-fed agriculture using traditional mode of production (CSA, 2006). The big African country is also diverse in terms of culture and agroecology.

The paper proceeds as follows. Description of the data and methodology employed is provided in the next section. In section three, the results and discusses are presented. The fourth section concludes the paper.

\subsection{Materials and Methods}

\subsubsection{Agricultural seasonality in Ethiopia in brief}

Similar to many sub-Saharan countries, agriculture is the dominant economic activity in Ethiopia, particularly in terms of employment. Over $80 \%$ of Ethiopian workforce is engaged in predominantly subsistence-oriented agriculture mainly for domestic use, often combination of crop production and livestock herding. The country's small-scale agriculture is largely dependent on two rainfall regimes, spring (belg) and summer (meher), The summer rains are concentrated between months of July and October, while the short spring rain occurs from March to May. The summer rain is the most important. Over 90\% of crop cultivation in Ethiopia is carried out during this season (Taffesse et al., 2012). This implies that Ethiopian farmers strongly depend on single rainy season to produce food for an entire calendar year, which also makes Ethiopia a suitable example for seasonality study. In Ethiopia, agriculture is often affected by limited and erratic rainfall and frequent drought.

In most agricultural areas in Ethiopia, a calendar year could be divided into four distinctive seasonal activities: growing season from July to September where most of annual crops are grown and extensive agricultural work is carried out; the harvest season from October to December where abundant food is available (Hirvonen et al., 2015); post-harvest season from January to April; and pre-growing season from May to June. The post-harvest season is characterized as a period of main crop sales and agricultural work abates, while the pregrowing season is known as a period of food stock dwindles, livestock sales, and start of agricultural work. 
Farmers in Ethiopia are highly diversified with a mix of various crops and livestock both for home consumption and sale (Sibhatu et al., 2015). In 2012, the average farm size reported was 1.8 hectares (FAO, 2015). In some agricultural areas, farmers also grow cash crops such as coffee, tea, sugarcane and chat. Outside farming, Ethiopian farmers involve in multiple offfarm activities to complement to their small incomes. Off-farm income including wage earnings and enterprise income contributes up to one-fifth of rural income in Ethiopia (Bachewe et al., 2016). Remittance from family members in abroad and cities, and public and private transfer payments are also dominant source of income to the Ethiopian farm households as well (FAO, 2015; World Bank, 2011).

\subsubsection{Data source}

Data for the empirical analysis are taken from the 2010/11 Household Consumption and Expenditure Survey (HCES) in Ethiopia collected by the country's Central Statistical Agency (CSA, 2012). The survey covered almost the entire country, except for some non-sedentary pastoralists in two administrative regions. The HCES is representative at national level and was carried out between July 2010 and June 2011. The HCES used stratified random sampling approach to select the respondents. The objective of this study is to compare the relative contribution of home produced foods and market purchases to food availability in agricultural households. In other words, we are particularly interested on farm households (head of households fully employed in agriculture) that at least some portion of their food comes from their own on-farm production. Hence, non-farming, observations with household head not self-employed in farming in the past 12 months and that had missing information for relevant variables are excluded. Additionally, we excluded households that did not report consumption of food from own on-farm production. This is to exclude urban farmers who own farms in rural areas and produce only non-food crops like coffee, tea and chat. They rely on market purchases for their food needs anyway. In the final analysis, we use 5755 observations.

Using structured questionnaire, detail information on food consumption and its sources were thoroughly collected during the previous 7-days recall period in each month in a calendar 
year. The main advantage of data collected every month in a colander year is that it enables to capture seasonal information and allows for seasonality analysis.

As food consumption was fundamental part of the HCES, food items and beverages consumed were collected using diary book from each household (every household member) by a carefully trained field enumerators and team leaders. Detailed list of all items consumed on daily basis was exhausted first on the diary book, and then household summary of every item consumed with its quantity was recorded in the main questionnaire. The sample households were also asked to specify the source for each food item consumed: whether from own production, purchased from farm income or purchased from off-farm income (including remittance from family members and public and non-profit organization transfer payments), which also provided motivation for this study. Kitchen balance scale was used to measure the quantity of the food items consumed. To minimize recall errors, each sample household was visited twice in the survey week (CSA, 2012).

\subsubsection{Measuring food availability}

There is no consensually agreed definition for food availability that we could locate in the literature. The literature does not also provide standard rule on how to measure food availability in developing countries. Here, we define food availability as the average annual actual quantity of food consumed at household level and supplied through own production or market purchases, or both channels. We utilize daily per capita calorie consumption and household dietary diversity score (HDDS) to measure food availability in this study. Both per capita calorie consumption (Frelat et al., 2016; Hengsdijk et al., 2014) and HDDS (Upton et al., 2016; Hirvonen et al., 2015; Headey and Ecker, 2013) are meaningful household level performance indicators for general food access and security in survey studies in developing countries. Frelat et al. (2016) have employed potential calorie availability per person per day as an indicator of food availability for sub-Saharan countries. Following this study, we employ actual daily per capita calorie consumption as an indicator of food availability in Ethiopia. It is calculated as:

$$
\text { Calorie Consumption }=\frac{E_{o c}+E_{o s c}+E_{o s}}{D \times N_{h h}}
$$


where Calorie Consumption is daily per capita calorie consumption (kcal/capita/day), $E_{o c}$ is total calorie consumed from own production (which we call it own production), $E_{o s c}$ is total calorie consumed from foods bought using farm income (we call it purchases from farm income), $E_{o S}$ is total calorie consumption from money earned from off-farm activities and remittance and transfer payments (we call it purchases from off-farm income), $D$ is food consumption recall period (7 days in this study), and $N_{h h}$ is household size. The total calorie consumption per person at household level is calculated by summing up household calorie consumption from own production, purchases from farm income and purchases from off-farm income, and adjusted by the recall days and size of a household.

An important concern in food sufficiency analysis is the minimum amount of calorie needed could easily be overestimated unless a methodology that accounts for food waste, processing losses and inedible portion is used. In the HCES dataset, both gross calorie (not adjusted for inedible portion) and estimated net calorie (adjusted for inedible portion) for every food item consumed is reported (CSA, 2012). Hence, in this study we utilize net calorie consumption per person per day at household level. The calorie calculation was based on Ethiopian composition tables (EHNRI and FAO, 1998).

Hirvonen et al. (2015) suggested that per capita calorie consumption and HDDS should be employed together for a better food security analysis. HDDS is commonly recognized as a meaningful proxy for general food access and security, because diverse diet helps intake of balanced nutrients (Raul, 2003; Hoddinott and Yohannes, 2002). HDDS of foods consumed over 7 days is calculated at each month in a calendar year. Following FAO (2011) we use 12 food groups in this study: cereals; white tubers and roots; legumes, legume products, nuts, and seeds; vegetables and vegetable products; fruits; meat; eggs; fish and fish products; milk and milk products; sweets, sugars, and syrups; oils and fats; and spices, condiments, and beverages.

In addition, we calculate 9 food groups that include relatively healthy foods. We exclude food groups related to caffeine, oils, alcoholic beverages, sweets, sugars and syrups. This is important in nutritional perspective due to the fact that market access might also facilitate access for cheap but unhealthy foods if consumed in large quantity (Popkin, 2009). Unlike the 
daily calorie consumption per person, the household dietary diversity score for all sources does not equal to the sum of the household dietary diversity scores of own production, purchases from farm income and purchases from off-farm income, as similar food group could be consumed across the different sources.

To distinguish the level of sufficiency of food availability among the respondent households, we also adopt an approach used by Frelat et al. (2016) that the sample is divided into three classes of food sufficiency: insufficient (less than $1500 \mathrm{kcal} / \mathrm{capita} / \mathrm{day}$ ), enough food available (between 1500 and $2500 \mathrm{kcal} / \mathrm{capita} / \mathrm{day}$ ), and more than enough food available (greater than $2500 \mathrm{kcal} / \mathrm{capita} /$ day). As explained above, unlike Frelat et al. (2016) who estimated potential supply, we use direct estimates of household food consumption on the bases of actual amount of foods consumed over 7-day recall data. Hence, the cutoff point between the two upper levels of food availability is applied at $2500 \mathrm{kcal} / \mathrm{capita} / \mathrm{day}$, the daily calorie need of an adult male (Frelat et al., 2016). This is slightly higher than the estimated national gross calorie consumption (2380 kcal/capita/day) in 2011 (CSA, 2012). We apply the three food sufficiently levels to explain the relative contribution of purchased and on-farm produced foods to household food sufficiency. Based on the calorie sufficiency classification approach we used, HDDS is also divided in to three classes.

\subsubsection{Statistical analysis}

Mean daily per capita calorie consumption and household dietary diversity score disaggregated by foods from own production, farm income, and off-farm income is computed. The results are displayed mainly in graphs and diagrams. A one-way ANOVA test is preformed to assess differences among categories whenever necessary.

The following regression model is also employed to assess seasonal and agroecological influence on the food sources.

$$
N_{i}=\beta_{0}+\beta_{1} X_{i}+v_{i}
$$

where $\boldsymbol{N}_{\boldsymbol{i}}$ stands alternatively for per capita daily calorie consumption, and household dietary diversity score of a farm household $i$. Calorie consumption and dietary diversity are affected alternatively by seasonal and agroecological variables $\left(\boldsymbol{X}_{\boldsymbol{i}}\right)$. $\beta_{0}-\beta_{1}$ are coefficients to be 
estimated. $v_{i}$ is a random error term. Standard Ordinarily Least Square (OLS) regression estimation is utilized for the estimation. The coefficients of the OLS regression could directly be interpreted as marginal effects. Robust standard errors are included in the analysis to account for possible heterogeneity (Greene, 2012). In the HCES, agroecology is classified in to four zones: highland, moderate, lowland and urban.

Table 4. 1: Descriptive statistics

\begin{tabular}{lcc}
\hline Variable & Mean & Std. Dev. \\
\hline Food availability indicators & 6.81 & 1.68 \\
HDDS of all foods (12 food groups) & 2177.63 & 1694.28 \\
Calorie from all foods (kcal/capita/day) & 0.15 & 0.36 \\
Agroecological zones* & 0.34 & 0.47 \\
Highland agroecology (Yes=1, Otherwise=0) & 0.36 & 0.48 \\
Moderate agroecology (Yes=1, Otherwise=0) & 0.15 & 0.36 \\
Lowland agroecology (Yes=1, Otherwise=0) & 0.24 \\
Urban agroecology (Yes=1, Otherwise=0) (reference) & 0.28 & 0.43 \\
Agricultural Seasons & 0.22 & 0.45 \\
Harvest: October-December (Yes=1, Otherwise=0) (reference) & 0.41 \\
Post-harvest: January-April (Yes=1, Otherwise=0) & 0.32 \\
Pre-growing: May-June (Yes=1, Otherwise=0) & 5755 \\
$\quad$ Growing: July-September (Yes=1, Otherwise=0) & 0.47 \\
Number of Observation & & 5 \\
\hline
\end{tabular}

Notes: HDDS is household dietary diversity score. * - We use agroecological classification as it is designed in the HCES: highland, moderate, lowland and urban conditions.

\subsection{Results and Discussion}

\subsubsection{Descriptive statistics}

Table 4.1 shows average dietary diversity score and daily calorie consumption per person at household levels. On average (12 months' average), 6.8 food groups and $2177.8 \mathrm{kcal}$ per person per day at household levels are scored. The average household dietary diversity score and calorie consumption are reasonable for the Ethiopian rain-fed farmers, as the calorie intake at the poverty line in sub-Saharan Africa is estimated to be $2100 \mathrm{kcal}$ per person per day (van Wesenbeeck et al., 2009; Ravallion, 1994). Similar number of food groups' 
consumption was also observed in Ethiopia in Sibhatu et al. (2015) and Hirvonen et al. (2015). Close to $36 \%$ of the respondents reside in lowland agroecological conditions and $34 \%$ in moderate areas, and the rest in highland and urban conditions. In the following subsections, we present analysis of the seasonal variation and contribution of own production of food, purchases of food from farm income and purchases of food from off-farm income to food availability in smallholder farm households.

\subsubsection{Seasonal market purchases and own on-farm production}

Seasonality could determine food availability in smallholder farm households, particularly farmers in Ethiopia where mostly rely on unimodal rainfall to produce their annual food needs. In this section, we examine how food availability and their sources change across agricultural seasons. Figure 4.1(A) displays average daily per capital calorie consumption categorized by the food sources at each month in a calendar year. Food consumption from own on-farm production is further categorized into to the part directly consumed at home (own production) and the part purchased from farm income. Across the whole year, off-farm income clearly stands out as the most important food source; about $70 \%$ of calorie consumption comes from food purchases using off-farm income. The food sources where farmers get their food slightly vary within the calendar year, which could be related to the seasonal nature of agricultural production. There is a clear tendency to shift away from purchased foods during the months of November, December and January. This is not surprising because in most agricultural areas of Ethiopia those months constitute harvesting season and are characterized by abundant food availability from own production. It might not also be surprising that the highest per capita calorie consumption is scored in the month of October (2403.0 kcal/capita/day) where the harvesting season starts. Some early maturing varieties of teff and maize are harvested in October. However, in January post-harvesting season starts and extensive farm works abate, hence, lower calorie consumption could be expected. Another explanation for the lower energy consumption in January might be because marriage ceremonies and feasts are predominantly carried out in January that many people travel and eat outside their homes. From April, calorie consumption from off-farm incomes starts to rise and reaches high in August, one of the lean months. By contrast, calorie consumption from own production decreases slightly. The relatively higher calorie 
consumption in the lean season (June, July and August) could be to compensate the extensive farm works.

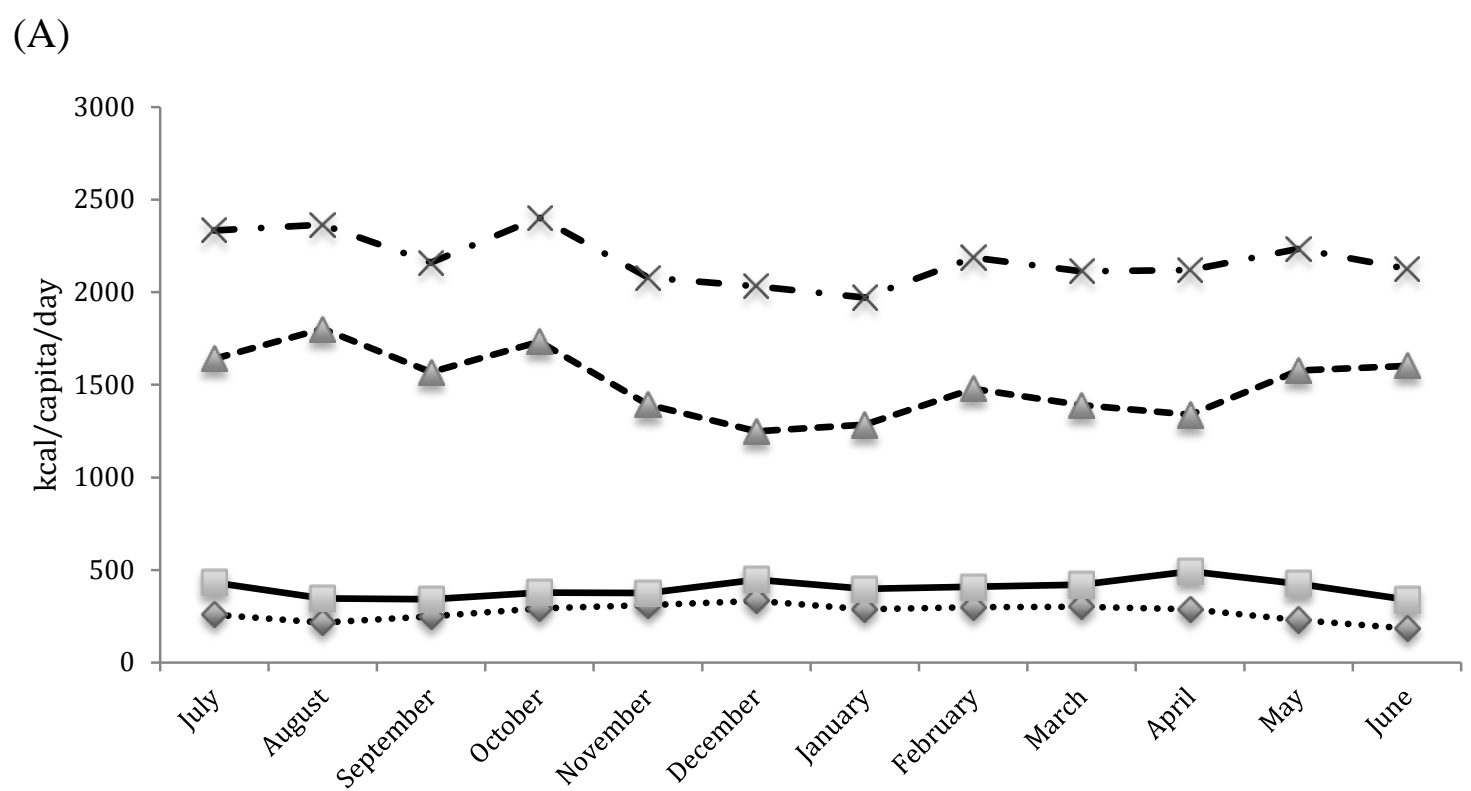

Months 2010-2011

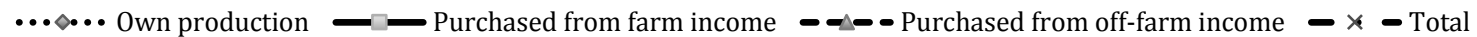

(B)

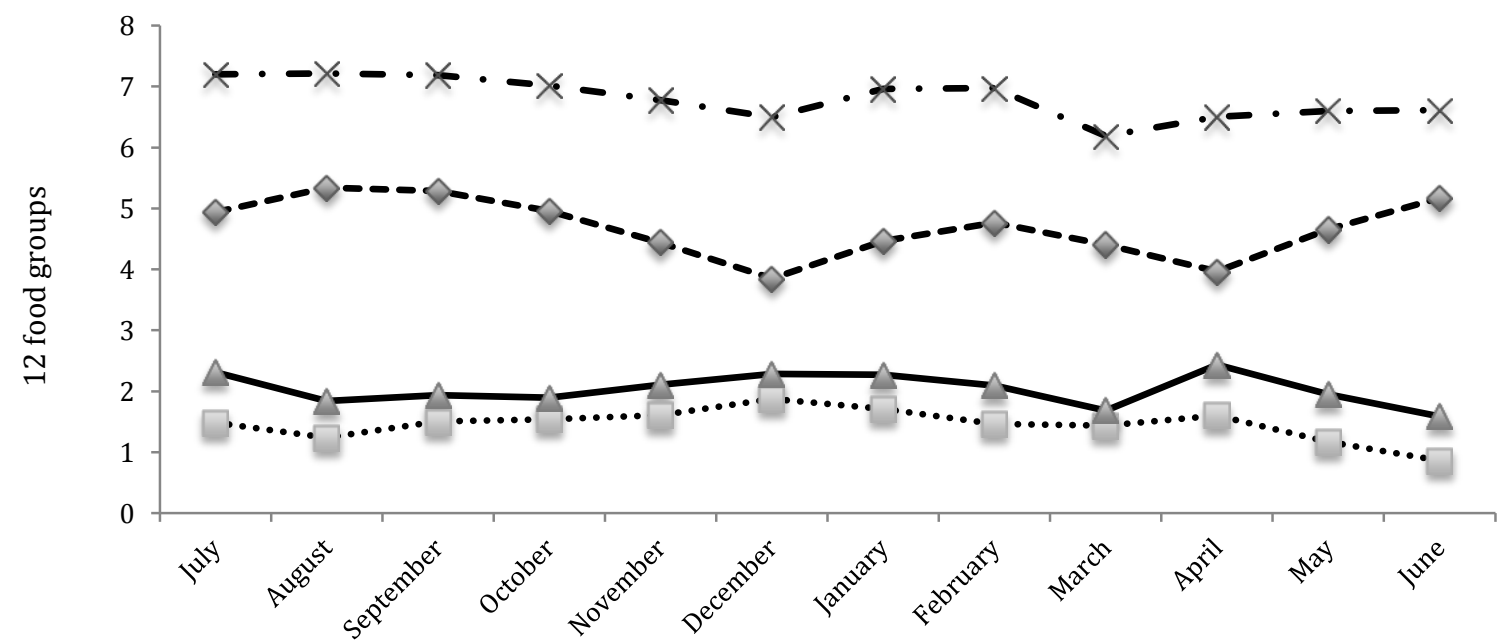

Months 2010-2011

- - - Purchased from off-farm income $\quad \cdots \cdot \cdots$ Own production $\quad \longrightarrow$ Purchased from farm income $\quad-x-$ Total

Figure 4. 1: Seasonal household calorie consumption and dietary diversity score categorized by food sources 
Figure 4.1(B) plots the diversity of foods consumed from market purchases and home production for each month. Two clear seasonal patterns stand out here. First, consistent with calorie consumption, the diversity of purchased foods consumed is much higher than the diversity of foods consumed from own production throughout the year. Interestingly, the diversity of foods purchased from the market using farm income is greater than the diversity of foods consumed directly from own production. Second, household seasonal calorie consumption is strongly corrected with the diversity of food groups consumed from purchases (correlation coefficient 0.40 and $\mathrm{p}=0.000$ ). Diversity of food is an important facilitator for balanced nutrients intake. During the lean season (from April to August where the stock of foods from own production declines), dietary diversity from off-farm income slightly increases. Generally, cash income from farm sales and off farm income seem the core elements for farm households' food availability, not own production.

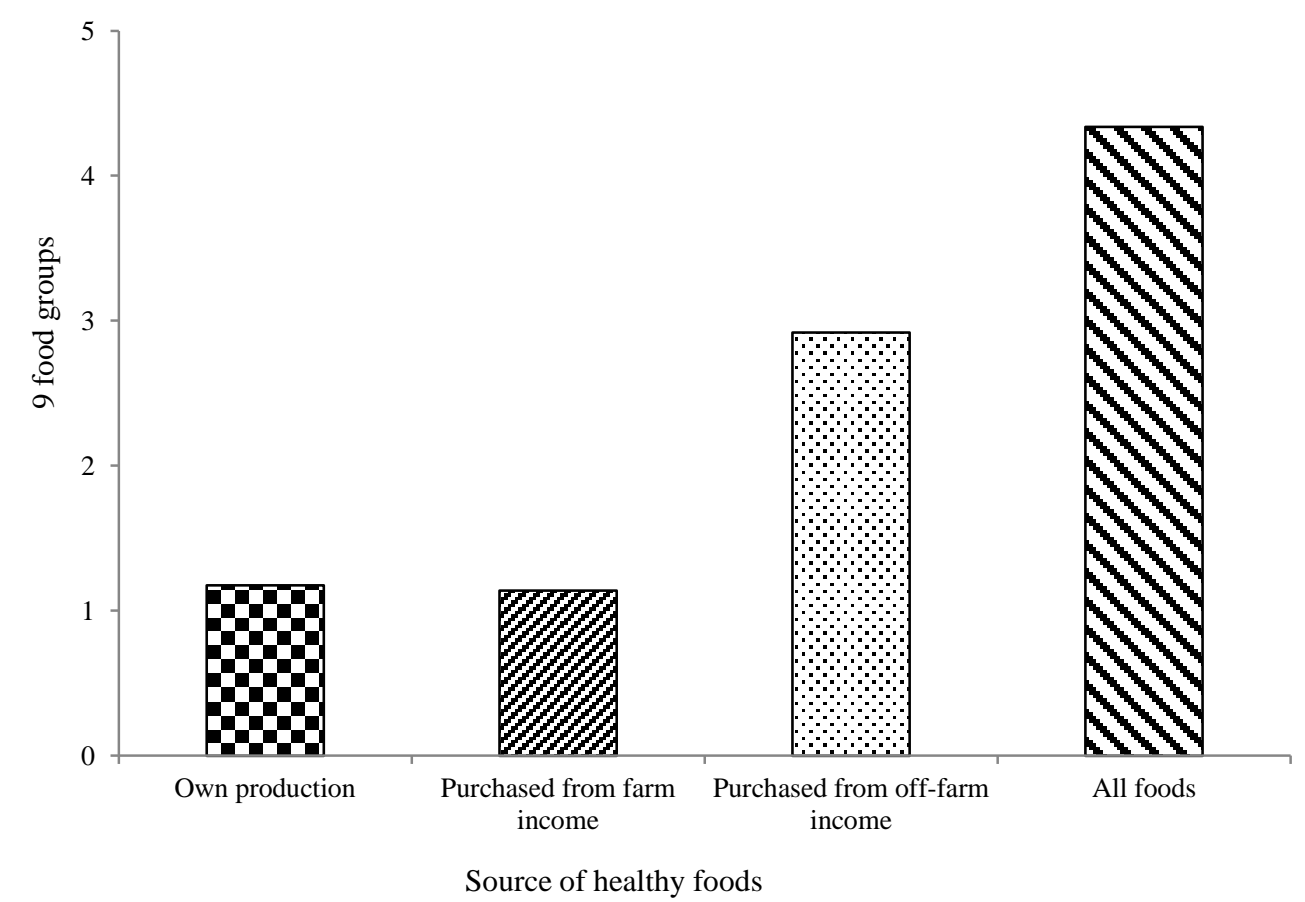

Figure 4. 2: Average household dietary diversity score of healthy foods categorized by food sources 
Interesting feature to observe in Figure 4.2 is that the diversity of relatively healthy foods purchased from market is three times higher than that of from own production. This implies that food purchases not only improve food availability in terms of calorie consumption, but also improves the diversity of healthy foods consumed by farm households.

\subsubsection{Contribution of market purchases and home production for sufficient food availability}

In this section, we examine the relative contribution of market purchases and on-farm production for household sufficient food availability. Figure 4.3 shows average contribution of purchases and own on-farm production for household food sufficiency. The average contribution of the three food sources varies from households with insufficient food available to those households with more than enough food available. In the households with insufficient food available ( $<1500 \mathrm{kcal} / \mathrm{capita} / \mathrm{day}), 25.4 \%$ of calorie consumption comes directly from own production, while the $35.7 \%$ is from cash income generated using sales of farm products and exchanged for food in market. Whereas, in households with more enough food available (>2500 kcal/capita/day) the larger proportion of calorie consumption $(82.9 \%)$ comes from purchases from off-farm income. Consumption of food directly from own on-farm production constitutes only $6.7 \%$ in those households. The result is consistent with the food availability expressed in terms household dietary diversity score (Figure 4.4). 


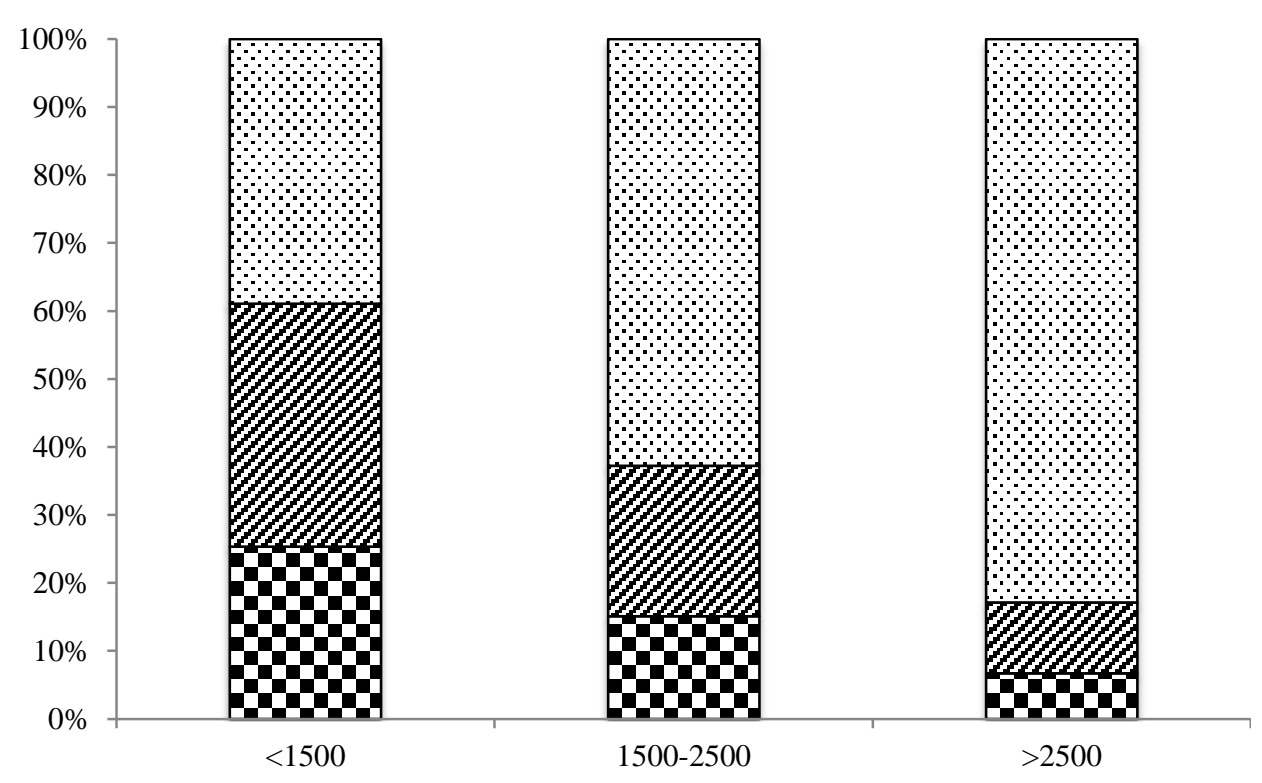

Own production $\boldsymbol{\nabla}$ Purchased from farm income $\boldsymbol{\nabla}$ Purchased from off-farm income

Figure 4. 3: Contribution of own production, purchases from farm income, and purchases from off-farm income to household food sufficiency.

Notes: Calorie consumption measures food availability. Out of 5755 households, $43.2 \%$ have insufficient food available ( $<1500 \mathrm{kcal} / \mathrm{capita} / \mathrm{day}), 28.8 \%$ enough food available $(1500-2500 \mathrm{kcal} / \mathrm{capita} / \mathrm{day})$ and $27.9 \%$ more than enough food available (>2500 kcal/capita/day).

Generally, the results suggest that the farm households cannot secure their daily food needs from what they produce; they obtain larger proportion of their food from market. Still contribution of on-farm production of foods for food availability is relatively more in households with insufficient food available, but cannot meet their food needs for the whole year. Households' access to market is very indispensable for sufficient food availability. Evidently, foods purchased from off-farm income and agricultural sales are more essential for food sufficiency for households with higher food available. There is a tendency to shift away from on-farm to off-farm as main source of food when the relative food sufficiently increases among the sample households. The contribution of own on-farm production substantially declines as the level of food sufficiency increases. By contrast, the contribution of food purchases becomes considerably important. To put it in other words, households who relatively rely more on own production tend to depend less on market purchases using cash generated from off-farm activities. Interestingly however, those households seem to suffer from insufficient food availability. Hence, food sufficiency is achieved mostlikely when more 
and diverse foods can be purchased from the market, not when relying more on own production of food for own use. It seems that the realistic pathways through which food security could be improved in farm households in Ethiopia is through better market access avenue not through subsistence.

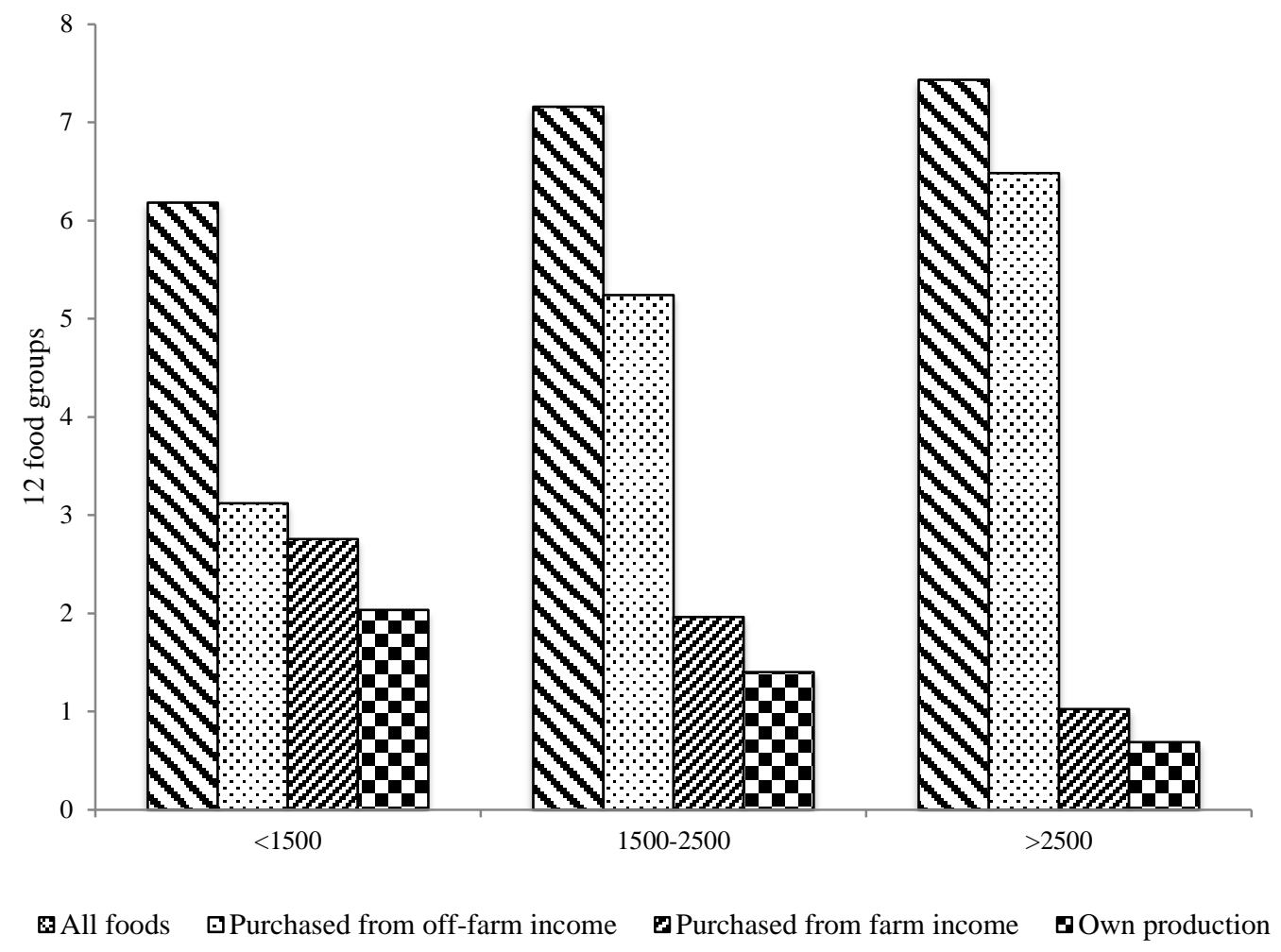

Figure 4. 4: Contribution of own production, purchases from farm income, and purchases from off-farm income for households' diverse food availability

Household dietary diversity score (HDDS) measures food availability.

\subsubsection{Estimation of agroecological influence}

In this section, we further analyze how agroecological and seasonal factors influence the different sources of food. We use regression models to analyze the associations. Unfortunately, very limited information was collected in the HCES and this could not allow us to include another variable that could have correlated with the dependent variable. For example, farm and production characteristics such as land area were not gathered in the survey. We estimate models for the individual food sources, as well as for all sources combined. We begin when the dependent variable is calorie consumption. The results are 
shown in columns (1-4) of Table 4.2. Agroecological conditions where farm households live also matter from which food sources to rely more. In the HCES, agroecology is classified in to four zones: highland, moderate, lowland and urban. Here, the urban zone is taken a reference. Farmers from the highland, moderate and lowland agroecological zones consume fewer calories driven from purchases using off-farm income. For example, Column (4) shows that households living in moderate and lowland agroecological zones consume 459.9 $\mathrm{kcal} / \mathrm{capita} /$ day and $467.5 \mathrm{kcal} / \mathrm{capita} /$ day less from purchases using off-farm income than those who reside in urban agroecological condition, respectively. Households located outside cities and towns relatively consume more from own production, both through farm to plate and through exchanging farm products to food in market. This implies that relatively farmers located outside urban and town areas rely more on farming to get food.

With regard to agricultural seasons, where harvesting season is taken as a reference in the estimation, the association varies among seasons and sources. Overall, farmers consume more energy in the growing season than in the harvesting although abundant food expected to be in the latter. As explained above, this could be due to extensive farm works in the growing season. However, food purchases provide more calorie than home production in general (Figure 4.4). The food provisioning pathways, from own production and purchases farm income contribute less in the growing season than in the harvesting season, which one would have expected in lean seasons.

As Columns (5-8) of Table 4.2 show, the result when food availability is measured using calorie is consistent with the results when food availability is expressed in terms of the 12 food groups, even in most cases, the effect is more pronounced and significant. As one would expect, more attractive off-farm employment and properly functioning markets are found in cities and towns than in rural areas. Evidently, the findings justify that farmers in urban areas and small towns substantially depend on foods purchases to meet their food needs. 


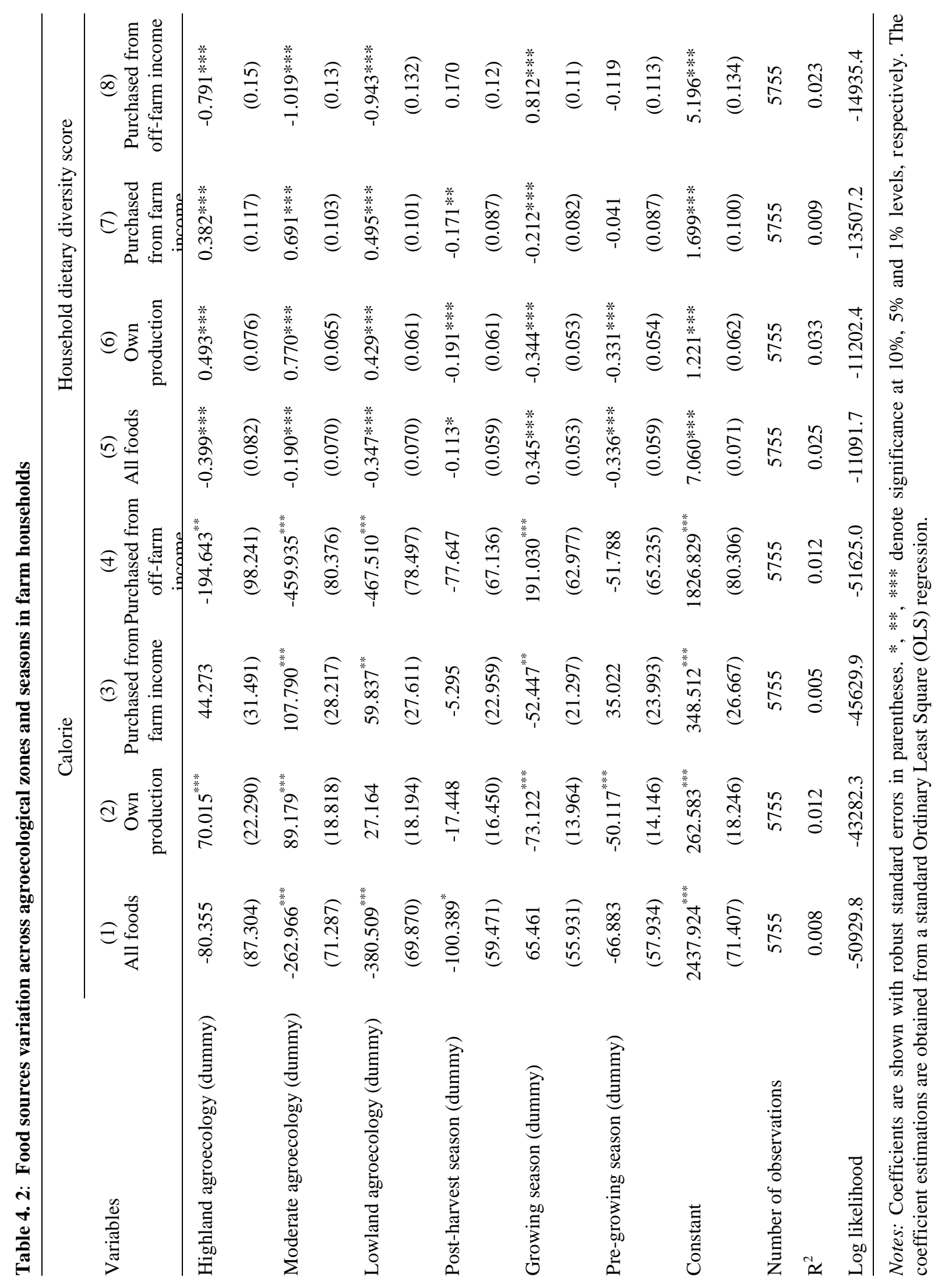




\subsection{Conclusion and Policy Implication}

Despite significant progress in food production, providing diverse and sufficient food to farm households in developing countries remains a staggering challenge, particularly to those who rely on single rainy season to produce their annual food. In this paper, we have analyzed how food sources, specifically market purchases and own on-farm production, contribute to food availability across agricultural seasons in farm households. We use a nationally representative survey data from Ethiopia as an example. We calculate actual daily per capital calorie consumption and household dietary diversity scores as indicators of food availability for each month in a calendar year. Food consumption from own on-farm production is also further categorized into the part directly consumed at home (from farm to plate), and the portion sold to the market and exchanged for food.

We have shown that farmers in Ethiopia extensively engage in selling and buying foods and are net buyers of food commodities. Unacceptably, large number of them is food insecure and cannot cover their daily food needs from what they produce on-farm across all agricultural seasons. Although there is a tendency to shift away from purchased foods during the harvesting season, but off-farm income seems to be the primary source of food to Ethiopian farm households for an entire calendar year. We have also shown that on-farm production relatively contributes more (both for direct consumption and farm sales) to food availability for households without sufficient food available. By contrast, households with sufficient food available, increasingly consume what they do not produce which was reflected with substantially more consumption of calorie from foods purchased using money generated by off-farm activities. Direct consumption of foods from own production is very small among households who enjoy sufficient food. Geographically, farmers in cities and towns seem to enjoy the benefits of off-farm income opportunities and utilize it to meet their food needs.

Now, the question is what is the best pathway to utilize for fighting against food insecurity and for sustainable provisioning of sufficient food in smallholder farm households who live in the rural areas of the developing world? That is, should policy makers promote for more subsistence through on-farm diversification or making famers fit to the market? Our suggestion is to promote for strengthening markets and making farmers fit to it, but not a 
panacea. First, in this study, we have shown that smallholder farmers extensively engage in market transaction and major portion of their food comes from purchases, a portion probably cannot be substituted by own production. We have also shown that households who substantially depend on own production are food insufficient or insecure. At the same time, farmers who depend on off-farm income enjoy sufficient and more diverse foods. Second, in our previous studies (Sibhatu et al., 2015; Sibhatu and Qaim, 2016) we found out that the contribution of on-farm production diversity to dietary diversity is very small. We also discovered that small farms in developing counters are already highly diversified and small in size. In Ethiopia, for example, a farm with as total land size of 1.6 hectares keeps ten different crop and livestock species and adding more species on top of that negatively affect dietary diversity (Sibhatu et al., 2015). We also demonstrated that the potential diversity of food that could be obtained from highly diversified farms is very small in comparison to what farmers actually purchase and consume from markets (Sibhatu and Qaim; 2016), which is very consistent with the current study. Furthermore, for production diversity to work there should be an economic motive. Although it needs more research, markets stimulate farm diversification could probably associate with higher income as was observed in our study in vegetable farmers in Kenya (Sibhatu and Qaim, 2016).

Therefore, we conclude that on-farm production might be important, especially to households with insufficient food available. However, markets access is critically essential for food security in smallholder farm households residing in the rural areas of the developing world. The argument that small farms in developing countries should rely on increasing on-farm production diversity to sustainably enhance food security is too extreme. Rather, the primary avenue to lift poor farmers out of food insecurity and malnutrition is strengthening market accesses and integration than promoting for more farm diversity for subsistence use. Policies should be steered towards making markets and enhancing off-farm income sources to the rural areas of developing countries. The implication of our study could also be applicable to other developing countries. That is, policy makers in areas that share similar agroecological and social structures with Ethiopia could use this information to design food security plans in agricultural households. Finally, we note that farmers also need cash to cover expenses for instance clothing, health and school fees, which we do not address here. 


\section{CHAPTER 5}

\section{Conclusion}

\subsection{Main Findings}

Through agricultural modernization, considerable progress has been made in food production over the last century. Despite this progress, providing sufficient and nutritiously diverse food for all remains a complex global challenge. Together, under-nourishment, micronutrient malnutrition and over-nourishment currently affect more than half of the world population. Nutritional deficiencies are the underlying cause for a large health burden in terms of lost productivity, impaired physical and mental human development, susceptibility to various diseases, and premature deaths, particularly in developing countries. Nutritional deficiencies and food insecurity are not only the result of low food quantities consumed, but also of poor dietary quality and diversity. Given that hunger and malnutrition are still widespread problems in many developing countries, where smallholder farmers are the main actors of food supply and paradoxically suffer most from nutrition related problems, the question on how to make smallholder agriculture more nutrition-sensitive is of high relevance for research and policy. Eradicating malnutrition in all its forms is a fundamental part of the post-2015 United Nations Sustainable Development Goals (SDGs).

In this dissertation, we have contributed to the literature by analyzing the link between production and consumption diversities in farm households. We have also analyzed how other factors, particularly market access, may influence the relationship between production and dietary diversity more generally. Using different indicators, we tested the robustness of previous studies. The relative contribution of market purchases and own production to food availability in small farm household across agricultural seasons was also examined. Calls for higher diversity of farm production to improve nutrition in smallholder households are widely heard in the international policy debate, but many of the underlying assumptions have not been tested rigorously. By using large datasets from various countries and diverse conditions we have addressed this shortcoming and are able to draw some broader conceptual and empirical lessons that go beyond case-study evidence. 
While a positive link exists between farm diversity and dietary diversity in many situations, the effect is generally small and not significant in all cases. Our findings have also shown that smallholder access to agricultural markets and off-farm employment have positive effects on dietary diversity. These market effects are larger than those of increased production diversity in most cases. Comparisons show that more commercialized farm households that produce cash crops for the market typically have more diverse diets than subsistence farm households. Households with higher cash incomes are capable to buy more diverse foods from the market. The diversity of foods consumed from market purchases cannot be fully substituted through diverse subsistence production. While improved market access often provides incentives for farmers to specialize, actual outcomes depend on many factors, not all of which were analyzed here. Where properly functioning markets for various commodities exist, commercial orientation of farms and high levels of production diversity are not necessarily a contradiction. This also needs to take into account institutional and cultural aspects at the local level. Promoting production diversity may help in some situations. But our results suggest that increasing on-farm diversity among smallholders is not always the most effective way to improve dietary diversity.

To test the robustness of these findings, we used different indicators of production and consumption diversity. When measuring farm diversity in terms of a simple count of crop and livestock species produced, we found a small, positive relationship with household dietary diversity. This small positive effect also remains when using other indicators of dietary quality, such as household consumption levels of calories and micronutrients. While dietary diversity scores are not a perfect predictor of specific nutritional deficiencies, they seem to work well in terms of capturing broader aspects of dietary quality in farm households. This is a welcome finding, because the calculation of dietary diversity scores requires less data than the calculation of nutrient consumption levels. We also tested the sensitivity of results with respect to changes in the production diversity indicator. When using production diversity scores instead of a simple species count, the effect on dietary quality gets smaller, in many cases it turns insignificant. This is an interesting finding. The production diversity score measures the number of different food groups produced on a farm, so one could have expected the effect on the number of food groups consumed in the farm household to be stronger. The fact that this is not the case suggests that the subsistence pathway is not the 
main mechanism underlying the production-consumption relationship. Cash income generated from agricultural sales seems to be a more important pathway contributing to improved dietary quality. Additional model estimates confirmed a significant positive association between agricultural cash revenues and dietary quality, measured either in terms of dietary diversity scores or nutrient consumption levels.

We have also shown that market access is more important for farm household nutrition than production diversity per se. Our data show that own production typically accounts for only a small proportion of the different food groups consumed in farm households; the larger proportion is purchased from the market. Diversifying the farm production portfolio such that more food groups were produced would foster subsistence, reduce cash incomes, and thus rather worsen dietary quality. Indeed, we have shown that a larger number of food groups produced on a farm is often negatively associated with agricultural cash revenues. This does not mean that farm diversity is bad. But the type of diversification should follow market incentives, building on farmer's comparative advantage, rather than trying to maximize the number of food groups produced. Our results clearly suggest that diversifying into cash crops can help improve diets through the income pathway.

Finally, using nationally representative survey data from Ethiopia and calculating daily per capita calorie consumption and household dietary diversity scores as indicators of food availability and dietary quality for each month in a calendar year, we have shown that farmers extensively engage in selling and buying foods. Many of the farms are net buyers of food. A large number of farm households is food insecure and cannot cover their daily food needs from what they produce on-farm across all agricultural seasons. Although there is a tendency to shift away from purchased foods during the harvesting season, off-farm income clearly stands out as the primary economic activity to secure food across the different seasons. Interestingly, households with insufficient food availability rely more on own farm production as a source of food, while households with enough food rely more on market purchases. Direct consumption of foods from own production is very small among households that enjoy access to sufficient food. The analysis shows that the contribution of market purchases and own production varies across agroecological and geographical zones. For 
farmers with better infrastructure conditions, off-farm income plays a larger role to meet their food needs.

\subsection{Policy Implications}

Putting the findings from the three essays together, we draw important conclusions and derive a few policy recommendations. In contrast to what is often assumed, increasing on-farm diversity is not always the most effective way to improve dietary diversity in smallholder households. The common assumption that higher farm production diversity is always conducive for household nutrition therefore needs adjustment. The most suitable policy mix to improve nutrition in smallholder farm households will vary from case to case. However, from a nutrition perspective, improving market access is more important than farm diversification as such. If diversification helps to increase household income, it will contribute to better nutrition. Otherwise, diversification can also be counterproductive from a dietary quality perspective.

Own production still plays an important role, especially for poor households with insufficient food available. However, market access is essential for food security and consumption of diversified diets. The argument that small farms in developing countries should primarily rely on increasing production diversity to sustainably enhance food security implicitly means conserving subsistence farming. However, subsistence farming is closely associated with poverty, vulnerability, and undernutrition. The primary avenue to lift poor farmers out of poverty and food insecurity is strengthening market accesses. It is unlikely that home production can be the primary avenue for sustainable food provisioning in smallholder farm households. Therefore, policies should be steered towards making markets more accessible and enhancing off-farm income opportunities for the rural poor. Beyond the food needs, farm households need cash income also to cover expenses for clothing, health, education, and other basic needs.

It should be stressed that our results refer to the individual farm level. At higher scales (villages, districts, provinces, countries etc.) sufficient diversity is important, because 
affordable access to diverse foods from the market certainly requires that somebody produces these foods. This means that policy biases towards only a small number of staple foods - as often observed in the past - need to be rectified. If markets and technologies exist for a wide range of products, food systems will become more diverse, even without every farmer having to maximize diversity on her own farm.

\subsection{Limitations of the Study and the Way Forward}

By using large datasets from various countries and diverse conditions we are able to draw some broader conceptual and empirical lessons that go beyond case-study evidence. However, our research is not without limitation and leaves a number of questions unanswered. For future inquiry, we highlight some of them.

First, the first two essays build on cross-sectional datasets and our interest is mere association analysis; we do not claim causality. Some of the variables are endogenous. We suggest that the estimation results should not be overinterpreted in a causal sense. Using panel datasets and econometric models that control for unobserved heterogeneity are important avenues for future research, to test the robustness of the results and provide further insights on causal chains.

Second, for comparisons across countries it is advantageous that all the relevant data on farm production and household food consumption were collected using the same survey format. We employed different robustness checks and used country dummies and robust standard errors to account for regional heterogeneity. Thus, we were able to pool the data for some of the analyses, in addition to looking at each country separately. However, in the first essay we have combined data from specific regional settings within countries with nationally representative surveys. Data from specific settings have their problems in terms of wider external validity. It is therefore recommended that future studies should seek to utilize nationally representative datasets whenever possible.

Third, our study uses 7-day recall consumption information at the household level. Although such information can serve to generate indicators of dietary diversity and general food access 
for households, it might not be an accurate indicator of the nutritional status of individual household members. In order to better understand the relationship between production diversity and nutrition at the individual, future studies should collect consumption information at individual level. In addition to individual-level food frequency surveys, the use of anthropometric data would also be a plus.

Finally, we note that our study did not consider all implications of production diversity. For instance, farm diversity can have an important environmental component, which was not the focus of this study. We have considered production diversity only from the perspective of nutrition and diets. Hence, more research is required to better understand how agriculture and food systems can be made more nutrition-sensitive from a broader sustainability perspective. 


\section{References}

Arimond, M., Ruel, M.T. (2004). Dietary diversity is associated with child nutritional status: Evidence from 11 demographic and health surveys. Journal of Nutrition 134: 25792585 .

Arimond, M., Wiesmann, D., Becquey, E., Carriquiry, A., Daniels, M.C. (2010). Simple food group diversity indicators predict micronutrient adequacy of women's diets in 5 diverse, resource-poor settings. Journal of Nutrition 140: 2059S-2069S.

Bachewe, F., Berhane, G., Minten, B., Taffesse, A.S. (2016). Non-farm income and labor markets in rural Ethiopia. Ethiopia Strategy Support Program Working Paper 90. IFPRI, Washington, DC:

Barrett, C.B. (2010). Food systems and the escape from poverty and ill-health traps in subSahara Africa. In Pinstrup-Andersen, P. (ed.). The African Food System and Its Interaction with Human Health and Nutrition. Cornell University Press in cooperation with the United Nations University, Ithaca, NY, pp. 242-260.

Barrett, C.B., Bevis, L.E.M. (2015). The micronutrients deficiencies challenge in African food systems. In Sahn, D.E. (ed.). The Fight Against Hunger and Malnutrition: The Role of Food, Agriculture, and Targeted Policies. Oxford University Press, Oxford, pp. $61-88$.

Berti, P.R. (2015). Relationship between production diversity and dietary diversity depends on how number of foods is counted. Proceedings of the National Academy of Sciences of the United States of America 112: e5656.

Bouis, H., Hunt, J. (1999). Linking food and nutrition security: Past lessons and future opportunities. Asian Development Review 17: 168-213.

Burlingame, B., Dernini, S. (ed.). (2012). Sustainable Diets and Biodiversity: Directions and Solutions for Policy, Research and Action. FAO and Bioversity International, Rome. 
Chege, C.G.K., Andersson, C.I.M., Qaim, M. (2015). Impacts of supermarkets on farm household nutrition in Kenya. World Development 72: 394-407.

Chiputwa, B., Qaim, M. (2016). Sustainability standards, gender, and nutrition among smallholder farmers in Uganda. Journal of Development Studies 52: 124-257.

Chiputwa, B., Spielman, D.J., Qaim, M. (2015). Food standards, certification, and poverty among coffee farmers in Uganda. World Development 66: 400-412.

Coates, J. (2013). Build it back better: deconstructing food security for improved measurement and action. Global Food Security 2: 188-194.

CSA, World Bank. (2013). Ethiopian Rural Socioeconomic Survey Report (ERSS): survey report.

Available

at: http://web.worldbank.org/WBSITE/EXTERNAL/EXTDEC/EXTRESEARCH/EXTLS MS/EXTSURAGRI/0,,contentMDK:22939096 pagePK:64168445 piPK:64168309 th eSitePK:7420261,00.html [Accessed on 02 January 2014].

CSA. (2006). Report on the 2005 National Labour Force Survey. Statistical Bulletin no.365. CSA, Addis Ababa.

CSA. (2012) Household Consumption and Expenditure (HCE) Survey 2010/11: Analytical Report. Statistical Bulletin no.563. CSA, Addis Ababa.

de Haen, H., Klasen, S., Qaim, M. (2011). What do we really know? Metrics for food insecurity and undernutrition. Food Policy 36: 760-769.

Deckelbaum, R.J., Palm, C., Mutuo, P., DeClerck, F. (2006). Econutrition: Implementation models from the Millennium Villages Project in Africa. Food and Nutrition Bulletin 27: 335-342.

DeClerck, F.A.J., Fanzo. J., Palm, C., Remans, R. (2011). Ecological approaches to human nutrition. Food and Nutrition Bulletin 32: S41-S50. 
Di Falco, S., Chavas, J.P. (2009). On crop biodiversity, risk exposure, and food security in the highlands of Ethiopia. American Journal of Agricultural Economics 91: 599-611.

Drewnowski, A., Henderson, A.S, Driscoll, A., Rolls, B.J. (1997). The Dietary Variety Score: assessing diet quality in healthy young and older adults. Journal of the American Dietetic Association 97: 266-71.

Dubé, L., Pingali, P., Webb, P. (2012). Paths of convergence for agriculture, health, and wealth. Proceedings of the National Academy of Sciences of the United States of America 109: 12294-2301.

EHNRI, FAO. (1998). Food Composition Table for Use in Ethiopia Part IV. EHNRI, Addis Ababa.

Ericksen, P.J., Ingram, J.S.I, Liverman, D.M. (2009). Food security and global environmental change: Emerging challenges. Environmental Science \& Policy 12: 373-377.

Euler, M., Schwarze, S., Siregar, H., Qaim, M. (2016). Oil palm expansion among smallholder farmers in Sumatra, Indonesia. Journal of Agricultural Economics 67: 658676.

FANTA. (2006). Developing and Validating Simple Indicators of Dietary Quality and Energy Intake of Infants and Young Children in Developing Countries: Summary of findings from analysis of 10 data sets. Working Group on Infant and Young Child Feeding Indicators. Food and Nutrition Technical Assistance (FANTA) Project, Academy for Educational Development (AED), Washington, D.C.

Fanzo, J., Hunter, D., Borelli, T., Mattei, F. (ed.). (2013). Diversifying Food and Diets: Using Agricultural Diversity to Improve Nutrition and Health. Routledge, London.

FAO, IFAD, WFP. (2015). The State of Food Insecurity in the World 2015. FAO, Rome.

FAO. (2009). Declaration of the World Food Summit on Food Security. FAO, Rome. 
FAO. (2010). World Food Dietary Assessment System, Version 2.0. International Network of Food Data Systems and FAO, Rome.

FAO. (2011). Guidelines for Measuring Household and Individual Dietary Diversity. FAO, Rome.

FAO. (2012). Smallholder and Family Farms. FAO, Rome. Available at: http://www.fao.org/fileadmin/templates/nr/sustainability_pathways/docs/Factsheet_SM ALLHOLDERS.pdf. [Accessed on 09.08.2016].

FAO. (2013). The State of Food Insecurity in the World 2013: The multiple dimensions of food security. FAO, Rome.

FAO. (2014). The State of Food and Agriculture. Innovation in Family Farming. FAO, Rome.

FAO. (2015). The Economic Lives of Smallholder Farmers: An Analysis Based on Household Data from Nine Countries. FAO, Rome.

Fischer, E., Qaim, M. (2012). Gender, agricultural commercialization, and collective action in Kenya. Food Security 4: 441-453.

Foley, J.A. et al. (2011). Solutions for a cultivated planet. Nature 478: 337-342.

Frelat, R. et al. (2016). Drivers of household food availability in sub-Saharan Africa based on big data from small farms. Proceedings of the National Academy of Sciences of the United States of America 113: 458-463.

Frison, E.A., Smith, I.F., Johns, T., Cherfas, J., Eyzaguirre, P.B. (2006). Agricultural biodiversity, nutrition, and health: Making a difference to hunger and nutrition in the developing world. Food and Nutrition Bulletin 27: 167-179.

Godfray, H.C.J. et al. (2010). Food security: the challenge of feeding 9 billion people. Science 327: $812-818$.

Gómez, M.I. et al. (2013). Post-green revolution food systems and the triple burden of malnutrition. Food Policy 42: 129-138. 
Greene, W.H. (2012). Econometric Analysis. (7th ed.). Prentice Hall, Upper Saddle River, New Jersey.

Haggblade, S., Hazell, P.B.R., Reardon, T. (ed.). (2007). Transforming the Rural Nonfarm Economy: Opportunities and Threats in the Developing World. Johns Hopkins University Press, Baltimore MD.

Hassen, I.W., Dereje, M., Minten, B., Hirvonen, K. (2016). Diet transformation in Africa: The case of Ethiopia. ESSP Working Paper 87. Addis Ababa.

Hatløy, A. et al. (2000). Food variety, socioeconomic status and nutritional status in urban and rural areas in Koutiala (Mali). Public Health Nutrition 3: 57-65.

Headey, D., Ecker, O. (2013). Rethinking the measurement of food security: From first principles to best practice. Food Security 5: 327-343.

Hengsdijk, H., Franke, A.C., van Wijk, M.T., Giller, K.E. (2014). How Small is Beautiful? Food Self-Sufficiency and Land Gap Analysis of Smallholders in Humid and Semi-Arid Sub-Saharan Africa. Wageningen UR, Wageningen, The Netherlands.

Herforth, A. (2010). Promotion of traditional African vegetables in Kenya and Tanzania: A case study of an intervention representing emerging imperatives in global nutrition. PhD Thesis. Cornell University, Ithaca NY.

Herrero, M. et al. (2010). Smart investments in sustainable food production: Revisiting mixed crop-livestock systems. Science 327: 822-825.

Hirvonen, K., Hoddinott, J. (2014). Agricultural production and children's diets: evidence from rural Ethiopia. Ethiopia Strategy Support Program Working Paper 69. IFPRI, Washington, DC.

Hirvonen, K., Taffesse, A.S., Hassen, I.W. (2015). Seasonality and household diets in Ethiopia. Public Health Nutrition 18: 1723-1730. 
Hoddinott, J., Yohannes, Y. (2002). Dietary diversity as a food security indicator. IFPRI, Washington, DC.

Horton, S., Steckel, R.H. (2013). Global economic losses attributable to malnutrition 19902000 and projections to 2050. In Lombard, B. (ed.). How Much Have Global Problems Cost the World? A Scorecard from 1900 to 2050. Cambridge University Press, Cambridge, pp. 247-272.

IFAD. (2013). Smallholders, Food Security and The Environment. IFAD, Rome.

IFPRI. (2014). Global Nutrition Report 2014: Actions and Accountability to Accelerate the World's Progress on Nutrition. IFPRI, Washington, DC.

IFPRI. (2015). Global Nutrition Report 2015: Actions and Accountability to Advance Nutrition and Sustainable Development. IFPRI, Washington, DC.

IFPRI. (2016). Global Nutrition Report 2016: From Promise to Impact: Ending Malnutrition by 2030. IFPRI, Washington, DC.

Jones, A.D., Shrinvas, A., Bezner-Kerr, R. (2014). Farm production diversity is associated with greater household dietary diversity in Malawi: Findings from nationally representative data. Food Policy 46: 1-12.

Kant, A.K., Schatzkin, A., Harris, T.B., Ziegler, R.G., Block, G. (1993). Dietary diversity and subsequent mortality in the First National Health and Nutrition Examination Survey epidemiologic follow-up study. American Journal of Clinical Nutrition 57: 434-440.

Kearney, J. (2010). Food consumption trends and drivers. Philosophical Transactions of the Royal Society of London B Biological Sciences 365: 2793-2807.

Keding, G.B., Msuya, J.M., Maass, B.L., Krawinkel, M.B. (2012), Relating dietary diversity and food variety scores to vegetable production and socio-economic status of women in rural Tanzania. Food Security 4: 129-140. 
Kennedy, G., Pedro, M.R., Seghieri, C., Nantel, G., Brouwer, I. (2007). Dietary diversity score is a useful indicator of micronutrient intake in non-breast-feeding Filipino children. Journal of Nutrition 137: 1-6.

Khoury, C.K. et al. (2014) Increasing homogeneity in global food supplies and the implications for food security. Proceedings of the National Academy of Sciences of the United States of America 111: 4001-4006.

Krishna, V.V., Euler, M., Siregar, H., Fathoni, Z., Qaim, M. (2015). Farmer heterogeneity and differential livelihood impacts of oil palm expansion among smallholders in Sumatra, Indonesia. EFForTS Discussion Paper 13, University of Goettingen, Germany.

Last, L. et al. (2014). Indicators for the on-farm assessment of crop cultivar and livestock breed diversity: a survey-based participatory approach. Biodiversity and Conservation 23: 3051-3071.

Lim, S.S. et al. (2012). A comparative risk assessment of burden of disease and injury attributable to 67 risk factors and risk factor clusters in 21 regions, 1990-2010: a systematic analysis for the Global Burden of Disease Study 2010. Lancet 380: 2224 2260.

Luckett, B.G., DeClerck, F.A.J., Fanzo, J., Mundorf, A.R., Rose, D. (2015). Application of the nutrition functional diversity indicator to assess food system contributions to dietary diversity and sustainable diets of Malawian households. Public Health Nutrition 18: 2479-2487.

Margalef, R. (1958). Temporal Succession and Spatial Heterogeneity in Natural Phytoplankton. In Buzzati-Traverso, A.A. (ed). Perspectives in Marine Biology. University of California Press: Berkeley, CA, USA. pp. 323-349.

Maxwell, D., Vaitla, B., Coates, J. (2014). How do indicators of household food insecurity measure up? An empirical comparison from Ethiopia. Food Policy 47: 107-116. 
Meng, E.C.H., Smale, M., Bellon, M.R., Grimanelli, D. (1998). Definition and measurement of crop diversity for economic analysis. In Smale, M. (ed). Farmers, Gene Banks, and Crop Breeding. Boston. Kluwer, pp. 19-31.

Moursi, M. et al. (2008). Dietary diversity is a good predictor of the micronutrient density of the diet of 6 to 23 months old children in Madagascar. Journal of Nutrition 138: 24482453.

Muller, C. (2009). Do agricultural outputs of partly autarkic peasants affect their health? Evidence from Rwanda. Food Policy 34: 166-175.

Olney, D.K., Talukder, A., Iannotti, L.L., Ruel, M.T., Quinn, V. (2009). Assessing impact and impact pathways of a homestead food production program on household and child nutrition in Cambodia. Food and Nutrition Bulletin 30: 355-369.

Pellegrini, L., Tasciotti, L. (2014). Crop diversification, dietary diversity and agricultural income: Empirical evidence from eight developing countries. Canadian Journal of Development Studies 35: 211-227.

Pingali, P. (2012). Green Revolution: impacts, limits, and the path ahead. Proceedings of the National Academy of Sciences of the United States of America 109: 12302-12308.

Pingali, P. (2015). Agricultural policy and nutrition outcomes - getting beyond the preoccupation with staple grains. Food Security 7:583-591.

Pinstrup-Andersen, P. (2007). Agricultural research and policy for better health and nutrition in developing countries: a food systems approach. Agricultural Economics 37: 187-198.

Pinstrup-Andersen, P. (2013). Nutrition-sensitive food systems: From rhetoric to action. Lancet 382: 375-376.

Popkin, B. (2009). The World Is Fat: The Fads, Trends, Policies, and Products That Are Fattening the Human Race. Penguin Group, New York. 
Popkin, B.M., Slining, M.M. (2013). New dynamics in global obesity facing low- and middleincome countries. Obesity Reviews 14: 11-20.

Powell, B., Thilsted, S.H., Ickowith, A., Termote, C., Sunderland, T., Herforth, A. (2015). Improving diets with wild and cultivated biodiversity from across the landscape. Food Security 7: 535-554.

Qaim, M. (2016a). Genetically Modified Crops and Agricultural Development. Palgrave Macmillan, New York.

Qaim, M. (2016b). Globalisation of agrifood systems and sustainable nutrition. Proceedings of the Nutrition Society 15: 1-10. doi: http://dx.doi.org/10.1017/S0029665116000598

Rajendran, S., Afari-Sefa, V., Bekunda, M., Dominick, I., Lukumay, P.J. (2014). Does crop diversity contribute to dietary diversity? Evidence from integration of vegetables into maize farming systems in Tanzania. Paper presented at the 88th Annual Conference of the Agricultural Economics Society, AgroParisTech, Paris.

Ravallion, M. (1994). Measuring social welfare with and without poverty lines. American Economic Review 84: 359-364.

Remans, R. et al. (2011). Assessing nutritional diversity of cropping systems in African villages. PLoS One 6: e21235.

Remans, R. Wood, A.S., Saha, N., Anderman, T.L., DeFries, R.S. (2014). Measuring nutritional diversity of national food supplies. Global Food Security 3: 174-183.

Ruel, M.T. (2003). Operationalizing dietary diversity: A review of measurement issues and research priorities. Journal of Nutrition 133: 3911S-3926S.

Schneeman, O. (2000). Linking agricultural production and human nutrition. Journal of the Science of Food and Agriculture 81: 3-9. 
Sibhatu, K.T., Krishna, V.V., Qaim, M. (2015). Production diversity and dietary diversity in smallholder farm households. Proceedings of the National Academy of Sciences of the United States of America 112: 10657-10662.

Sibhatu, K.T., Qaim, M. (2016). Farm production diversity and dietary quality: Linkages and measurement issues. GlobalFood Discussion Paper 80, University of Goettingen, Germany.

Smale, M., Hartell, J., Heisey, P.W., Senauer, B. (1998). The Contribution of Genetic Resources and Diversity to Wheat Production in the Punjab of Pakistan. American Journal of Agricultural Economics 80: 482-93.

SMILING. (2013). Food Composition Table for Indonesia. South East Asian Ministers of Education Organization, Indonesia Ministry of Health, Indonesia, Wageningen University, The Netherlands. Available at: http://www.fao.org/infoods/infoods/tablesand-databases/asia/en/ [Accessed on 28.07.2015].

Snapp, S.S., Fisher, M. (2015). "Filling the maize basket" supports crop diversity and quality of household diet in Malawi. Food Security 7: 83-96.

Steyn, N.P., Nel, J.H., Nantel, G., Kennedy, G., Labadarios, D. (2006). Food variety and dietary diversity scores in children: are they good indicators of dietary adequacy? Public Health Nutrition 9: 644-650.

Stifel, D., Minten, B. (2015). Market Access, welfare, and nutrition: Evidence from Ethiopia. Ethiopia Strategy Support Program Working Paper 77. IFPRI, Washington, DC.

Swindale, A., Bilinsky, P. (2006). Household Dietary diversity score (DDS) for Measurement of Household Food Access: Indicator Guide. Food and Nutrition Technical Assistance Project (FANTA), Academy for Educational Development, Washington, DC.

Taffesse, A.S., Dorosh, P., Gemessa, S.A. (2012). Crop production in Ethiopia. In Dorosh, P., Rashid, S. (ed.). Food and Agriculture in Ethiopia. Philadelphia, PA: University of Pennsylvania Press, pp. 53-83. 
Tschirley, D., Reardon, T., Dolislager, M., Snyder, J. (2015). The rise of a middle class in East and Southern Africa: Implications for food system transformation. Journal of International Development 27: 628-646.

United Nations. (2015). Transforming Our World: The 2030 Agenda for Sustainable Development. United Nations, New York.

Upton, J.B., Cisse, J.D., Barrett, C.B. (2016). Food Security as Resilience: Reconciling Definition and Measurement. Working Paper. Cornel University.

USDA. (2005). Composition of Foods: Raw, Processed, Prepared, National Nutrient Database for Standard References, Release 18. USDA, Washington, DC.

van Wesenbeeck, C.F., Keyzer, M.A., Nubé, M. (2009). Estimation of undernutrition and mean calorie intake in Africa: methodology, findings and implications. International Journal of Health Geographics 8: 1-18.

von Braun, J., Kennedy, E. (ed.). (1994). Agricultural Commercialization, Economic Development, and Nutrition. The Johns Hopkins University Press, Baltimore MD.

Waijes, M., Feskens, M., Ocke, C. (2007). A critical review of predefined quality scores. British Journal of Nutrition 97: 219-231.

WHO. (2013). Global Nutrition Policy Review: What does it Take to Scale Up Nutrition Action? WHO, Geneva.

World Bank. (2007a). From Agriculture to Nutrition: Pathways, Synergies, and Outcomes. World Bank, Washington, DC.

World Bank. (2007b). World Development Report 2008. Agriculture for Development. World Bank, Washington, DC.

World Bank. (2011). Outlook for Remittance Flows 2011-13, Migration and Development Brief. World Bank, Washington, DC. 
World Bank. (2013). Living Standards Measurement Study: Integrated Surveys on Agriculture. World Bank, Washington, DC. Available at: http://go.worldbank.org/BCLXW38HY0 [Accessed on 2 January 2015]. 